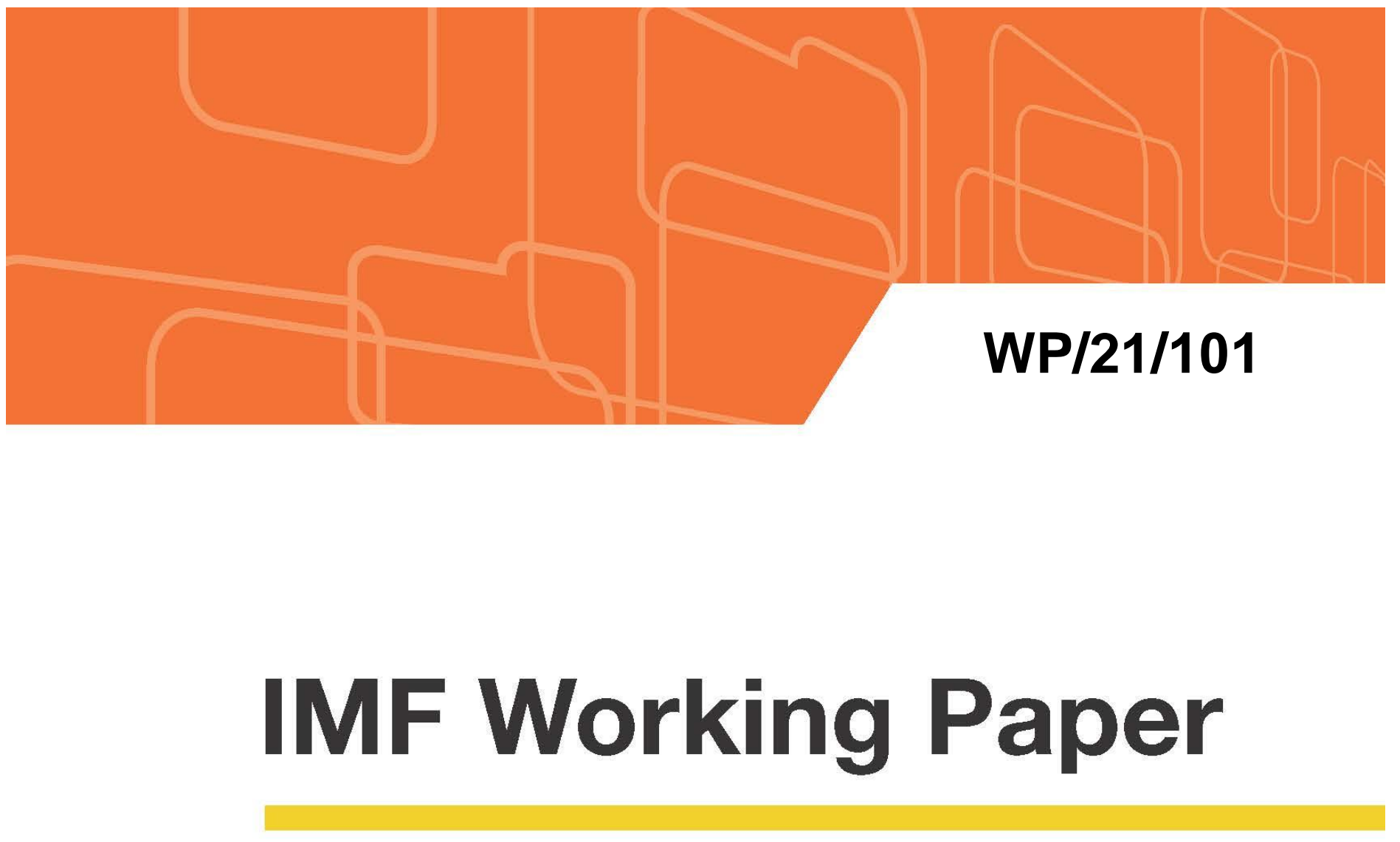

\title{
Parameterizing Debt Maturity
}

by Philip Barrett and Christopher Johns

IMF Working Papers describe research in progress by the author(s) and are published to elicit comments and to encourage debate. The views expressed in IMF Working Papers are those of the author(s) and do not necessarily represent the views of the IMF, its Executive Board, or IMF management. 


\title{
IMF Working Paper
}

Research Department

Parameterizing debt maturity

Prepared by Philip Barrett and Christopher Johns

Authorized for distribution by Malhar Nabar

April 2021

\section{IMF Working Papers describe research in progress by the author(s) and are published to} elicit comments and to encourage debate. The views expressed in IMF Working Papers are those of the author(s) and do not necessarily represent the views of the IMF, its Executive Board, or IMF management.

\begin{abstract}
This paper examines ways to summarize the maturity structure of public debts using a small number of parameters. We compile a novel dataset of all promised future payments for US and UK government debt from every month since 1869, and more recently for Peru, Poland, Egypt, and Nigeria. We show that there is a unique parametric form which does not arbitrarily restrict debt issuance - portfolios of bonds with exponential coupons. Compared to the most popular alternative, this form 1) more accurately describes changes in debt maturity for these six countries and 2) gives a quite different interpretation of historical debt maturity. Our work can be applied not just to analyze past debt movements, but - because parameter estimates are relatively similar across countries - also for monitoring changes in debt maturity, including in countries where data are partial or incomplete.
\end{abstract}

JEL Classification Numbers: E62, F34, H63

Keywords: Public Debt, Debt Maturity

Author's E-Mail Address: pbarrett@imf.org, cwj20@georgetown.edu 


\title{
Parameterizing debt maturity
}

\author{
Philip Barrett* and Christopher Johns ${ }^{\dagger}$
}

March 2021

\section{Introduction}

Sovereigns' public debts are typically very complex objects. For example, in July 2020 the United States Federal Government had some 420 different debt securities outstanding at 157 different monthly maturities with coupon and principal payments due in almost every month until 2050. Such complexity means that the analysis of many topics in public finance necessitate the compression of public debts into a small number of more manageable summary statistics (or "parameters"). While the pros and cons of summary measures of the magnitude of a sovereign's debt are well-studied, ${ }^{1}$ those compressing the distribution of the various times to repayment (the "maturity density") are less so.

Although summary measures of maturity do exist - and some, such as the average maturity of the public debt, are commonly used - they very often omit a large amount of useful information. For instance, the average maturity yields very little information about the amount of debt coming due in, say, the next two or three or even twelve months. For many fundamental fiscal policy questions - such as incentives for default, the likelihood of sudden stops in funding, and optimal debt management in the presence of shocks to interest rates or primary balances - a fuller synopsis of debts due at each horizon is required. ${ }^{2}$

The standard approach to this issue is to represent a government's full portfolio of outstanding debts using just a small number of hypothetical securities, each typically with payments due in many future periods. Then, changes in the entire distribution of future obligations can be approximated by changes in the outstanding amount of these hypothetical

${ }^{*}$ International Monetary Fund. Email: pbarrett@imf.org

${ }^{\dagger}$ Department of Economics, Georgetown University. Email: cwj20@georgetown.edu

${ }^{1}$ See Dias et al. (2016) for a comparison of the face value, market value, and zero-coupon equivalent measures of the total debt stock.

${ }^{2}$ See, for example: Angeletos (2002), Buera and Nicolini (2004), Arellano and Ramanarayanan (2012), and Ellison and Scott (2020) 
securities. While the literature includes many different ways to parametrically approximate the public debt maturity in this way, ${ }^{3}$ there is no apparent consensus on which is best, or even an exploration of their relative advantages and disadvantages.

This paper is an attempt to fill this gap. In doing so, we make three main contributions. Our first contribution, in Section 2, is to assemble a novel and comprehensive dataset of of the maturity distribution of all payments required to meet the public debt obligations of the United States and United Kingdom. We collect data on every debt outstanding at monthly frequency for the last 150 years ${ }^{4}$ mostly from primary sources on individual bonds outstanding. ${ }^{5}$ From these data we compute the entire stream of payments from coupons, principal payments and so forth for each outstanding asset in every month, aggregating them to produce debt maturity densities - the fraction of outstanding repayments at each horizon in each month. These densities allow for a direct comparison of the entire maturity structure across times and countries even when very different debt assets are being issued. Thus, we provide (what we think is) not only the most complete and detailed picture possible of the maturity structure of public debt in these two countries, but also one easily comparable across time and between countries.

Our second contribution, in Section 3, is an assessment of what types of approximate debt securities can provide a theoretically-coherent approximation to the maturity structure of public debts. An important finding is that many commonly-used models represent the public debt in a way which arbitrarily restricts issuance in particular markets. A simple example illustrates the basic problem. Imagine that public debt is modeled by outstanding bonds of a given fixed duration. For the sake of illustration, imagine further that this fixed duration is ten years. This of course implies there must exist a ten-year bond market in which the government issues debt. But in order to maintain outstanding obligations at only a ten-year horizon there must also be a nine-year bond market, to which the government has access but no choice; every period it simply buys back the entire debt stock, issued in the preceding period. Thus, the modeling simplification (that outstanding bonds are of fixed duration) demands that two bond markets exist but prohibits the government from using one of them. ${ }^{6}$

\footnotetext{
${ }^{3}$ See, for example: Bhandari et al. (2019), Bocola and Dovis (2019), and Shin (2007).

${ }^{4}$ Although we collect data back to 1869 , major changes in issuance around the start of World War I mean that our focus is on 1920-2020.

${ }^{5}$ For the United Kingdom we use a combination of primary sources and the Ellison and Scott (2020) dataset on gilts.

${ }^{6}$ Of course, one could assume that the government has a free hand in the nine-year bond market. At which point a similar argument demands markets for bonds of eight years, seven years, and so on, increasing the state space from one variable (the number of ten year bonds outstanding) to ten (the number of bonds at each horizon up to ten years). But this is just the list of all outstanding debts, and so does not usefully compress the maturity density at all.
} 
This problem is not unique to the preceding example but shows up in many commonlyused simplifications of public debt maturity. A natural question is therefore: what sort of settings avoid this problem? Our main theoretical result answers precisely this question. We show that there is only one approximation which both avoids this problem and can represent the debt maturity structure with fewer parameters than the data themselves: the exponential-coupon bond. Although such bonds have been used in the literature, ${ }^{7}$ they are certainly not the only approach used. Showing that this is the unique way to compress the maturity density without imposing arbitrary constraints on debt issuance is, we believe, a novel finding.

Our third contribution, in Section 4, is an empirical analysis of historical debt maturity. This is a complement to our theoretical analysis, as the debt parameterizations identified by the theory of Section 3 might not necessarily be the best empirical description of the data; there could in principle be a trade-off between theoretical coherence and empirical fit. We therefore estimate both the parameterization suggested by our theoretical work - a portfolio of exponential-coupon bonds - and one representative of other common alternatives - a portfolio of constant-coupon bonds - and assess their ability to parsimoniously describe changes in the data described in Section 2 for the United States and the United Kingdom since 1920. There are two important results. First, it turns out that there is no tradeoff between empirics and theory: the exponential-coupon-bond approach performs better empirically than the alternatives. Second, poorer-fitting alternative parameterizations tell fundamentally different stories about how debt maturity has changed over time. This last point emphasizes that because the interpretation of history depends on how it is distilled to a few key aspects (i.e. parameters) it is essential to make sure that one has good justification for them. In this case, our justification for our preferred interpretation is twofold: it is theoretically consistent, and empirically superior to the alternative.

In Section 5 we develop this contribution further, extending our analysis to look at four emerging market economies: Peru, Poland, Egypt, and Nigeria. Emerging markets are often a focus of research on fiscal topics, such as sovereign default, simply because episodes of fiscal stress are more frequent. And so one might be curious to know if our results carry over to such environment. Although our selected countries are not necessarily the most prominent emerging market borrowers, they are to our knowledge the only emerging markets for which one can compile an exhaustive list of the quantity and terms of all outstanding government debt assets for more than a few years. This allows us to produce a complete characterization

\footnotetext{
${ }^{7}$ Also known as Hatchondo-Martinez bonds, after their origin in Hatchondo and Martinez (2009) exponential-coupon bonds pay out a fixed fraction of the remaining total obligations each period. The distribution of outstanding payments therefore has an exponential distribution.
} 
of monthly public debts, in both domestic and foreign currency, back to 1999 for Peru, 1991 for Poland, 1995 for Egypt, and 2002 for Nigeria. We re-run our analysis on these datasets and show two key findings. First, that our findings for advanced economies hold: exponentialcoupon bonds fit the data better than those with fixed coupons and that interpreting of historical maturity changes varies greatly with the approximating distribution. Second, that the estimated values of the parameters governing the approximating of exponential-coupon bonds are remarkably similar across all countries except Peru.

Our work has further applications in two areas. First, by showing how to approximate the full maturity structure of public debt in a theoretically- and empirically-justifiable way, this paper provides a framework for monitoring changes in the debt maturity structure which might otherwise not be apparent. Second, we provide a vehicle for analysis of central fiscal policy questions - such as debt sustainability, exposure to liquidity shocks, and the like. By use of our framework, such analysis can handle subtle changes in the distribution of public debt maturities while remaining relatively simple.

Related Literature This paper is most closely related to three literatures: debt maturity under optimal fiscal policy, sovereign default with long-duration debt, and empirical measures of public debts. ${ }^{8}$

A longstanding literature on debt maturity management under optimal fiscal policy has its modern origins in seminal contributions by Angeletos (2002) and Buera and Nicolini (2004) who study this question when there is a complete set of non-contingent bonds (i.e. bonds at all maturities). Yet the curse of dimensionality and concerns about incomplete markets mean that quantitative assessments of optimal maturity management typically assume a highly stylized maturity choice: Bhandari et al. (2017), Bhandari et al. (2019) and Debortoli et al. (2017) all study models where the government can issue only one-period bonds and infinite-maturity consols. An important recent generalization is Bigio et al. (2019), who show that optimality itself leads to an issuance distribution that (in the long run, at least) can be described by a single parameter. In contrast, our theoretical results rely not on optimality, but on far weaker assumptions about the government's choice set.

A second related literature is that of sovereign default, where incentives for present and future default are a function of the maturity structure of the government debt, and where concerns for the size of the state space motivate a parametric representation of the maturity structure. While the earliest papers on this topic considered only one-period bonds

\footnotetext{
${ }^{8}$ Debt maturity is also an important issue in corporate finance, and requires models of this choice typically entail a simple parameterization of outstanding obligations (see, for example, Manuelli and Sánchez (2018) and Darst and Refayet (2019)). However, the sheer volume and complexity of public debt offerings far dwarf that of most firms and so parameterization is much more dramatically stylized in the public sector case.
} 
(e.g. Arellano (2008)), the quantitative importance of longer-term bonds was demonstrated by Hatchondo and Martinez (2009) and Chatterjee and Eyigungor (2012), who consider a fixed debt maturity structure with its shape governed by a single parameter. Subsequent extensions by Arellano and Ramanarayanan (2012), Bocola and Dovis (2019), Bai et al. (2015), and Sánchez et al. (2018) allow the maturity structure to be a choice variable of the government, joint with the default decision. These later papers assume a wide diversity of parameterizations of outstanding public debt maturity.

The third related literature is that on empirical approaches to measuring how public debts change over time. In this area, the most closely related works are that of Ellison and Scott (2020), whose bond-level data constitute an important building block of our datacollection exercise for the UK, and Dias et al. (2014), whose zero-coupon-equivalent measure of outstanding obligations is closely related to the debt densities we compute. A further interesting point of comparison is Shin (2007) who collect data on UK government debt and expenditures during the eighteenth century, and assesses the choice of maturity structure against an Angeletos-Buera-Nicolini style optimal debt management framework using just two bonds - again a consol and a one-period bond.

\section{Data}

We start by documenting the complexity and variation of governments' outstanding debts. We focus on the United States and the United Kingdom simply because we can paint a remarkably complete picture of historical debt maturity structure for these countries. No other countries offer as complete a set of public monthly statements on outstanding debts. We compile data from several sources to generate a comprehensive bond-level dataset on the entirety of issuance, terms (i.e. coupon and maturity), and buy-backs at a monthly frequency over a period of more than 150 years for each country.

Using these data, we construct in each month the distribution of all future promised payments (i.e. both principal and coupon) each month. This is just about the richest portrayal possible of the historical government debt structure and is, as far as we are aware, a novel undertaking.

As well as describing our sources and methodology, in this section we also present some simple summary measures of the data. This last step also motivates the rest of our paper. The high dimensionality of these data - some 1800 monthly observations, each a distribution of future obligations due in hundreds of subsequent months - makes reduction of these distributions to parameters essential. 


\section{$2.1 \quad$ Sources}

We obtain data on the quantity, coupon rate, frequency of coupon payments, and maturity date of each marketable US debt security outstanding at the end of each month (January, 1869- present) from the US Treasury's Monthly Statement of the Public Debt (MSPD) (prior to July, 1974 furnished in the month end Daily Statement of the United States Treasury) and cross-check issuances with the US Treasury's database of treasury auction results (19822020). ${ }^{9}$

Similar data for the UK come from three sources. For data on Gilts (coupon-bearing debts of more than 12 months maturity) and Consols (debts with no maturity) prior to 2018 we use marketable debt data from Ellison and Scott (2020). For 2019-2020, Gilts outstanding data are obtained from the UK Debt Management Office's (DMO) Gilts in Issue reports. For UK Treasury Bills (zero-coupon debts of fewer than or equal to 12 months maturity) we combine multiple sources to achieve a dataset of the weekly amount by maturity sold during auction using a competitive bidding process since UK treasury bills were first offered in $1877 .{ }^{10}$ The treasury bill dataset uses The Economist Historical Archive (1877-1946, 195068), Financial Times Historical Archive (1973-86, 1997-98), Bank of England Quarterly Bulletins and Annual Reports (1946-50, 1968-73, 1986-99), and UK DMO's Treasury Bill Tender Results (2000-20).

Although we gather data from 1869 onwards, large changes in financial markets postWorld War I mean that for our headline results we use data for the period 1920-2020. We thus focus on this period for the rest of this section.

\subsection{The maturity structures of US and UK public debts}

Figures 1 and 2 present a summary of the data. Each sub-figure in the panel of figures shows the entire outstanding set of government debt assets for the first month of each decade, and each bar represents an individual debt security with the months to maturity on the $x$-axis and the number of units of the debt (the face value) on the $y$-axis, expressed as a share of GDP. ${ }^{11}$ Bars are colored by the type of security.

\footnotetext{
${ }^{9}$ In Appendix A.2, we compare to an important commercial bond-level data source for the US, CRSP. Post-1950, our dataset agrees exactly with CRSP. However, CRSP coverage of US debts is incomplete pre1950 and almost non-existent prior to 1931. In contrast, our coverage is a) universal back to 1869 and b) available freely to other researchers.

${ }^{10}$ Where data are not available in the form of tender allotments (i.e. the amount sold), we instead use tender offers (i.e. the amount offered for sale)

${ }^{11}$ Despite the infinite maturity of consols, we truncate the $x$-axis for presentation purposes. And in order to abstract from changes in total issuance and instead focus on the distribution of outstanding obligations, we do not harmonize the $y$-axis across panels.
} 


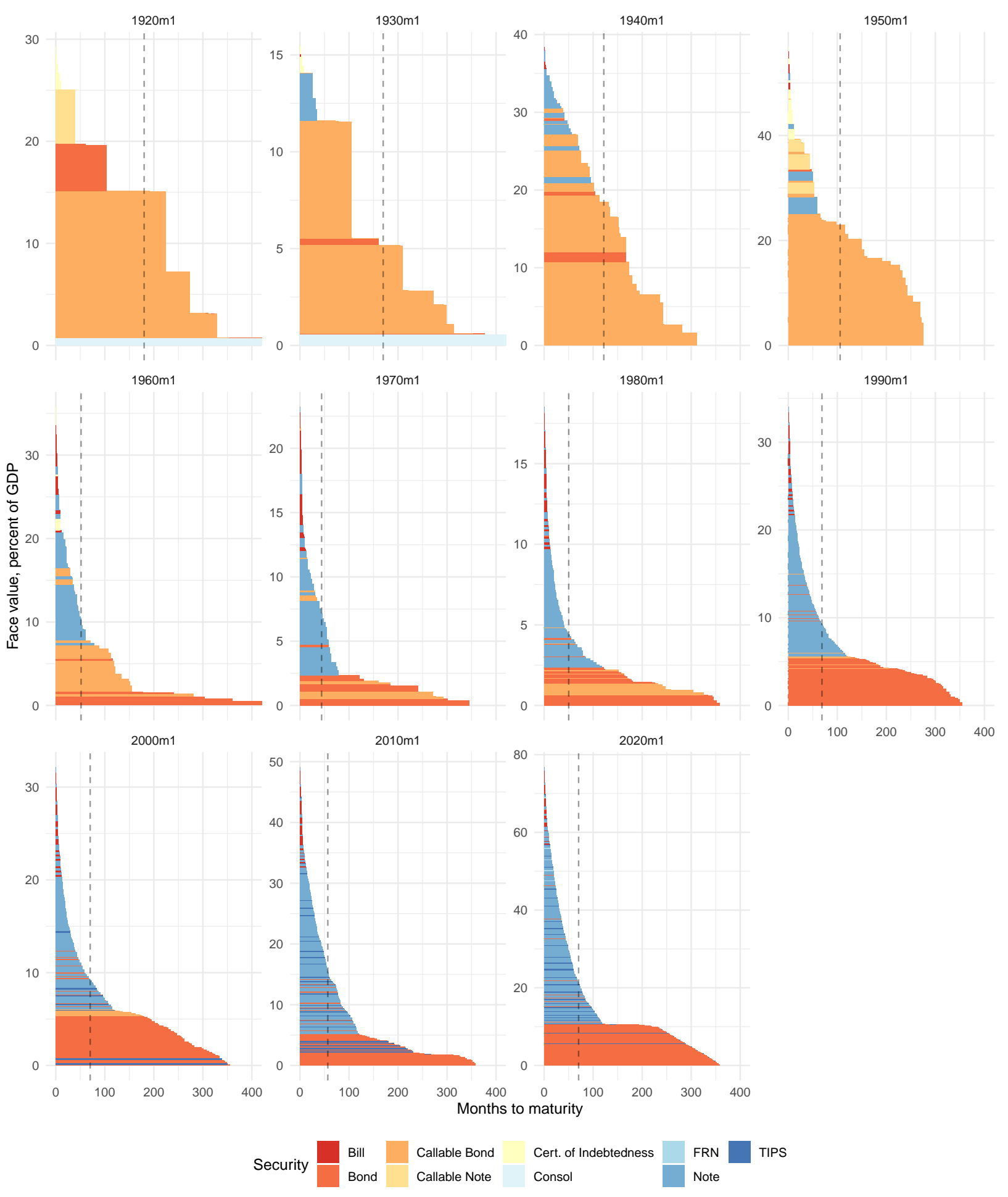

Figure 1: United States Federal government debt obligations by decade, 1920-2020. Vertical line indicates average maturity. 


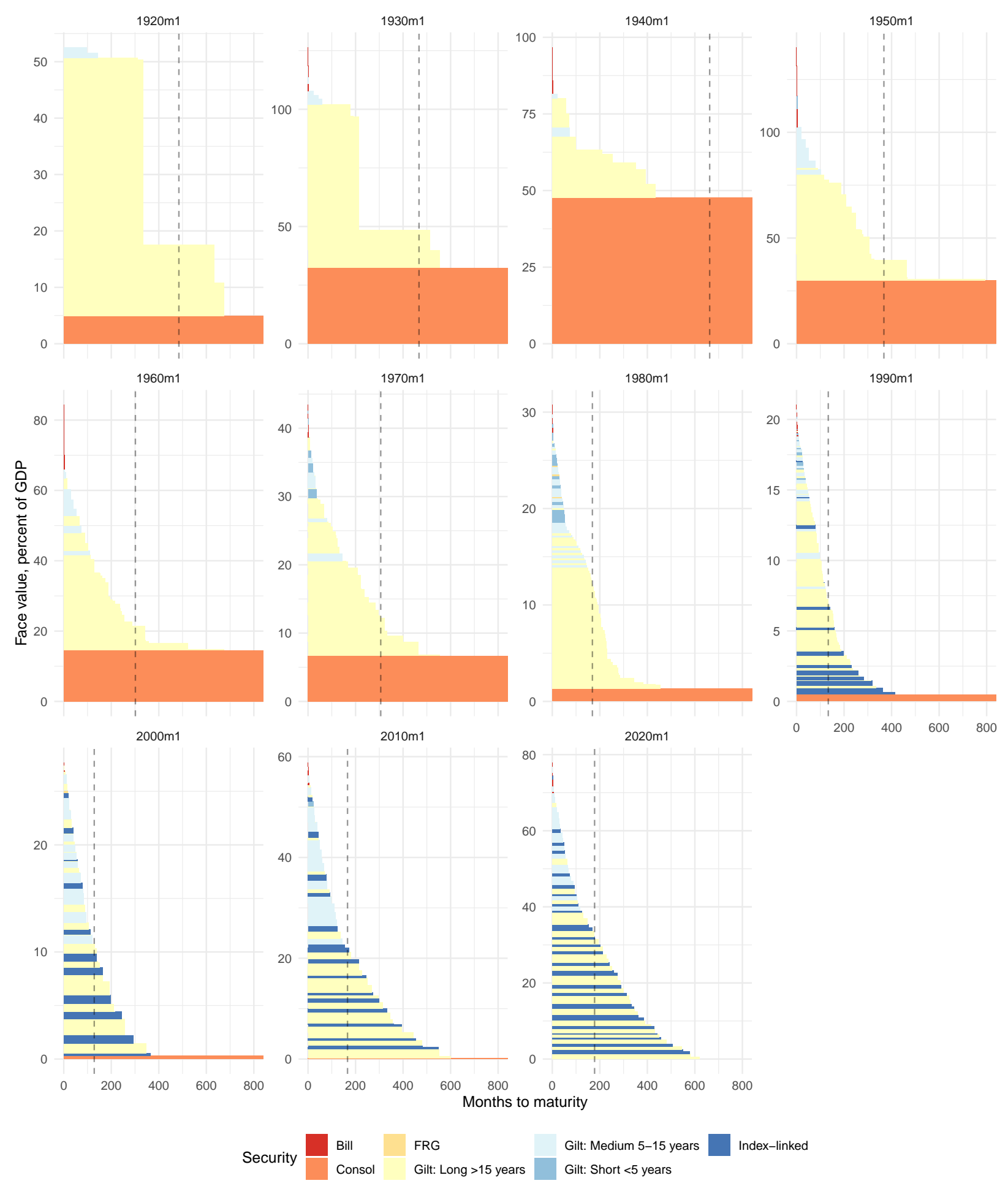

Figure 2: United Kingdom government debt obligations by decade, 1920-2020. Vertical line indicates average maturity. 
From these charts, several features stand out. The most obvious is that there has been a vast increase in number of debt securities - and thus the complexity of government debts for both the US and UK, as shown by the increased variety of the horizontal bars in Figures 1 and 2, and explicitly in Figure 3. ${ }^{12}$ Also rather obvious is the fact that the average maturity of the UK government's debt is far longer than that of the US, and was very long in the 1930s and 1940s (see Figure 4).

Other, more subtle points are also apparent. For example, the US government debt distribution has acquired much fatter tails, with an increasing share of very short and very long bonds. And in the UK, changes in the maturity structure have been largely dominated by the rise and fall of the the consol, at least up until around 1980 .

Despite their comprehensiveness, Figures 1 and 2 leave many interesting questions unanswered. For example, how representative are these one-time snapshots of their representative decades? How have the higher moments of these distributions changed? And perhaps most important of all: what features of these distributions can we map into stylized models of the debt maturity choice?

Answering these questions demands a framework for compressing these data into a small number of easily interpretable parameters. As Figure 4 should make clear, the choice of what parameters one uses to summarize the data (the average maturity being one) can potentially omit very great deal of meaningful information. The rest of this paper is devoted to assessing several ways to do this.

\subsection{Constructing the empirical payment density}

We next establish a common form for aggregating the payouts associated with the different bonds on which we collect data. Each of the bonds in Figures 1 and 2 represents a promise to make a stream of payments at certain future periods. These promises may differ markedly across the different securities. We take account of these differences by converting each bond into a common framework - the stream of future payments - before aggregating across all outstanding assets to form the distribution of future payments outstanding at the end of

\footnotetext{
${ }^{12}$ For the US, in particular, the number of issuances in circulation has skyrocketed since the early $2000 \mathrm{~s}$ - more than doubling in the past 15 years (see Figure 3). This dramatic rise in the number of individual securities outstanding for the US is driven almost entirely by new notes. While the number UK government debt securities peaked in the mid-1980s, it has also grown in the 2000s due to an increase in the number of index-linked gilts and bills outstanding. Also noteworthy are several large spikes in the number of bills outstanding. For much of the past 100 years, the UK auctioned only one three-month bill per week. Spikes in number of bills outstanding are due to deviations from this one-issue-per-week baseline. For example, the spike in number of UK bills in the early 1990s (see Figure 3) represents the UK's weekly issuance of six-month bills from May 1989 to August 1993 - the first issuance of bills with duration exceeding three months in the post-WWI era- which ran parallel with the usual three-month issue.
} 

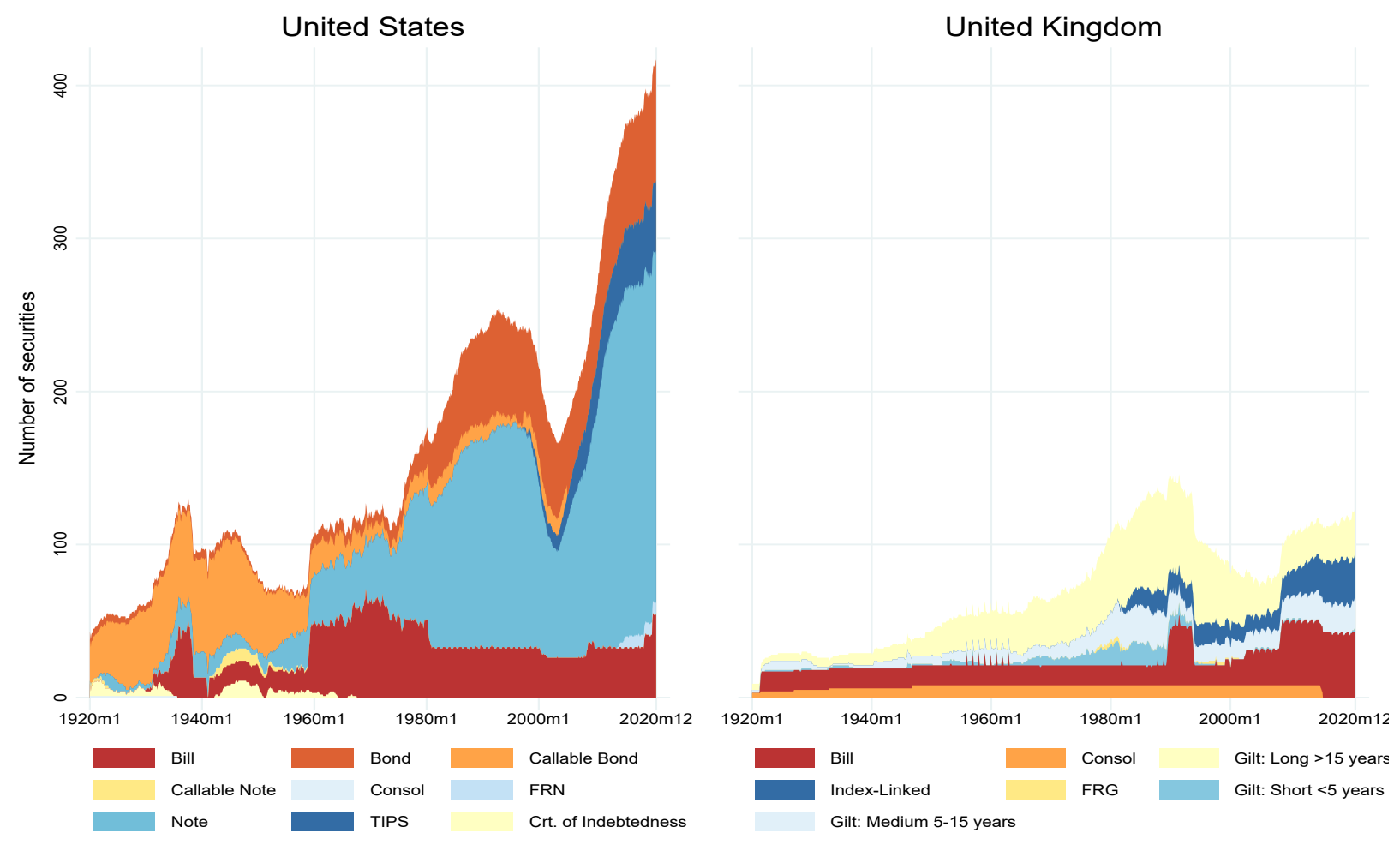

Figure 3: Number of debt assets outstanding, 1920-2020

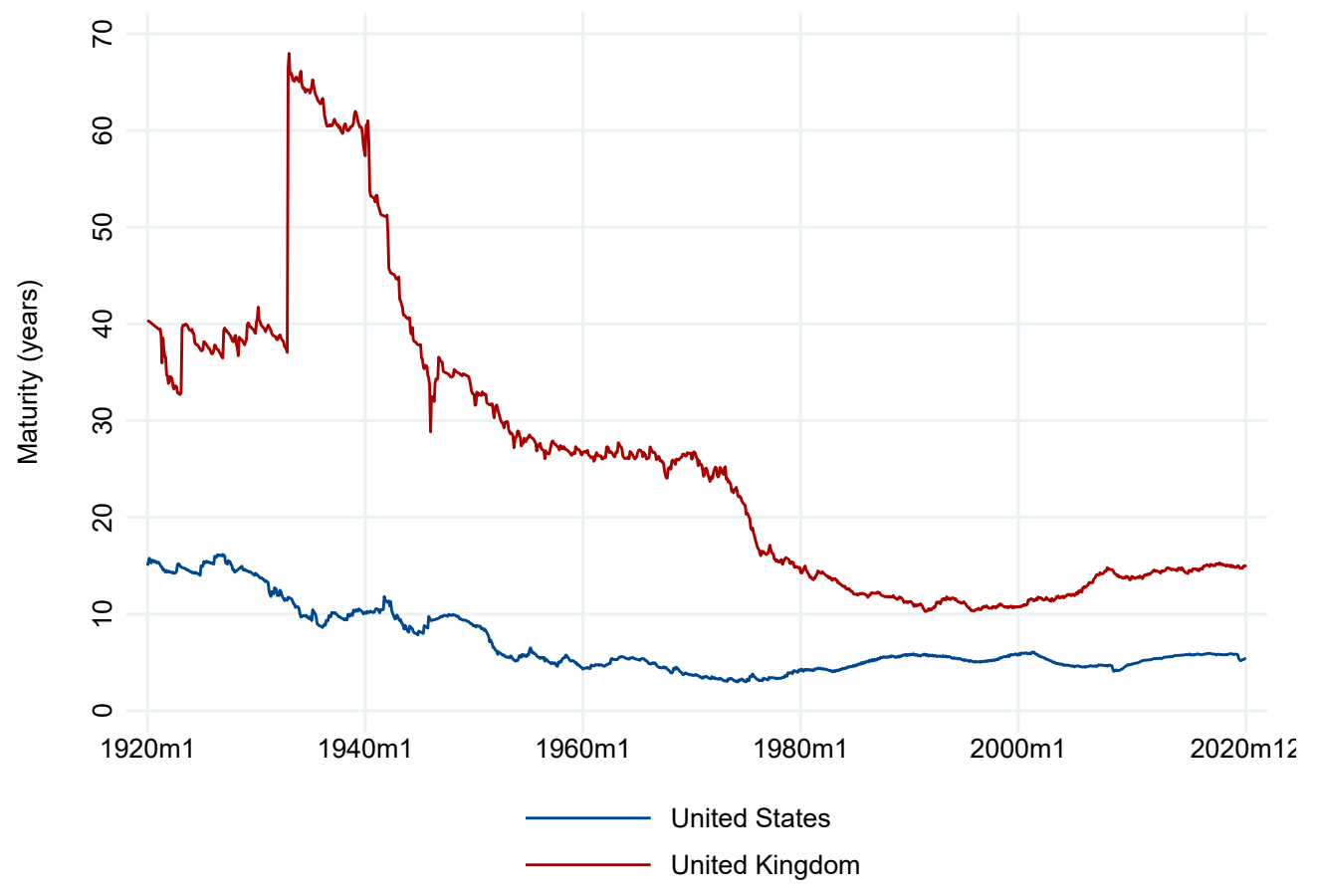

Figure 4: Average debt maturity, 1920-2020 
each calendar month.

We describe the details of this exercise in Appendix A.3 and plot the results this exercise in Figures 5 and 6 (capping coupons at a maturity of 1000 months). Here, each dot represents a promised payment - positioned according to its due date ( $x$-axis) and fraction of total payments ( $y$-axis). These payment densities for the US and UK therefore display the future distribution of promised obligations. These may not be as striking as the Figures 1 and 2, but they are truthful, as they convert the security types into a common unit: promises of future payments. Despite this honesty, it remains difficult to interpret these figures, and so our key problem remains: how best should one parameterize these distributions to interpret their variation. We address this question from a theoretical standpoint in the next section, and from an empirical one in Section 4.

\section{Conceptual framework}

In this section we investigate the implications of standard theoretical assumptions for the set of densities which might be used to model the distribution of public debt maturities. The specific assumptions we study are very light - basic accounting, and that governments can freely trade in a fixed set of asset markets - and are presumably desirable features of any modeling framework.

These simple assumptions have an important consequence. It turns out that there is only one parametric model of the debt maturity structure which both satisfies these assumptions and is more parsimonious than the list of all future obligations. Specifically, it is where the government can trade a fixed set of exponential-coupon bonds. Any other setting either imposes arbitrary restrictions on government debt issuance, or must have as many parameters as the longest horizon at which obligations are due.

Formalizing these ideas and, in particular, proving uniqueness requires some rather dense mathematical analysis. In this section we proceed with two examples: one where there is no restriction on issuance and one where there is. For a more in-depth discussion, including a proof of uniqueness, the interested reader is referred to Appendix B, which provides the requisite mathematical detail.

\subsection{The dynamic evolution of debt}

We assume that time is discrete and indexed by $t=1,2, \ldots$. The government's total obligations at the start of period $t$ coming due in period $t+s$ are denoted by $b_{t}^{s}$. If net issuance of maturity- $s$ claims in period $t$ is $i_{t}^{s}$, then the maturity- $s$ debt stock evolves according to: 


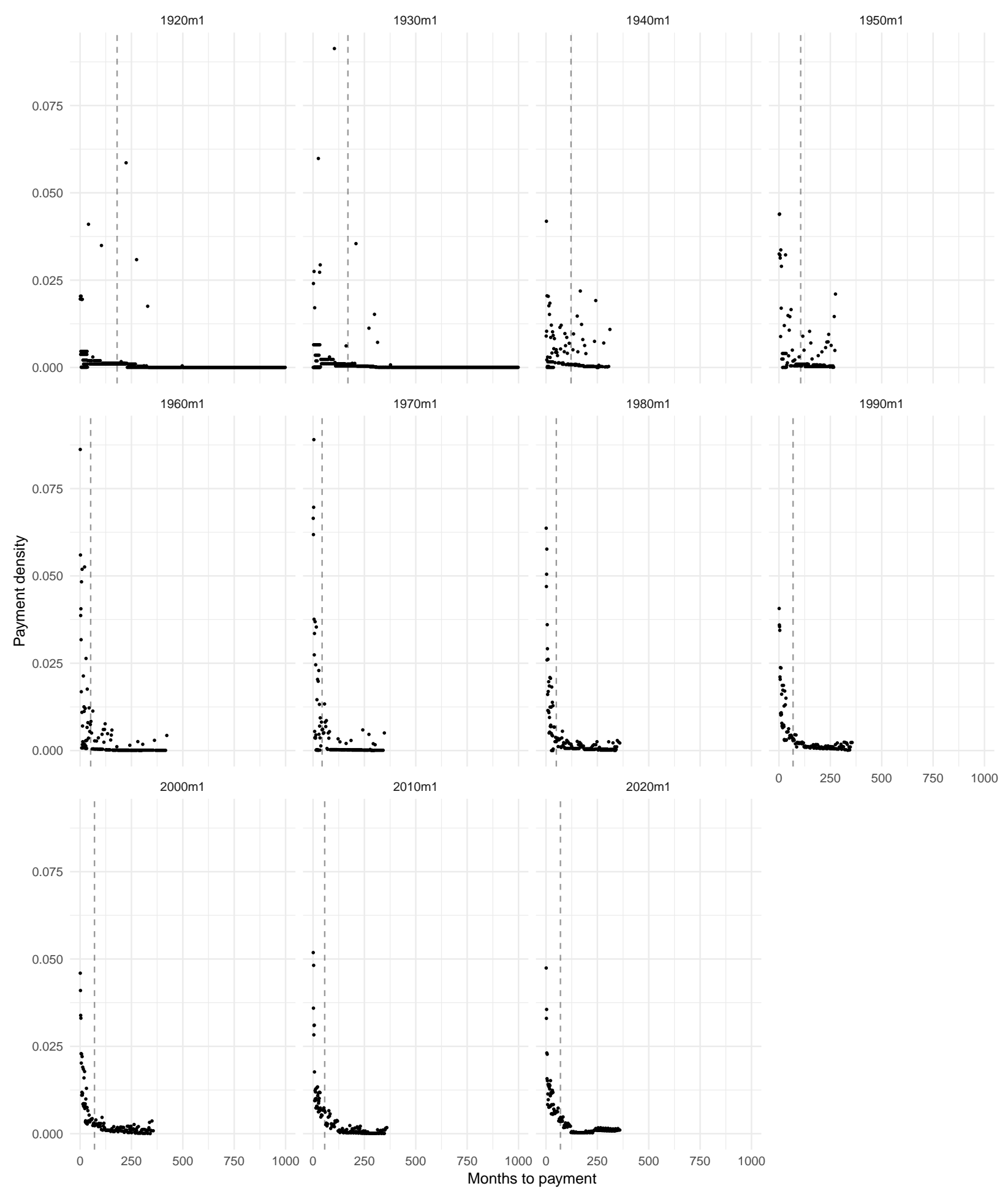

Figure 5: United States federal government debt density by decade, 1920-2020. Vertical line indicates average months to payment. 


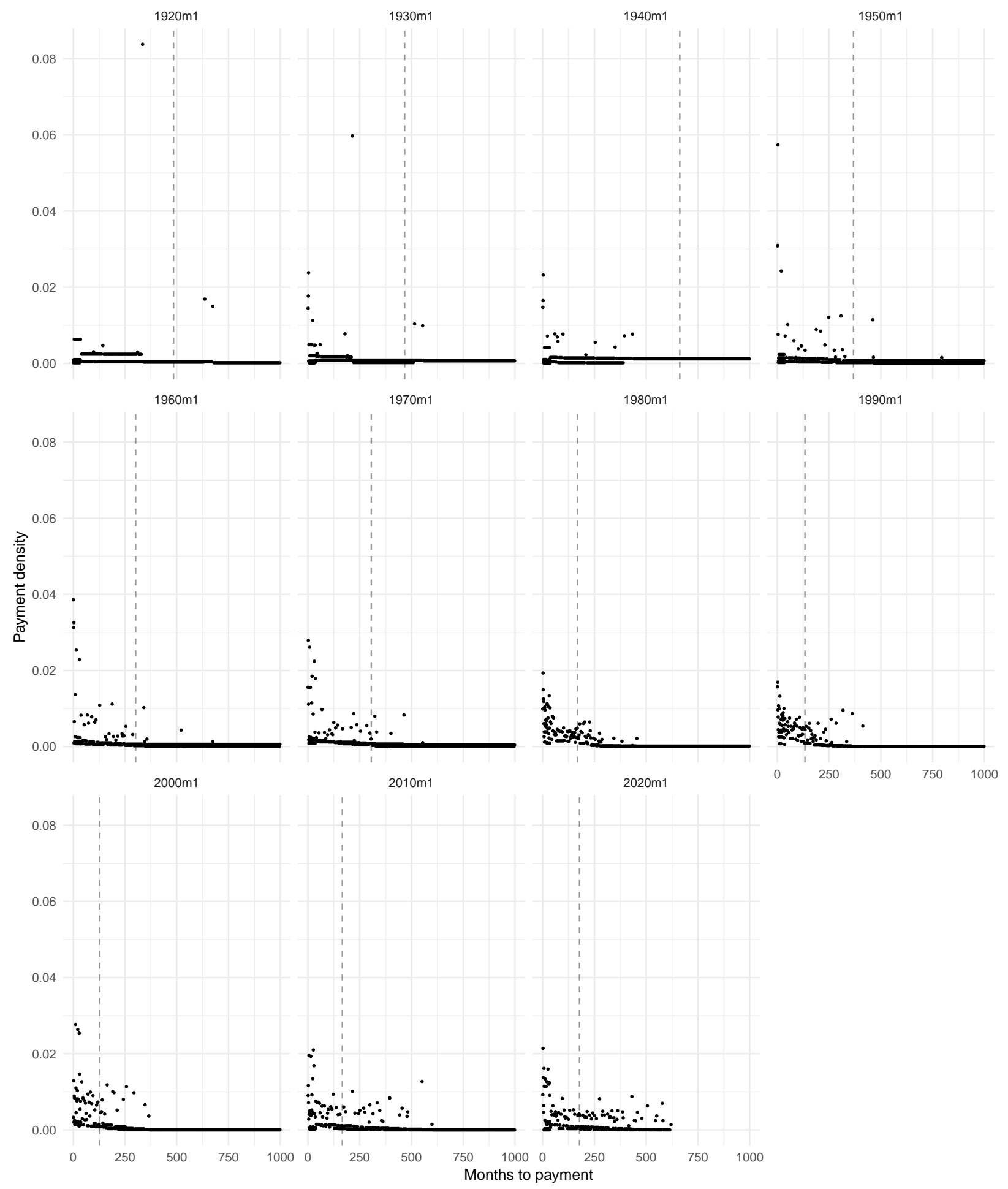

Figure 6: United Kingdom government debt density by decade, 1920-2020. Vertical line indicates average months to payment. 


$$
b_{t+1}^{s}=b_{t}^{s+1}+i_{t}^{s} \quad s \geq 1
$$

Letting $b_{t}, i_{t}$ represent the corresponding debt and issuance totals, so $b_{t}=\sum_{s=1}^{\infty} b_{t}^{s}$ etc. then the aggregate debt evolution equation is:

$$
b_{t+1}=b_{t}-b_{t}^{1}+i_{t}
$$

Equivalently, this says that total issuance $i_{t}$ is equal the change in borrowing, $b_{t+1}-b_{t}$, plus maturing debt, $b_{t}^{1}$. Note that writing the government budget constraint in this way subsumes into $i_{t}$ the impact of the yield curve and deficits. Of course, the price of future claims will determine the mapping from issuance to deficits, but this is not our main concern here - the evolution of the maturity structure depends only on the net issuance of claims, no matter their source or price. ${ }^{13}$

We define the debt and issuance ratios as:

$$
f_{t}(s)=\frac{b_{t}^{s}}{b_{t}} \quad g_{t}(s)=\frac{i_{t}^{s}}{i_{t}}
$$

These functions both sum to one, of course, and so we refer to them both as densities, and $f_{t}(s)$ is the direct theoretical equivalent of the empirical debt distribution, $y_{t}^{s}$ defined in Appendix A.3. We further impose that $f_{t}(s) \geq 0 \forall s$, consistent with the data and meaning that $f_{t}(s)$ is also a probability mass function. Requiring $g_{t}(s)$ to meet a similar non-negativity constraint would be overly restrictive, as many situations where the government changes the maturity structure of its debt, such as a debt swap, will necessarily require that $g_{t}(s)$ be negative for some $s$.

\section{$3.2 \quad$ Two examples}

We now analyze some commonly-used debt parameterizations used in the literature, showing how they map into our framework. We are particularly interested in understanding how assumptions about the debt density $f_{t}(\cdot)$ impose on the issuance density $g_{t}(\cdot)$.

As we show in Appendix B, equations (1) - (3) imply that new debt $f_{t+1}(\cdot)$, can be expressed as a weighted average of un-matured old debt $f_{t}(\cdot)$ and issuance $g_{t}(s)$ :

$$
f_{t+1}(s)=\left(1-w_{t}\right) g_{t}(s)+w_{t}\left(\frac{f_{t}(s+1)}{1-f_{t}(1)}\right) \quad \forall s
$$

\footnotetext{
${ }^{13}$ Specifically, issuance is gross financing needs divided by the issuance-weighted average price of debt, i.e. $i_{t}=\frac{d_{t}+b_{t-1}^{1}}{\sum_{s=1}^{\infty} g_{t}(s) q_{t}^{s}}$, where $d_{t}$ is the overall deficit in period $t$ and $q_{t}^{s}$ the price of the $s$-period zero-coupon bond.
} 
Where $w_{t} \in[0,1]$ is a decreasing function of aggregate issuance relative to outstanding debt, $i_{t} / b_{t}$.

We are interested in thinking about the settings where new and old debt can be represented by the same family of distributions. This is a convenient way to compress the debt maturity structure because it means that debt in each period can be described by a parameter vector $\omega_{t}$, which we write as $f_{t}(s)=f\left(s \mid \omega_{t}\right)$ and $f_{t+1}(s)=f\left(s \mid \omega_{t+1}\right)$. Then the evolution of the debt over time is described not by arbitrary functions, but instead by a much smaller object: the sequence of parameters $\omega_{1}, \omega_{2}, \ldots$ Of course, equation (4) means that imposing a particular functional form on $f_{t}(\cdot)$ and $f_{t+1}(\cdot)$ also imposes some restrictions on the issuance function $g_{t}(s)$. Our aim here is to understand when the resulting $g_{t}(s)$ can be interpreted as allowing the government free access to a variety of debt markets. As we will see, in many cases it cannot.

Exponential-coupon bonds. We start with the only setting where there is no restriction on issuance, the case where outstanding debts are all exponential-coupon bonds. Specifically, we assume that there are $M$ outstanding bonds indexed by $i$. Bond $i$ has decay rate $\theta_{i}$, which means that each period a fraction $\theta_{i}$ of the outstanding balance $i$ comes due. The share of bond $i$ in total time- $t$ obligations is $\omega_{i, t}$. Then $\omega_{t}=\left(\omega_{1, t}, \ldots, \omega_{M, t}\right)$ is the parameter vector describing the entire maturity density at time $t$ :

$$
f_{t}(s)=f\left(s \mid \omega_{t}\right)=\sum_{i=1}^{M} \omega_{i, t} \theta_{i}\left(1-\theta_{i}\right)^{s-1}
$$

Our aim is now to show that there is a market structure for issuance which can guarantee that $f_{t+1}(\cdot)$ is expressible in the same way, which does not put arbitrary constraints on issuance. In this case, it is enough to assume that the government has access to each of the $M$ bond markets with amortization rates $\theta_{1}, \ldots, \theta_{M}$. Then the issuance density is given by:

$$
g_{t}(s)=\sum_{i=1}^{M} \sigma_{i, t} \theta_{i}\left(1-\theta_{i}\right)^{s-1}
$$

where $\sigma_{i, t}$ is the share of issuance in market $i$.

It is straightforward to show then that for any aggregate issuance $w_{t} \in[0,1]$ and bondspecific issuance shares $\sigma_{i t}$, that the distribution for new debt is in the same family. That is, $f_{t+1}(s)=f\left(s \mid \omega_{t+1}\right)$ where:

$$
\omega_{t+1}=\left(1-w_{t}\right) \sigma_{i, t}+w_{t}\left(\frac{\omega_{i, t}\left(1-\theta_{i}\right)}{1-\sum_{j=1}^{M} \omega_{j, t} \theta_{j}}\right) \quad \forall s
$$


Crucially, this holds for any weights $\omega_{t}, \sigma_{t}$, and $w_{t}$. More intuitively, for a government which starts with any set of outstanding exponential-coupon bonds and then chooses any new issuance of those same securities, the new debt portfolio is also a set of outstanding exponential-coupon bonds. The deep reason that this holds is because an exponential-coupon bond decays at the same rate at all horizons, the residual maturity of an exponential-coupon bond is itself an exponential-coupon bond.

Bullet bond with a coupon. A alternate simple model of the government's bond structure is one where it owes only bonds which pay out a coupon $c$ for $T$ periods until a terminal payment of one unit is due. For simplicity, we consider the case where there is just one bond with coupon $c$ and fixed maturity $T$. Then the outstanding debt density is always given by:

$$
f_{t}(s)=y_{c, T}(s) \equiv \begin{cases}c /(1+c T) & s<T \\ 1+c /(1+c T) & s=T \\ 0 & s>T\end{cases}
$$

Dvorkin et al. (2020) use this type of bond with $c=0$ in a model of government debt renegotiation. And Manuelli and Sánchez (2018) use a version with stochastic maturity $T$ for a model of corporate debt issuance.

In this case, the government must trade in two markets. First, it buys back old bonds in their entirety, so there must be a market for bonds of maturity $T-1$. Second, it issues new debt, which can only be of duration $T$. In other words, issuance is given by:

$$
g_{t}(s)=\underbrace{\left(1-\sigma_{t}\right) y_{c, T}(s)}_{\text {New issuance }}+\underbrace{\sigma_{t} y_{c, T-1}(s)}_{\text {Buying back old debt }}
$$

The crucial difference with the previous example is that now, the choice of issuance in the two available markets is not free. For equation (4) to hold, it must be the case that $\sigma_{t}=-w_{t} /\left(1-w_{t}\right)$, i.e. that the government buys back the whole outstanding debt stock in every period. In other words, by assuming that the government debt stock is always a bond of maturity $T$, we have to assume that the market for bonds of length $T-1$ exists, but that the government cannot issue in this market. This is wholly arbitrary - there is no fundamental or economic reason for this beyond convenience.

This turns out to be a problem for every other parameterization of the debt maturity structure bar one. The obvious extension which is exempt from this critique is that where the maturity structure of debt allows bullet bonds at all horizons out to $T$. In this case, $\omega_{t}$ 
is simply a vector of weights on each of the $i$ bonds, and:

$$
f(s \mid \omega)=\sum_{i=1}^{T} \omega_{i, t} x_{c, i}(s)
$$

In this case, the government can issue freely in all markets of all bullet bonds up to maturity $T$. Yet this is not a terribly useful parameterization, as it fails to reduce the dimensionality of debt maturity structure at all. This illustrates our claim that the exponential-coupon setup is the only one which can represent the debt maturity structure parsimoniously without arbitrarily restircting issuance..

\section{Empirical evidence: Summarizing changes in US and UK debt maturity}

In this section, we assess empirically different approaches to parameterizing debt densities. The choice of any parametric representation of debt maturity structures sets up a trade-off between accuracy and parsimony. On the one hand, an approach with more parameters can always provide a better fit to historical data. But this comes at the cost of greater complexity, which might be particularly undesirable if one wishes to fit a tractable theoretical model to the data.

Our headline estimates come from fitting portfolios of bonds with exponentially-decaying coupons. The justification for this is in the preceding section. That is, this parameterization can be rationalized by unrestricted market access. However, to gain additional context in terms of an empirical benchmark we also compare our results to those from by fitting portfolios of constant-coupon bonds to the data.

We also limit our sample to post-1920 for both countries, consistent with evidence of a structural break following the start of World War I.

\subsection{Methodology}

We start by estimating a parameterizaton of the debt maturity structure which arises if the government has access to a finite number $M$ of constant-maturity exponential-coupon bonds.

The decay rate of the bond in market $i$ is denoted by $\theta_{i}$ and the share of that asset in the time- $t$ estimated density by $\omega_{i, t}$. Observations are indexed by $t=1, \ldots, T$, which here are months. We also assume a maximum empirical maturity $S$, which we set to 1200 . 
In this case, the likelihood is a mixture distribution,

$$
l(\theta, \omega \mid y)=\sum_{t=1}^{T} \sum_{s=1}^{S} y_{t}^{s} \log \left(\sum_{i=1}^{M} \omega_{i t} \theta_{i}\left(1-\theta_{i}\right)^{s-1}\right)
$$

We maximize (5) over the parameter space subject to:

$$
\sum_{i=1}^{M} \omega_{i t}=1 \quad \forall t=1, \ldots, T
$$

Given this constraint, there are $M+T \times(M-1)$ parameters to estimate.

\subsection{Headline results}

Table 1 presents our headline results. The top half of the table reports the estimated bond decay parameters $\theta_{i}$. For example, when $M=3$, this implies that the best fit for a threebond exponential-coupon framework is one with three bonds, each with decay parameters of $0.8 \%, 3.2 \%$ and $23.7 \%$, respectively. Perhaps a more intuitive interpretation is that the best three-market approximation of the US government debt maturity structure is one with bonds with durations of 10 years, 2-3 years, and 4 months. ${ }^{14}$

With over 1200 periods, we do not report the estimated time-varying weights directly in Table 1, but instead their averages over the sample. This is shown in the lower half of the table, with standard errors computed from the full variance-covariance matrix by the delta method. This says that on average over the last 100 years, the appropriate weights on US government debt are a rough 60-25-15 split across the long, medium, and short markets defined by the bond decay parameters.

To give a better sense of the time series variation in the data, we also show in Figure 7 the average weights split by decade. ${ }^{15}$ Compared to the simple average maturity in Figure 4 , this provides a much richer description of the debt maturity structure over the last hundred years. At the same time, it not only remains relatively easy to understand but also has a solid theoretical and empirical justification. Specifically, Figure 7 says that in the first half of our sample, the US government substituted very long-maturity obligations first for short debt (in the 1930s and 40s) and later medium-dated securities. By the 1970s, most government debt was in the middle of the term structure, accounting for around half of all

\footnotetext{
${ }^{14}$ As $1 / 0.008 / 12 \simeq 10.4,1 / 0.032 / 12 \simeq 2.6$ and $1 / 0.237 \simeq 4.2$.

${ }^{15}$ Although point estimates of the $\omega_{i t}$ are relatively stable at monthly frequencies, standard errors are large. By aggregating to decades we preserve an accurate description of the changes in the composition of the public debt over time while retaining a useful measure of the uncertainty in our estimates.
} 
Table 1: MLE Estimates, Exponentially decaying coupon 1920-2020

\begin{tabular}{|c|c|c|c|c|c|c|c|c|}
\hline & \multicolumn{4}{|c|}{ United States } & \multicolumn{4}{|c|}{ United Kingdom } \\
\hline & $M=1$ & $M=2$ & $M=3$ & $M=4$ & $M=1$ & $M=2$ & $M=3$ & $M=4$ \\
\hline & \multicolumn{8}{|c|}{ Bond decay parameters } \\
\hline \multirow[t]{2}{*}{$\theta_{1}$} & $0.012^{* * *}$ & $0.009 * * *$ & $0.008^{* * *}$ & $0.008^{* * *}$ & $0.004^{* * *}$ & $0.003^{* * *}$ & $0.002^{* * *}$ & $0.002^{* * *}$ \\
\hline & $(0.0003)$ & $(0.0003)$ & $(0.0004)$ & $(0.0003)$ & $(0.0001)$ & $(0.0001)$ & $(0.0001)$ & $(0.0001)$ \\
\hline \multirow[t]{2}{*}{$\theta_{2}$} & & $0.129 * * *$ & $0.032^{* * *}$ & $0.030^{* * *}$ & & $0.008^{* * *}$ & $0.006^{* * *}$ & $0.006^{* * *}$ \\
\hline & & $(0.0185)$ & $(0.0052)$ & $(0.0044)$ & & $(0.0005)$ & $(0.0005)$ & $(0.0005)$ \\
\hline \multirow[t]{2}{*}{$\theta_{3}$} & & & $0.237^{* * *}$ & $0.177^{* * *}$ & & & $0.009 * * *$ & $0.009 * * *$ \\
\hline & & & $(0.0344)$ & $(0.0377)$ & & & $(0.0009)$ & $(0.0006)$ \\
\hline \multirow[t]{3}{*}{$\theta_{4}$} & & & & $0.334^{* * *}$ & & & & $0.446^{* * *}$ \\
\hline & & & & $(0.1056)$ & & & & $(0.0685)$ \\
\hline & & & & Average & weights & & & \\
\hline \multirow[t]{2}{*}{$\bar{\omega}_{1}$} & & $0.744^{* * *}$ & $0.605^{* * *}$ & $0.601^{* * *}$ & & $0.466^{* * *}$ & $0.437^{* * *}$ & $0.457^{* * *}$ \\
\hline & & $(0.0146)$ & $(0.0207)$ & $(0.0154)$ & & $(0.0191)$ & $(0.0138)$ & $(0.0193)$ \\
\hline \multirow[t]{2}{*}{$\bar{\omega}_{2}$} & & $0.256^{* * *}$ & $0.243^{* * *}$ & $0.235^{* * *}$ & & $0.534^{* * *}$ & $0.220^{* * *}$ & $0.201^{* * *}$ \\
\hline & & $(0.0146)$ & $(0.0227)$ & $(0.0179)$ & & $(0.0191)$ & $(0.0290)$ & $(0.0358)$ \\
\hline \multirow[t]{2}{*}{$\bar{\omega}_{3}$} & & & $0.152^{* * *}$ & $0.109^{* * *}$ & & & $0.343^{* * *}$ & $0.304^{* * *}$ \\
\hline & & & $(0.0147)$ & $(0.0201)$ & & & $(0.0335)$ & $(0.0316)$ \\
\hline \multirow[t]{2}{*}{$\bar{\omega}_{4}$} & & & & $0.055^{* * *}$ & & & & $0.038^{* * *}$ \\
\hline & & & & $(0.0181)$ & & & & $(0.0065)$ \\
\hline $\mathrm{T}$ & 1212 & 1212 & 1212 & 1212 & 1212 & 1212 & 1212 & 1212 \\
\hline S & 1200 & 1200 & 1200 & 1200 & 1200 & 1200 & 1200 & 1200 \\
\hline Params. & 1 & 1214 & 2427 & 3640 & 1 & 1214 & 2427 & 3640 \\
\hline Log lik & -6607.68 & -6414.59 & -6390.90 & -6388.83 & -7919.62 & -7795.21 & -7786.92 & -7744.89 \\
\hline $\mathrm{AIC}$ & 13217.36 & 15257.18 & 17635.80 & 20057.67 & 15841.25 & 18018.43 & 20427.84 & 22769.78 \\
\hline
\end{tabular}


debt, and the remaining repayments split evenly between short- and long-term debt. In the years since, however, long-maturity bonds have once more accounted for the majority of future promises, with reliance on the short end of the term structure declining, particularly in the last decade.

For the UK, the story is a little different. The UK government's tradition of issuing very long debt, particularly consols, is reflected in the estimated parameters $\theta_{i}$. In fact, our approach provides a useful quantitative point of comparison to the US case. For $M=3$, for example, the shortest bond needed to approximate the UK's debt maturity structure is approximately as long as the longest bond used in the US case $\left(\theta_{3}^{U K}=0.009\right.$ vs $\left.\theta_{1}^{U S}=0.008\right)$. Moreover, the time series description tells a story of wholesale changes to the maturity structure rather than a balance of different maturities as in the US. The story of public debt maturity in the UK is one of a change from ultra-long debt before around $1950\left(\theta_{1}=0.002\right.$ has an average duration of over 40 years) to simply long debt in the 1970s and 80s $\left(\theta_{3}=0.009\right.$, or around 9 years), to slightly longer debt in the 2010s (average duration of around 16 years).

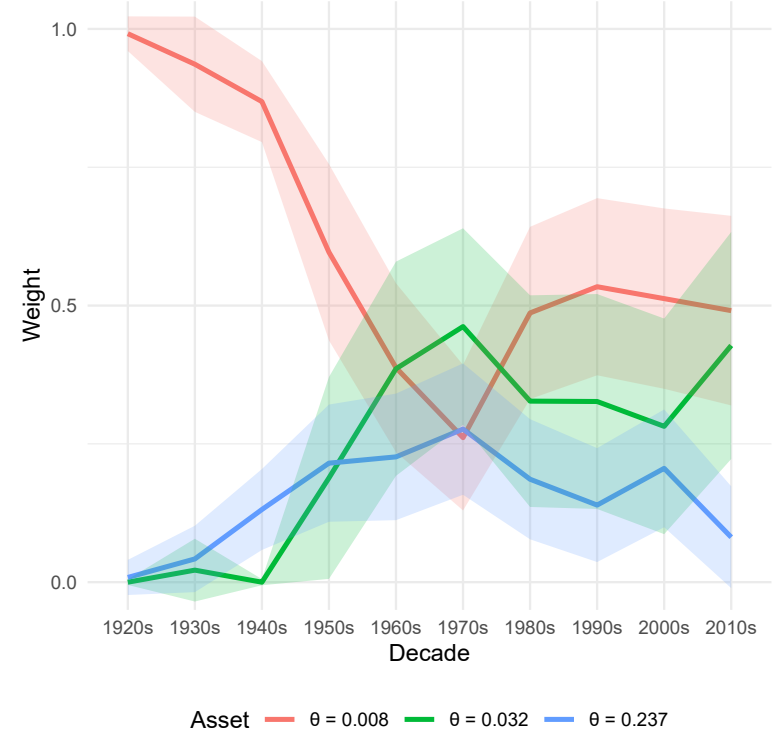

(a) United States

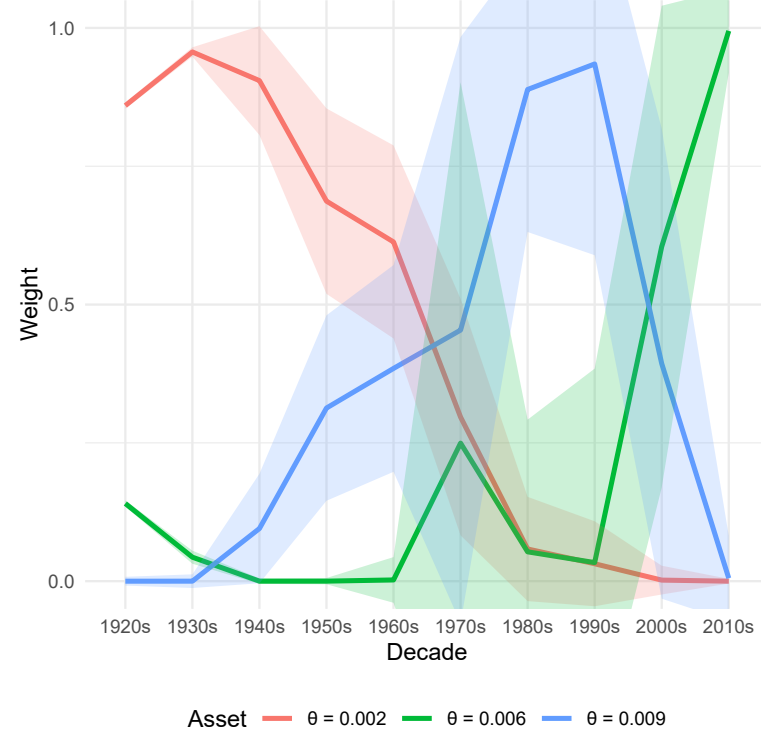

(b) United Kingdom

Figure 7: Weights on exponential-coupon bonds for $M=3$, decadal mean and two-standarddeviation range (shaded areas), 1920-2020.

\subsection{Model selection}

We now turn to the issue of model selection, asking: which model specification is, in some meaningful sense, best? We proceed in two stages, first assessing the exponential-coupon- 
style models reported in the previous section, before going on to compare these against other approaches used in the literature.

One standard approach is to use the model with the minimum Akaike Information Criterion (AIC). This adjusts the fitted log likelihood with a penalty on the number of parameters to deter over-fitting. The AIC is reported in Table 1 and for both countries is minimized at $M=1$. A dimensionality issue is faced as the gain from reducing the likelihood is not sufficient to offset the penalty from the larger number of free parameters, which increase by $T \simeq 1200$ for every unit increment in $M$.

This result might come as somewhat surprising, saying as it does that the government debt maturity structure is statistically indistinguishable from simply being constant over time. A possible driver of this result might be long payout horizons we consider, which will naturally have a very large effect on the estimation simply because there are so many more horizons at which long-dated debt can be repaid. ${ }^{16}$ If one is particularly interested in debt at short maturities, say, then perhaps fitting the short end of the maturity structure might be more important. As a means of investigating this issue further, we recompute the AIC throwing away observations from the long end of the maturity structure. Figure 8 plots the results of this exercise, with a cutoff maturity on the $x$-axis and the AIC using only the debt up to that cutoff on the $y$-axis. Clearly, the long-dated debt is not driving this result, as $M=1$ minimizes the AIC even when recalculated at very short horizons.

While apparently statistically robust, picking a model with $M=1$ is economically somewhat unsatisfying, as it precludes any analysis of changes in the debt maturity structure. As an alternative, we also consider a more intuitive measure of the goodness of fit of the various models, the absolute average error on the fitted distribution. Up to horizon $s$, we can define this as

$$
\operatorname{err}(s)=\frac{1}{s T} \sum_{t=1}^{T} \sum_{u=1}^{s}\left|f_{t}(u)-\hat{f}\left(u, \theta, \omega_{t}\right)\right|
$$

Where $f_{t}(u)$ and $\hat{f}\left(u, \theta, \omega_{t}\right)$ are the empirical and fitted payment densities for horizon $u$ at time $t$. Figure 9 presents this measure of the forecast error (with an alternative which takes the maximum absolute error across observations). It shows that for the United States, there is a substantial improvement in the fit of the estimated density when $M$ increases from one to two. This suggests that, for the US at least, modeling the debt maturity structure with only two bonds is hard to improve on. For the UK, the benefits of using extra assets to approximate the the debt maturity structure are less evident, with a noticeable improvement

\footnotetext{
${ }^{16}$ That is, each maturity distribution has only twelve observations with a maturity one year or less, but given we consider maturities up to 1200 months - almost 900 of more than ten years.
} 


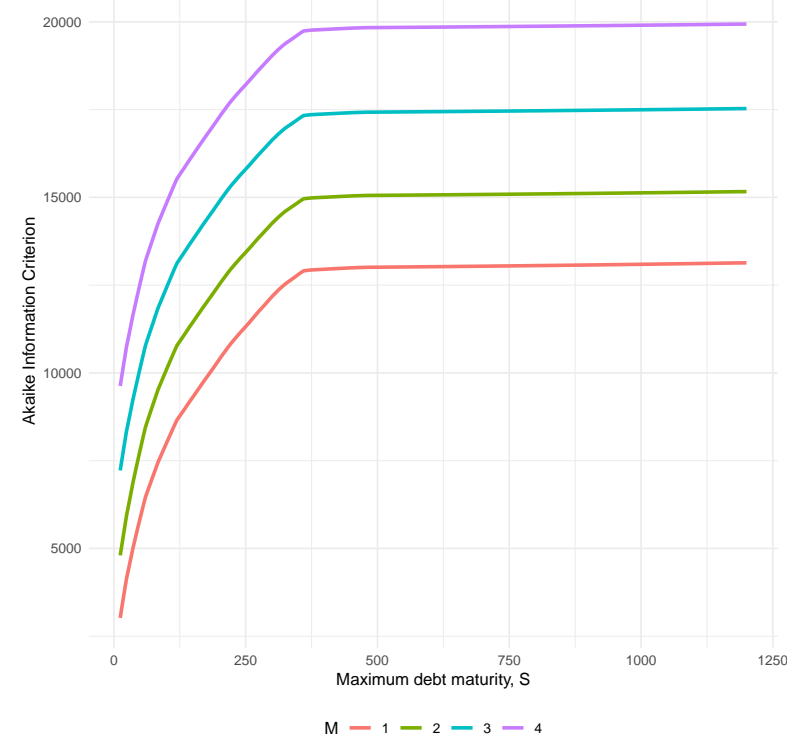

(a) United States

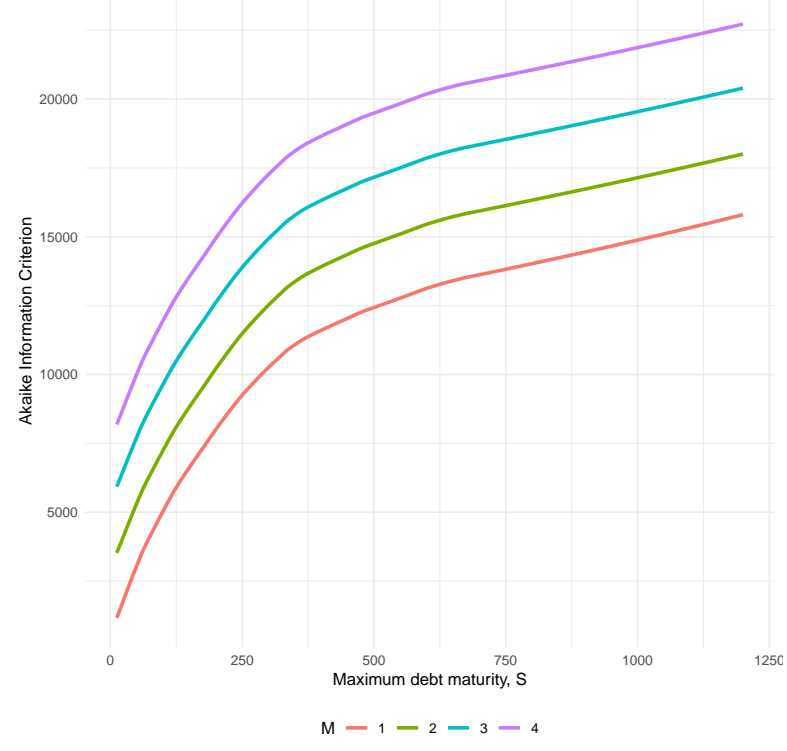

(b) United Kingdom

Figure 8: Akaike information criterion, dropping observations with maturity greater than $s$ months, full sample estimation 1920-2020.

at the short end of the maturity structure only arising once $M=4$.

Another way of reading the evidence on model selection is that it shows that the number of assets used to accurately describe the maturity structure of the public debt is really a free choice for the modeller. There is no strong statistical evidence that there is a minimum number of assets required to well-represent changes in the maturity structure. In this sense, our estimates therefore provide backing for those models which do use a small number of exponential-coupon bonds.

\subsection{Comparison to alternate approaches}

So far we have considered only families of exponential-coupon bonds, on the grounds that they are theoretically coherent. Of course, theoretical coherence may come at the cost of empirical fit. So in this section we estimate an alternate framework, where the government has access to $M$ finite-duration constant-coupon bonds, with the duration of market $i$ represented by $\mu_{i}$.

The density for each market is thus a uniform distribution, adjusted for non-integer durations: 


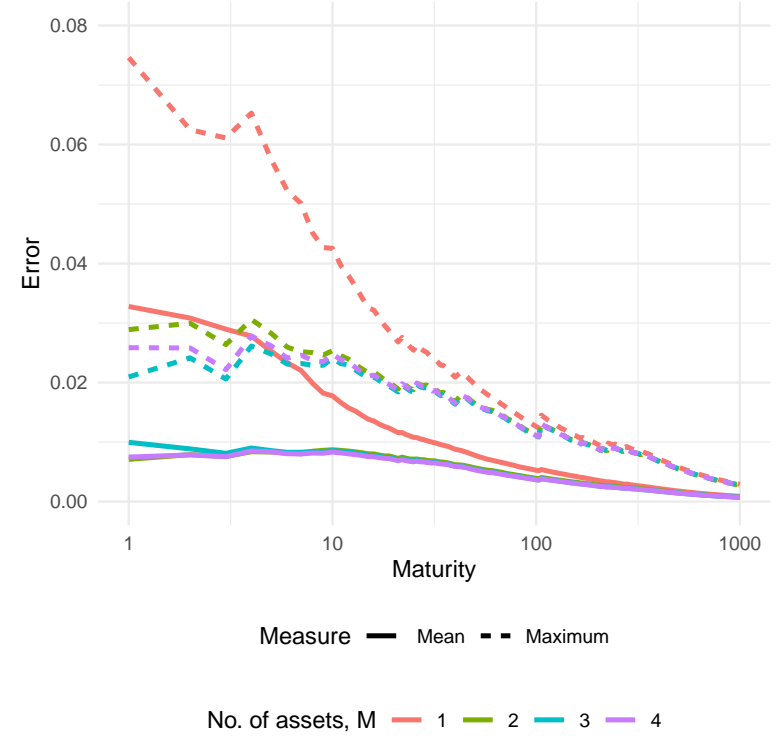

(a) United States

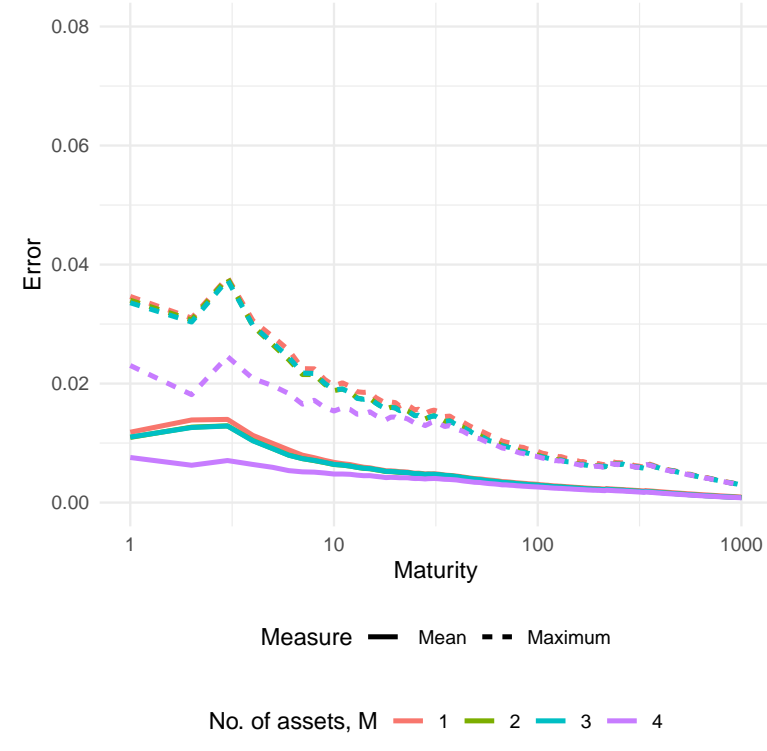

(b) United Kingdom

Figure 9: Average absolute error of fitted density up to each issuance horizon, average an maximum across monthly observations, 1920-2020.

$$
f\left(s \mid \mu_{i}\right)= \begin{cases}1 / \mu_{i} & s<\left\lfloor\mu_{i}\right\rfloor \\ 1-\left\lfloor\mu_{i}\right\rfloor / \mu_{i} & \left\lfloor\mu_{i}\right\rfloor \leq s<\left\lfloor\mu_{i}\right\rfloor+1 \\ 0 & \left\lfloor\mu_{i}\right\rfloor \leq s<\left\lfloor\mu_{i}\right\rfloor+1\end{cases}
$$

In line with our earlier discussion, this debt density cannot be rationalized by unrestricted market access unless $\mu_{i}=i \forall i$ (i.e. a full set of constant-coupon bond markets). However, this finite-maturity approach is broadly representative of a wide set of models in the literature who do use bonds with constant coupons, including Bai et al. (2015) and Dvorkin et al. $(2020)^{17}$. Thus, this approach represents a reasonable alternative benchmark against which to assess the exponential-coupon estimates.

The results of our estimation are shown in Table 2. The $\mu_{i}$ are in months and the average duration of bond $i$ is $\mu_{i} / 2$, so for $M=3$ the US fitted bonds have average durations of around 1,4 , and 14 years with average weights split 30-30-40 percent. ${ }^{18}$

\footnotetext{
${ }^{17}$ See discussion in Section 3.2. Of course, some of these specifications also have an extra terminal payment. We ignore this on the grounds that it makes the analysis more complicated and - by adding a mass point to the density - a worse fit.

${ }^{18}$ As $22.3 / 12 / 2 \simeq 0.93,100.4 / 12 / 2 \simeq 4.2$, and $339.4 / 12 / 2 \simeq 14$. To avoid infinite log likelihoods we replace zeros in the fitted density with a tiny number, $10^{-12}$. In the US case, this is roughly equivalent to assuming that an outstanding twenty-dollar consol is omitted from the data. Without this adjustment, we would have $\mu_{1}=S=1200$ for all estimates
} 
The constant-coupon approach has a far worse fit to the data, with inferior likelihoods. Indeed, for the US, the fit of the constant-coupon model when $M=4$ is actually worse than the exponentially-decaying-coupon model with $M=1$. This arises because the payment schedule for governments is naturally downward sloping, simply because a smaller fraction of bonds continue to pay out at longer horizons. As a result, the constant-coupon model, which essentially seeks to approximate the payment density by a histogram, has a far poorer within-period fit. This is particularly true at the short end of the maturity structure, as the sharp decay in outstanding obligations simply cannot be matched by the flat maturity profile implied by a constant-coupon bond.

The poorer fit of the constant-coupon framework also has an important impact on the qualitative description of changes in the maturity structure of the public debt. Figure 10 presents the time series shares of different bonds for the case where $M=3$. In particular, for the United States, the clear picture presented in Figure 7 of long-duration bonds returning to pre-eminence in the second half of the twentieth century is completely lost, and instead conveys the impression that short- and in the last decade medium-term bonds have become a larger share of the government debt.

This last point is important, as it shows that two different ways of measuring changes in the debt maturity structure which might seem equally plausible ex ante lead to two rather different interpretations of the basic facts. Having solid grounds to prefer one means of parameterizing the debt maturity structure over another is therefore valuable. In this case, the story told by the exponential-coupon parameterization is clearly superior. Not only is it theoretically coherent in a way that the other is not, as it can be rationalized by unrestricted market access, but it is also has a superior empirical fit.

\section{$5 \quad$ Extension to select emerging markets}

Thus far we have focused our analysis on the US and the UK on the grounds of data availability. Both have remarkably long histories of marketable debt and complete public records of the asset types available. However, as rich countries with a long history of fiscal credibility, it could be argued that this is not where study is most needed. Emerging markets, in contrast, are frequently much more interesting from a fiscal perspective, with episodes of fiscal stress

- including defaults and the like - much more common. And so the characterization of the maturity structure might vary greatly across advanced and emerging market economies.

A challenge one faces, however, is that the things which make emerging markets interesting also make them harder to understand. A proper analysis of the debt maturity structure demands a clear and comprehensive record of all public debt, something often absent in 
Table 2: MLE Estimates, Constant coupon 1920-2020

\begin{tabular}{|c|c|c|c|c|c|c|c|c|}
\hline & \multicolumn{4}{|c|}{ United States } & \multicolumn{4}{|c|}{ United Kingdom } \\
\hline & $M=1$ & $M=2$ & $M=3$ & $M=4$ & $M=1$ & $M=2$ & $M=3$ & $M=4$ \\
\hline & \multicolumn{8}{|c|}{ Bond maturities } \\
\hline \multirow[t]{2}{*}{$\mu_{1}$} & $339.2^{* * *}$ & $74.3^{* * *}$ & $22.3^{* * *}$ & $11.4^{* * *}$ & $1122.0^{* * *}$ & $98.6^{* * *}$ & $66.3^{* * *}$ & $60.0^{* * *}$ \\
\hline & $(0.23)$ & $(0.22)$ & $(0.21)$ & $(0.18)$ & $(0.85)$ & $(0.44)$ & $(0.72)$ & (1.13) \\
\hline \multirow[t]{2}{*}{$\mu_{2}$} & & $333.4^{* * *}$ & $100.4^{* * *}$ & $82.3^{* * *}$ & & $1080.0^{* * *}$ & $222.6^{* * *}$ & $98.9^{* * *}$ \\
\hline & & $(0.48)$ & $(0.49)$ & $(0.49)$ & & $(0.85)$ & $(0.62)$ & (1.91) \\
\hline \multirow[t]{2}{*}{$\mu_{3}$} & & & $339.4^{* * *}$ & $119.8^{* * *}$ & & & $1140.0^{* * *}$ & $223.7^{* * *}$ \\
\hline & & & $(0.55)$ & $(1.00)$ & & & $(0.85)$ & $(0.68)$ \\
\hline \multirow[t]{3}{*}{$\mu_{4}$} & & & & $335.5^{* * *}$ & & & & $1106.0^{* * *}$ \\
\hline & & & & $(0.61)$ & & & & $(0.28)$ \\
\hline & \multicolumn{8}{|c|}{ Average weights } \\
\hline \multirow[t]{2}{*}{$\bar{\omega}_{1}$} & & $0.531^{* * *}$ & $0.278^{* * *}$ & $0.218^{* * *}$ & & $0.317^{* * *}$ & $0.144^{* * *}$ & $0.099 * * *$ \\
\hline & & $(0.02)$ & $(0.02)$ & $(0.01)$ & & $(0.02)$ & $(0.02)$ & $(0.02)$ \\
\hline \multirow[t]{2}{*}{$\bar{\omega}_{2}$} & & $0.469^{* * *}$ & $0.306^{* * *}$ & $0.246^{* * *}$ & & $0.683^{* * *}$ & $0.393^{* * *}$ & $0.083^{* * *}$ \\
\hline & & $(0.02)$ & $(0.02)$ & $(0.02)$ & & $(0.02)$ & $(0.02)$ & $(0.02)$ \\
\hline \multirow[t]{2}{*}{$\bar{\omega}_{3}$} & & & $0.415^{* * *}$ & $0.161^{* * *}$ & & & $0.463^{* * *}$ & $0.358^{* * *}$ \\
\hline & & & $(0.02)$ & $(0.02)$ & & & $(0.02)$ & $(0.02)$ \\
\hline \multirow[t]{2}{*}{$\bar{\omega}_{4}$} & & & & $0.375^{* * *}$ & & & & $0.461^{* * *}$ \\
\hline & & & & $(0.02)$ & & & & $(0.02)$ \\
\hline $\mathrm{T}$ & 1212 & 1212 & 1212 & 1212 & 1212 & 1212 & 1212 & 1212 \\
\hline S & 1200 & 1200 & 1200 & 1200 & 1200 & 1200 & 1200 & 1200 \\
\hline Params. & 1 & 1214 & 2427 & 3640 & 1 & 1214 & 2427 & 3640 \\
\hline Log lik & -7558.37 & -7096.08 & -6868.62 & -6843.33 & -8891.58 & -8652.42 & -8154.14 & -8298.77 \\
\hline AIC & 15118.75 & 16620.16 & 18591.25 & 20966.65 & 17785.17 & 19732.85 & 21162.28 & 23877.53 \\
\hline
\end{tabular}




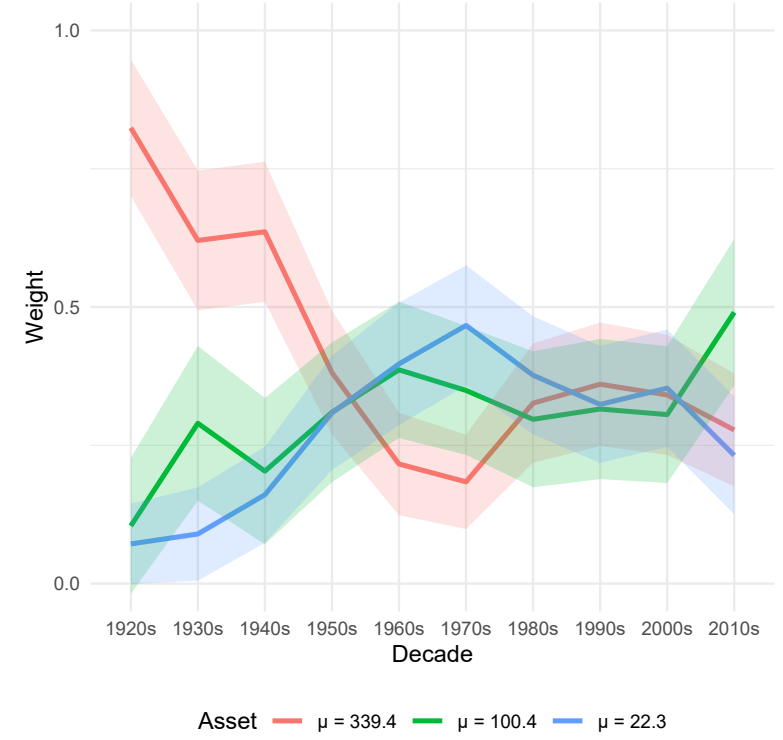

(a) United States

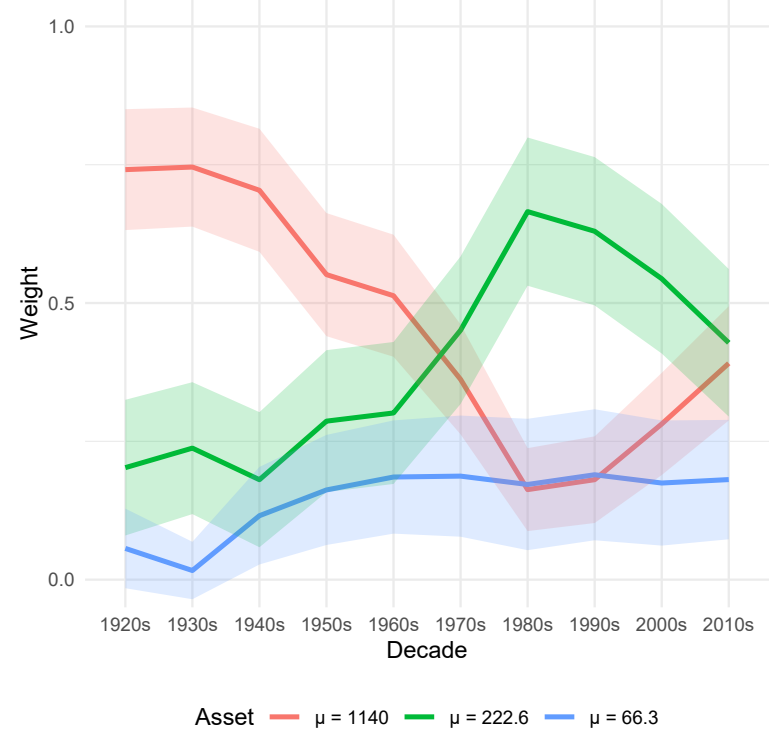

(b) United Kingdom

Figure 10: Weights on constant-coupon bonds for $M=3$, decadal mean and two-standarddeviation range (shaded areas), 1920-2020.

times of fiscal distress. Indeed, we could only find four emerging market economies which have sufficiently rich data over a long enough time period to be able to include in our study: Peru, Poland, Egypt, and Nigeria. All countries produce comprehensive accounts of their public debts, albeit with much shorter histories than for the US and the UK.

\section{$5.1 \quad$ Data}

We gather Peruvian bond-level data from September 2006 to December 2020 using daily reports of public debt outstanding published by the Ministry of Economy and Finance of Peru. This dataset is extended back to 1999 using the complete history of issuance listed in Bloomberg. For Polish data we draw on a remarkably complete database of bond transactions from the Ministry of Finance of Poland. The detailed sale and buy-back data here allow us to completely describe the marketable debts outstanding at any given time from May 1991 to April 2020. For Egypt and Nigeria, we use a combination of debt issuance data provided by each country's respective central bank as well as Egypt's Ministry of Finance and Nigeria's Debt Management Office (with each country having data going back to 2002). In the case of Egypt, we are able to extend back these data to 1995 using Bloomberg data as we did with Peru. ${ }^{19}$

\footnotetext{
${ }^{19}$ In general, Bloomberg is not a sufficient source for reconstructing the full portfolio of public debt obligations. We attempted to use this as a source for several emerging markets, but found that totaling up
} 
It is important to note that we only capture marketable debt, consistent with our work on the US and the UK. Other obligations, such as bilateral debts with other sovereign, or nonmarketable debt held by other state entities, are not included in these numbers. Moreover, as subnational governments rarely have access to liquid bond markets at multiple maturities, we focus on central government debt. As a result, differences in coverage mean that this is typically only a subset of emerging market debt, meaning that the total face value of debts in our sample diverges from commonly-cited aggregate measures. Figure 19 presents the time series of marketable debt (aggregated from our bond-level data) against headline general government debt for each of the four emerging markets we discuss. The differences in recent years between total outstanding debts in our sample and headline debt-to-gdp numbers are most notable in Egypt and Nigeria. That said, we are certain that the data we collect are comprehensive for the subset of marketable debts, which are really the only ones for which changes in maturity structure are relevant.

Similar to Figures 1 and 2, Figure 11 summarizes the public debts outstanding for Poland, this time shown by half-decade (Figures 20 - 22 in Appendix D present the same exercise for the other three countries). A notable difference between the latter four figures and the former two is that there now exist bonds denominated in foreign currency - labeled "International". International bonds account for a substantial portion of face value in each of these emerging markets. One notable feature of these charts is that, unlike other countries in the sample, Peru and Poland have made use of floating-rate bonds at various points in time.

The figures also show a contrast in transitions to marketable debt with Poland favoring short-duration debt in early years and Peru favoring long-duration debt - a strategy for Peru that is still followed with having issued a 100-year bond in November 2020. Also notable is that Poland's transition strategy is very similar to those practiced shortly after in Egypt and Nigeria.

As with the US and UK, we use the terms of each debt security to construct the empirical payment density. For this exercise, Table 4 and the discussion that immediately follows it almost fully captures the methodology with respect to all types of debt securities present in Peru, Poland, Egypt, and Nigeria. The only differences are that: 1) foreign-currency denominated securities are converted to the respective home currency assuming that future exchange rate movements are perfectly foreseen; 2) foreign-currency denominated floatingrate bonds of Poland are indexed to one of either the 3-month LIBOR, 6-month LIBOR, or 3-month EURIBOR; 3) for four Polish Brady bonds with "step-up" coupon rate terms

bond-level issuance rarely matched aggregate sources, presumably because complicated patterns of buybacks, debt swaps, and extra issuance of past bonds are not easy to record and so likely omitted from this source. In the case of Peru, though, official data from 2006 onwards do corroborate summed issuance from Bloomberg, implying that in this case it is a comprehensive source. Likewise for Egypt prior to 2002. 
that are not fully known, we use a fixed rate of $4.75 \%$ - roughly the average of the future "step-ups"; and 4) Peru yield curve data are insufficient to project floating-rate coupons so we assume future coupon payments are perfectly foreseen.

\subsection{Results}

Tables 3 and 11 in Appendix D summarize our headline results for Peru and Poland, and Egypt and Nigeria, respectively.

This highlights how our quantitative framework is able to characterizes quite clearly exactly how these countries' debt maturity structures differ. In particular, Peru's debt maturity structure is on average quite different, and variation in the debt maturity can by explained using long-dated bonds. We interpret these results as saying that Peruvian debt markets are similar to UK ones at the short end (e.g. both have a decay rate for $\theta_{3}$ of 0.9 percent per month in the $M=3$ case) but more like US markets at the long end (the longest-maturity debt decays at 0.6 percent per month, much closer to the US equivalent of 0.8 percent than the UK's 0.2 percent).

In contrast, describing the maturity structures of Poland, Egypt, and Nigeria demands shorter bonds. For them, the longest-maturity bond market is always one with decay rate of around 2-3 percent for $M=1$ or 1.5-2 percent for larger $M .^{20}$ And the shortest bonds are much faster to mature, decaying at rates above 20 percent per month. This is consistent with issuance concentrated in very short maturities, as shown in Figures $20-22$.

In fact, we can make much more specific quantitative comparisons. Although Peruvian government debt can be described using a similar set of assets to that of the US and the UK, the weights on each are quite different. For example, in the $M=3$ case, the weight on the longest bond, $\omega_{3}$ is on average around five percent of the Peruvian government debt. In contrast, the equivalent number for the US and UK debt maturity structures are 15 and 34 percent respectively. For Poland and Egypt, the average weight of the longest bonds in the government's debt portfolio, $\omega_{1}$, is around 55 to 75 percent. But for Nigeria, shorter debt plays a more important role, accounting for more than half of the debt.

The dynamic pattern of the weights on bonds of different maturities also provides a relatively simple lens through which to interpret past issuance. As an example, Figure 12 shows, in panel (a), the monthly weights on each of the exponential-coupon bonds estimated in the $M=3$ case using Poland as an example. ${ }^{21}$ This shows a swift initial transition

\footnotetext{
${ }^{20}$ That is, average durations of 3-4 years for $M=1$ and 4-6 years for larger $M$

${ }^{21}$ These are equivalent to the time series of weights shown in Figure 10, except that 1) with a shorter time series we show the full monthly values for the $\omega_{i}$, rather than decadal averages, and 2) we omit the standard errors for presentational clarity.
} 


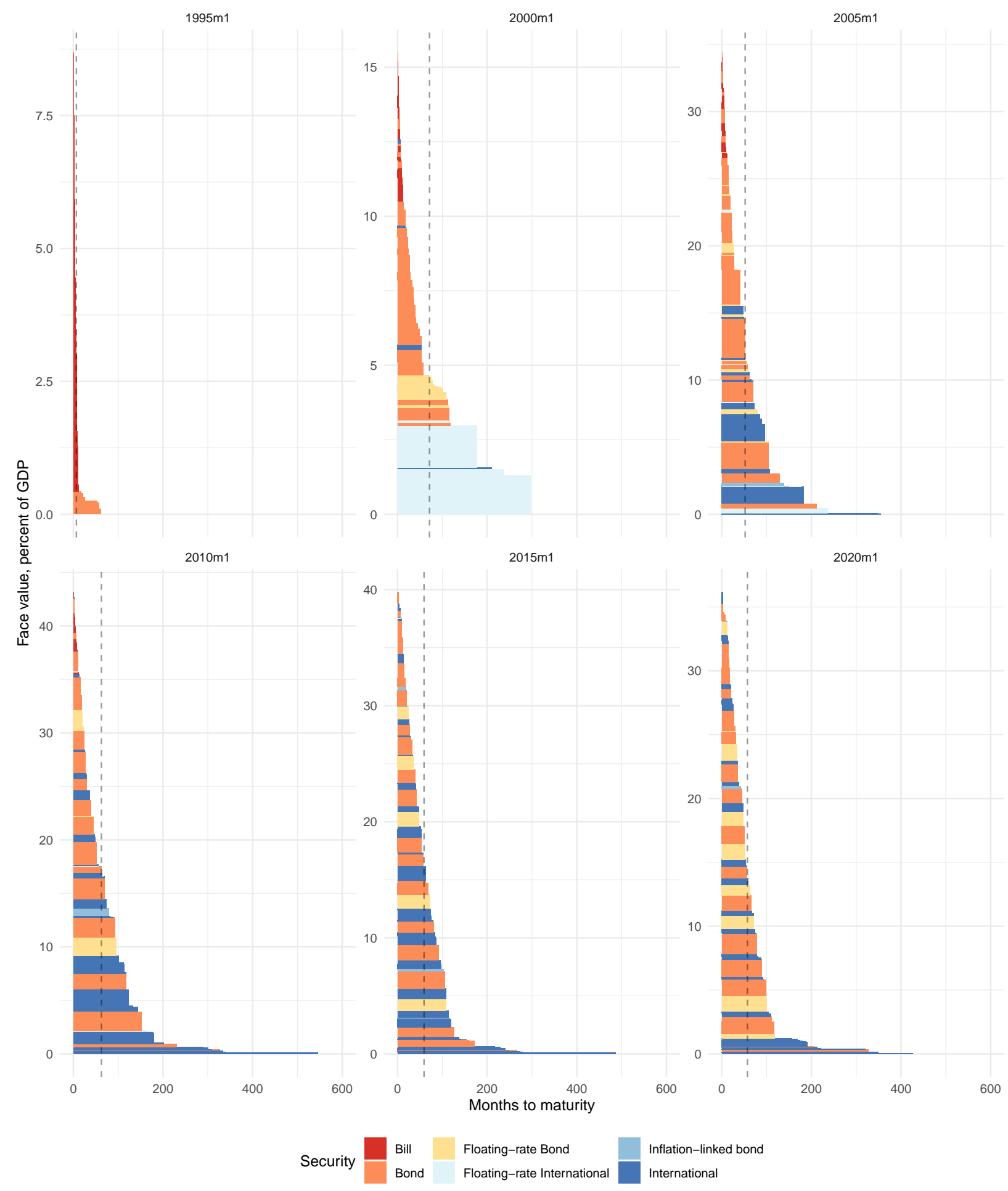

Figure 11: Poland government debt obligations by half-decade, 1995-2020. Vertical line indicates average maturity. 
from very short-term debt - relying initially on an asset with duration of only around two months (as $\theta_{3}=0.52$ ) - to slightly longer bonds as Polish debt markets were re-established following the fall of the Iron Curtain. Then, from the mid-1990s to the mid-2000s, a steady lengthening of the debt, until finally a relatively stable and long-duration debt structure from 2005 onwards (reflecting the similarity since 2005 of the snapshots in Figure 11).

Again, the story is very different if one tries to interpret this history through the lens of a constant-coupon model. Panel (b) of Figure 12 presents the monthly weights estimated using this approach, which omits two key features of the story told in panel (a). First, this conveys no sense of the rapid lengthening of the maturity of Polish public debt in early 1990s. Second, the fluctuation in the weights since 2005 seems to suggest that the maturity structure is changing a lot at high frequency, when really this reflects only that this approach struggles to fit the data. This is also reflected in measures of the goodness of fit of the constant-coupon parameterization of the maturity structure. As shown in Tables 12 and 13 in Appendix D, the log likelihood of the constant-coupon specification is always inferior to that of the exponential-coupon setting.

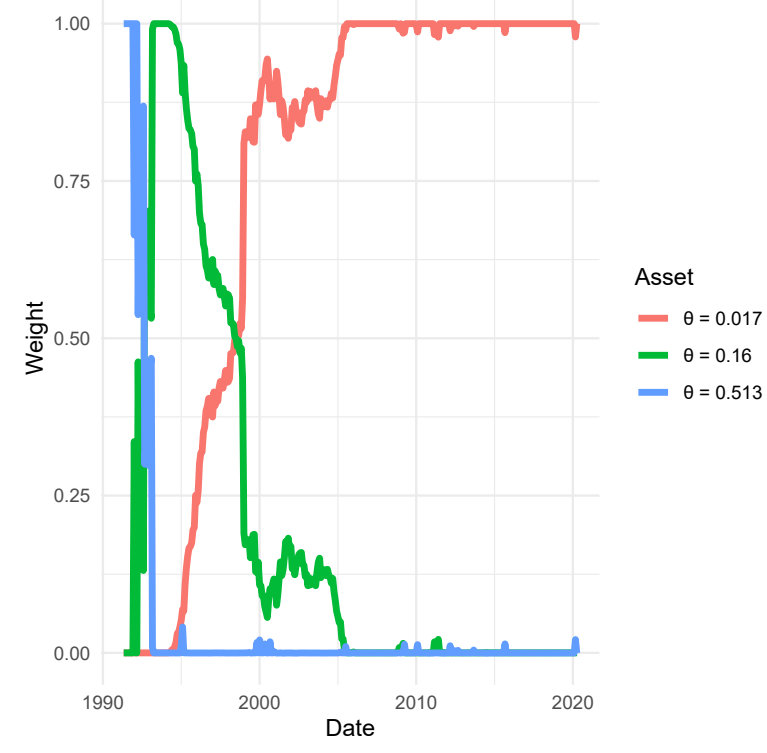

(a) Exponential-coupon bond

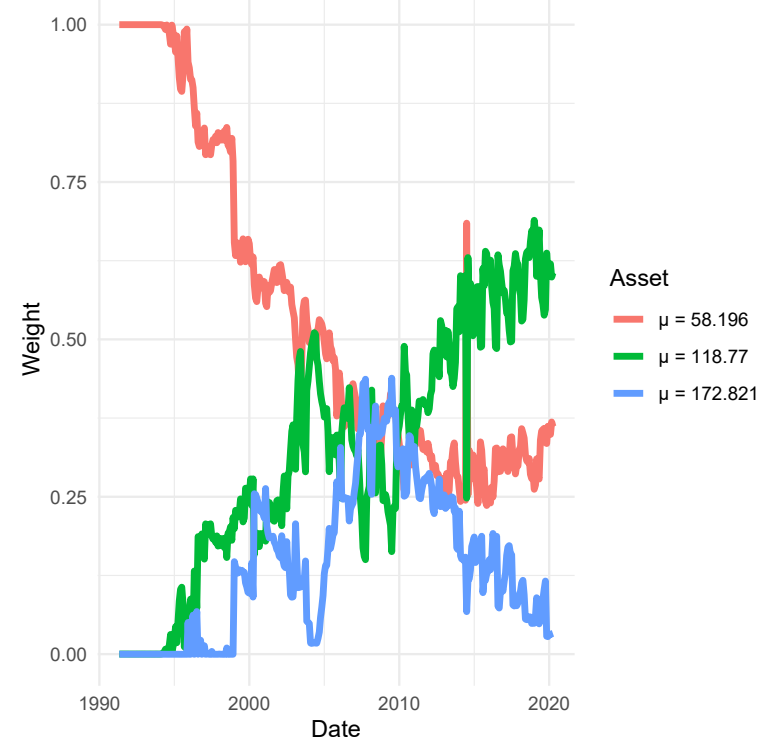

(b) Constant-coupon bond

Figure 12: Monthly weights on bonds for $M=3$, Poland, 1991-2020.

\section{Conclusion}

The maturity structure of government debt is an important issue for many fiscal policy questions. For example, long-run debt sustainability and short-run debt-servicing risks of 
Table 3: MLE Estimates, Exponentially decaying coupon

\begin{tabular}{|c|c|c|c|c|c|c|c|c|}
\hline & \multicolumn{4}{|c|}{ Peru, 1999-2020 } & \multicolumn{4}{|c|}{ Poland, 1991-2020 } \\
\hline & $M=1$ & $M=2$ & $M=3$ & $M=4$ & $M=1$ & $M=2$ & $M=3$ & $M=4$ \\
\hline & \multicolumn{8}{|c|}{ Bond decay parameters } \\
\hline \multirow[t]{2}{*}{$\theta_{1}$} & $0.007^{* * *}$ & $0.006^{* * *}$ & $0.006^{* * *}$ & $0.006^{* * *}$ & $0.021^{* * *}$ & $0.017^{* * *}$ & $0.017^{* * *}$ & $0.016^{* * *}$ \\
\hline & $(0.0004)$ & $(0.0005)$ & $(0.0005)$ & $(0.0006)$ & $(0.0011)$ & $(0.0011)$ & $(0.0010)$ & $(0.0010)$ \\
\hline \multirow[t]{2}{*}{$\theta_{2}$} & & $0.008^{* * *}$ & $0.007^{* * *}$ & $0.006^{* * *}$ & & $0.202^{* * *}$ & $0.160 * * *$ & $0.153^{* * *}$ \\
\hline & & $(0.0008)$ & $(0.0008)$ & $(0.0008)$ & & $(0.0248)$ & $(0.0237)$ & $(0.0224)$ \\
\hline \multirow[t]{2}{*}{$\theta_{3}$} & & & $0.009^{* * *}$ & $0.007 * * *$ & & & $0.513^{* * *}$ & $0.324^{* * *}$ \\
\hline & & & $(0.0030)$ & $(0.0008)$ & & & $(0.1346)$ & $(0.0866)$ \\
\hline \multirow[t]{3}{*}{$\theta_{4}$} & & & & $0.009^{* * *}$ & & & & $0.726^{* * *}$ \\
\hline & & & & $(0.0028)$ & & & & $(0.2131)$ \\
\hline & \multicolumn{8}{|c|}{ Average weights } \\
\hline \multirow[t]{2}{*}{$\bar{\omega}_{1}$} & & $0.583^{* * *}$ & $0.568^{* * *}$ & $0.365^{* * *}$ & & $0.768^{* * *}$ & $0.756^{* * *}$ & $0.754^{* * *}$ \\
\hline & & $(0.0485)$ & $(0.0018)$ & $(0.0017)$ & & $(0.0126)$ & $(0.0027)$ & $(0.0028)$ \\
\hline \multirow[t]{2}{*}{$\bar{\omega}_{2}$} & & $0.417^{* * *}$ & $0.379^{* * *}$ & $0.233^{* * *}$ & & $0.232^{* * *}$ & $0.195^{* * *}$ & $0.183^{* * *}$ \\
\hline & & $(0.0485)$ & $(0.0215)$ & $(0.0016)$ & & $(0.0126)$ & $(0.0049)$ & $(0.0030)$ \\
\hline \multirow[t]{2}{*}{$\bar{\omega}_{3}$} & & & $0.053^{* *}$ & $0.353^{* * *}$ & & & $0.048^{* * *}$ & $0.039^{* * *}$ \\
\hline & & & $(0.0223)$ & $(0.0093)$ & & & $(0.0054)$ & $(0.0034)$ \\
\hline \multirow[t]{2}{*}{$\bar{\omega}_{4}$} & & & & $0.048^{* * *}$ & & & & $0.024^{* * *}$ \\
\hline & & & & $(0.0105)$ & & & & $(0.0049)$ \\
\hline $\mathrm{T}$ & 264 & 264 & 264 & 264 & 348 & 348 & 348 & 348 \\
\hline $\mathrm{S}$ & 1212 & 1212 & 1212 & 1212 & 1200 & 1200 & 1200 & 1200 \\
\hline Params. & 1 & 266 & 531 & 796 & 1 & 350 & 699 & 1048 \\
\hline Log lik & -1588.40 & -1586.74 & -1586.54 & -1586.45 & -1685.19 & -1585.63 & -1577.77 & -1576.28 \\
\hline AIC & 3178.81 & 3705.48 & 4235.09 & 4764.91 & 3372.37 & 3871.26 & 4553.55 & 5248.56 \\
\hline
\end{tabular}


are first order fiscal issues. Yet a full understanding of the evolution of the debt maturity structure is hampered by the sheer complexity of government debt portfolios. In the absence of a coherent framework for interpreting changes in debt maturity ad hoc simplification such as a focus on merely the average debt maturity - have predominated. By providing such a framework, we aim to paint a richer and more complete picture of the evolving debt maturity structure, compressing the maturity distribution of public debts via parametric representation. We then apply this theoretical formulation to fit the data underlying the US's and UK's maturity distributions over the past 100 years.

The first step in tackling this issue is to be able to document the full distribution of obligations by horizons - the maturity distribution. We construct for the first time a securityby-security level historical dataset that covers the complete history of the post-Civil War US. As a point of comparison to the US, we expand on the Gilts outstanding dataset from Ellison and Scott (2020) and add treasury bills outstanding beginning from the first offering in 1877. We compile similar data for Peru, Poland, Egypt, and Nigeria.

The results of our theoretical approach mesh well with our empirical findings. Modeling government balance sheets as a small number of exponentially-decaying bonds performs far better at fitting the data than a constant-coupon approach. Most importantly for those seeking to understand fiscal policy - including policy-makers themselves - our preferred approach yields results that tell a different economic story than the next-best alternative. This holds true in the emerging markets we study.

Although we are the first (to our knowledge) to model the historical development of governments' debt in a theoretically-coherent and easily-interpretable fashion, our paper naturally leaves questions unanswered for future research to address. First, as the opening paragraph of this section alludes to, answers to optimal fiscal policy questions may be sensitive to how the government's outstanding debts are modeled. For example, optimal debt management in the face of shocks to yield curves will depend on how the debt maturity structure is parameterized. Second, although we offer an interpretation of two governments with long histories of debt management, our coverage of episodes of extreme fiscal stress is somewhat lacking. The key constraint here is data availability. Very few countries have sufficiently rich publicly available data to compute the full maturity distribution of the public debt, and even fewer of those have been through episodes of extreme fiscal stress. Despite our best efforts, we could only find four emerging markets with enough data to make investigation worthwhile. An interesting and useful extension of our work might be to invert this process, using our model to fill in the gaps in countries with more limited data. For example, if one were willing to accept that the debt markets in some country were similar to those estimated for, say, Poland or Egypt, then one could take the values of $\theta_{1}, \ldots, \theta_{M}$ 
from our estimates. Then, with more limited moments of the maturity density, such as time series for "short" or "long" debt, one could impute a fuller distribution of obligations by estimating weights $\omega_{1, t}, \ldots, \omega_{M, t}$ to match the time series of moments. Finally, our model selection analysis could be strengthened by estimating a statistical process for the weights $\omega_{t}$. Of course, given that the weights are not directly observed, some sort of filtering process would likely be required. Nevertheless, this extension would greatly reduce the size of the parameter space, making richer models of public debt more competitive in model selection when compared to, say, a one-bond model.

\section{References}

Angeletos, G.-M. (2002). Fiscal policy with noncontingent debt and the optimal maturity structure. The Quarterly Journal of Economics 117(3), 1105-1131.

Arellano, C. (2008). Default risk and income fluctuations in emerging economies. American Economic Review 98(3), 690-712.

Arellano, C. and A. Ramanarayanan (2012). Default and the maturity structure in sovereign bonds. Journal of Political Economy 120(2), 187-232.

Bai, Y., S. T. Kim, and G. P. Mihalache (2015). The maturity and payment schedule of sovereign debt.

Bhandari, A., D. Evans, M. Golosov, T. Sargent, et al. (2019). The optimal maturity of government debt.

Bhandari, A., D. Evans, M. Golosov, and T. J. Sargent (2017). Fiscal policy and debt management with incomplete markets. The Quarterly Journal of Economics 132(2), 617663.

Bigio, S., G. Nuño, and J. Passadore (2019). A framework for debt-maturity management.

Bocola, L. and A. Dovis (2019). Self-fulfilling debt crises: A quantitative analysis. American Economic Review 109(12), 4343-77.

Buera, F. and J. P. Nicolini (2004). Optimal maturity of government debt without state contingent bonds. Journal of Monetary Economics 51(3), 531-554.

Chatterjee, S. and B. Eyigungor (2012). Maturity, indebtedness, and default risk. American Economic Review 102(6), 2674-99.

Darst, R. M. and E. Refayet (2019). A collateral theory of endogenous debt maturity.

Debortoli, D., R. Nunes, and P. Yared (2017). Optimal time-consistent government debt maturity. The Quarterly Journal of Economics 132(1), 55-102. 
Dias, D. A., C. Richmond, and M. L. Wright (2014). The stock of external sovereign debt: Can we take the data at 'face value'? Journal of International Economics 94 (1), 1-17.

Dias, D. A., M. L. Wright, et al. (2016). Debt statistics a la carte: Alternative recipes for measuring government indebtedness. Chicago Fed Letter 362.

Dvorkin, M., J. M. Sánchez, H. Sapriza, and E. Yurdagul (2020). News, sovereign debt maturity, and default risk. Journal of International Economics, 103352.

Ellison, M. and A. Scott (2020). Managing the uk national debt 1694-2018. American Economic Journal: Macroeconomics 12(3), 227-57.

Hatchondo, J. C. and L. Martinez (2009). Long-duration bonds and sovereign defaults. Journal of international Economics 79(1), 117-125.

Manuelli, R. and J. M. Sánchez (2018). Endogenous debt maturity: Liquidity risk vs. default risk. FRB St. Louis Working Paper (2018-34).

Nelson, C. R. and A. F. Siegel (1987). Parsimonious modeling of yield curve. The Journal of Business 60(4), 473-489.

Sánchez, J. M., H. Sapriza, and E. Yurdagul (2018). Sovereign default and maturity choice. Journal of Monetary Economics 95, 72-85.

Shin, Y. (2007). Managing the maturity structure of government debt. Journal of Monetary Economics 54(6), 1565-1571.

Svensson, L. E. O. (1994). Estimating and interpreting forward interest rates: Sweden 1992-1994. (114). 


\section{A Further details on the data}

\section{A.1 Definitions}

In Section 2.3 we discussed the consequences of different marketable security types as they pertain to the calculations of their respective stream of payments. To help provide further context to the variation in stream of payment calculations across security types, we discuss in detail the definitions of each security type.

The following security types discussed all fall into the broader category of marketable securities. Marketable securities are broadly defined as securities that can be bought and sold in the open market. Gross debt is thus split between marketable and nonmarketable debt.

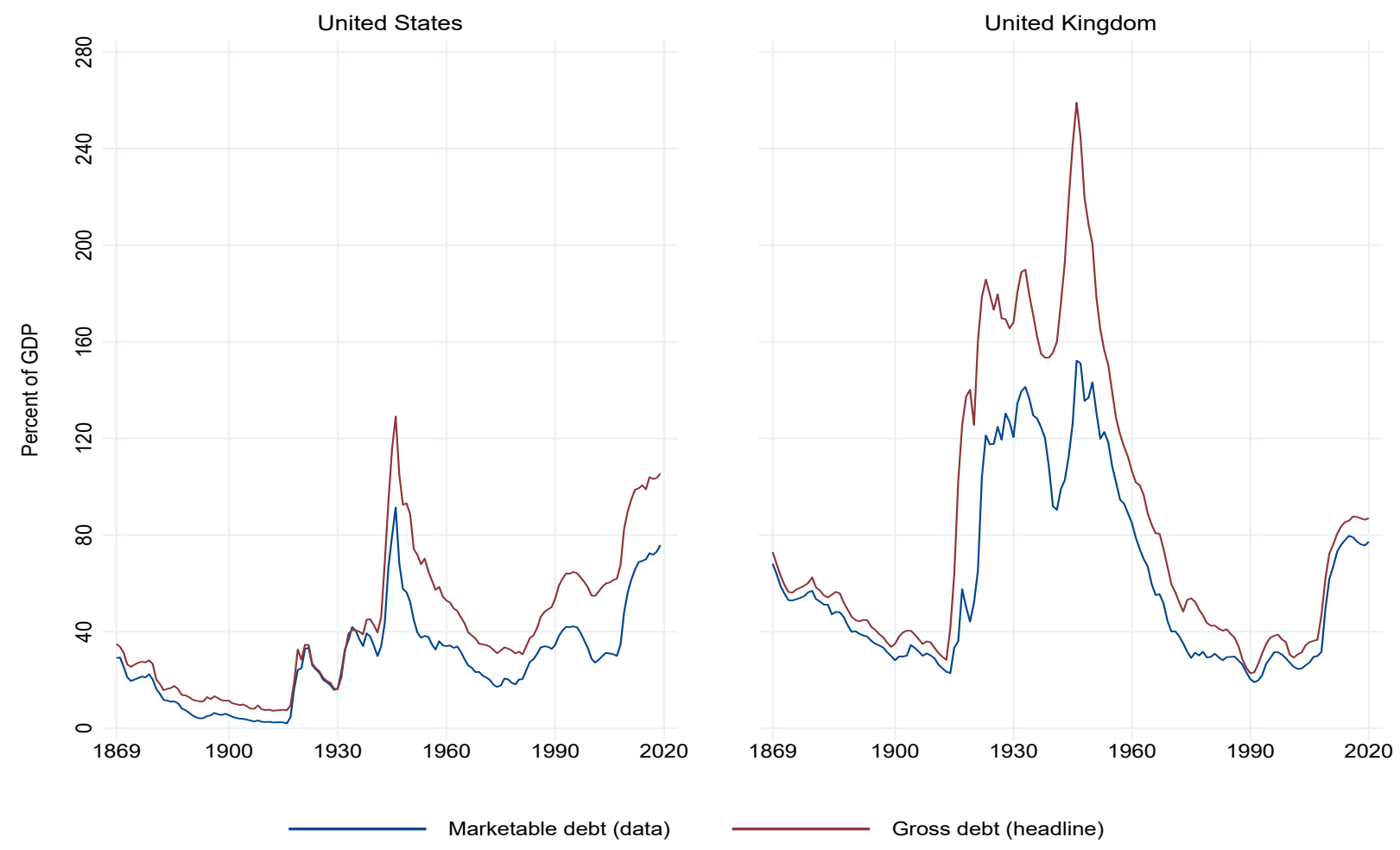

Figure 13: Face value of total and marketable debt outstanding, 1869-2020.

Figure 13 shows the face value of total marketable debt outstanding-aggregated using our dataset. For comparison, we also show the face value of gross debt (marketable and nonmarketable) as reported in headline data. ${ }^{22}$ Each series is scaled by GDP and

\footnotetext{
${ }^{22}$ US headline gross debt data are from the US Treasury's Historical Debt Outstanding dataset. UK headline gross debt data are from the Bank of England's A Millenium of Macroeconomic Data database for years 1869-2016 and spliced forward with the UK's Office of National Statistics for years 2017-2020.
} 
reported as its fiscal year value (March for UK; month varies for US). ${ }^{23}$ The US only started making significant use of nonmarketable debt after World War I, but has had a steady uptick in use since. The UK on the other hand, made significant use of nonmarketable debt prior to the $1950 \mathrm{~s}$, but has had a steady decline in usage since.

Nominal coupon-bearing instruments This class of debt instrument includes bonds/gilts, notes, and certificates of indebtedness. It pays face value at maturity and interest at a set frequency (normally semiannually, but also quarterly and annually).

Zero-coupon instruments As the name entails, this class of debt instrument does not pay coupons and only pays face value at maturity. Treasury bills fall under this category.

Real coupon-bearing instruments Unlike nominal coupon bearing-instruments, the principal payment and the coupon payments of real instruments are adjusted for inflation each month. The US issues treasury inflation-protected securities (TIPS) which are indexed to changes in the US Consumer Price Index (CPI), whereas the UK issues index-linked gilts which are indexed to the General Index of Retail Prices in the UK (RPI). Thus, the expected future cash flows with respect to this class of securities is subject to inflation expectations taken at time $t$ for monthly horizons 1 through maturity $M$.

For the US, expected CPI inflation is obtained from the Federal Reserve Bank of Cleveland, who reports estimates of the expected rate of CPI inflation over a 30year horizon from monthly vintages beginning in January 1982 (pre-dating the 1997 emergence of TIPS).

For the UK, expected RPI inflation is obtained from the Bank of England's estimates of the implied inflation term structure - published in conjunction with its yield curve estimates. Estimates of the expected rate of RPI inflation are made for shortrun horizons of 25 to 60 months and long-run horizons of up to 25 years (at half-year intervals) from monthly vintages beginning in January $1985 .{ }^{24}$ However, since UK inflation-indexed gilts commenced in 1981 and Bank of England estimates are not con-

\footnotetext{
${ }^{23}$ US GDP data are from the Global Financial Data (GFD) database and UK GDP data are from the Bank of England's A Millenium of Macroeconomic Data database.

${ }^{24}$ For both US CPI and UK RPI, published projections are interpreted as the average rate of inflation expected to rule over a given period (e.g. a 10-year inflation projection represents the average inflation over 10 years). For our purposes in estimating the stream of payments due, we transform the averages over a given period to the projected inflation at a given period (e.g. a 10-year inflation projection now represents the average inflation in year 10). Where estimates are of average inflation at annual (semiannual) horizons for the US (UK), we translate annual (semiannual) into monthly horizons by applying the horizon's projection to each month within its respective year (half-year).
} 
sistently of 25 years length until January 1998, we impute 25-year inflation expectations for 1981-1997. To impute our own estimates, we conduct a 3-step process:

1. Regress each horizon $h$ 's RPI inflation expectation at time $t$ on lags of RPI inflation $^{25}$ of orders up to 120 months where:

$$
E_{t} \pi_{t+h}=\alpha+\sum_{j=1}^{p} \beta_{j} \pi_{t-j}+\epsilon_{t+h} \quad \forall p \in\{1,2,3, \ldots, 120\}
$$

and

$$
\rho=\sum_{j=1}^{p} \beta_{j}
$$

2. For each horizon $h$, select the optimal lag order using the choice of $p$ that minimizes the Bayesian information criterion (BIC). The parameters of the chosen optimal models are summarized in Figure 14. For reference, these parameters are compared to those of US CPI forecasts following a similar procedure. We save our discussion of imputed CPI forecasts for Appendix C.2. Notably, there is much more movement in the estimated RPI parameters from short- to long-horizon.

3. Calculate "imputed" values for each forecast horizon $h$ from monthly vintages prior to 1998 by summing the estimated constant and each lag of RPI weighted with lag weights from the optimal model.

Figure 15 summarizes the results of our UK RPI inflation imputed forecasts using the process described above. Here, for reference, we show selected forecasts taken every five years and compare to actual RPI inflation out-turns. Peru and Poland CPI inflation forecasts are imputed from US inflation forecasts using the procedure described above.

Floating-rate coupon-bearing instruments These instruments do not have a fixed coupon and instead pay varying amounts of interest that rise and fall based on current relative yields. The US Treasury began issuing floating rate notes (FRNs) in January 2014 which have a duration of two years. Similarly, the UK has issued floating rate gilts (FRGs) at various points in its history with the last remaining FRG redeemed in July 2001. More extensive, however, is the use of floating rate bonds in Peru and Poland. The calculation of forward rates used in projecting future payments is relatively straightforward and described in the main text. The more difficult aspect comes in developing appropriate yield curves to compute monthly forward rates at any horizon. The methodology is country-specific and is summarized below:

\footnotetext{
${ }^{25} \mathrm{RPI}$ inflation data are sourced from the Global Financial Data (GFD) database.
} 

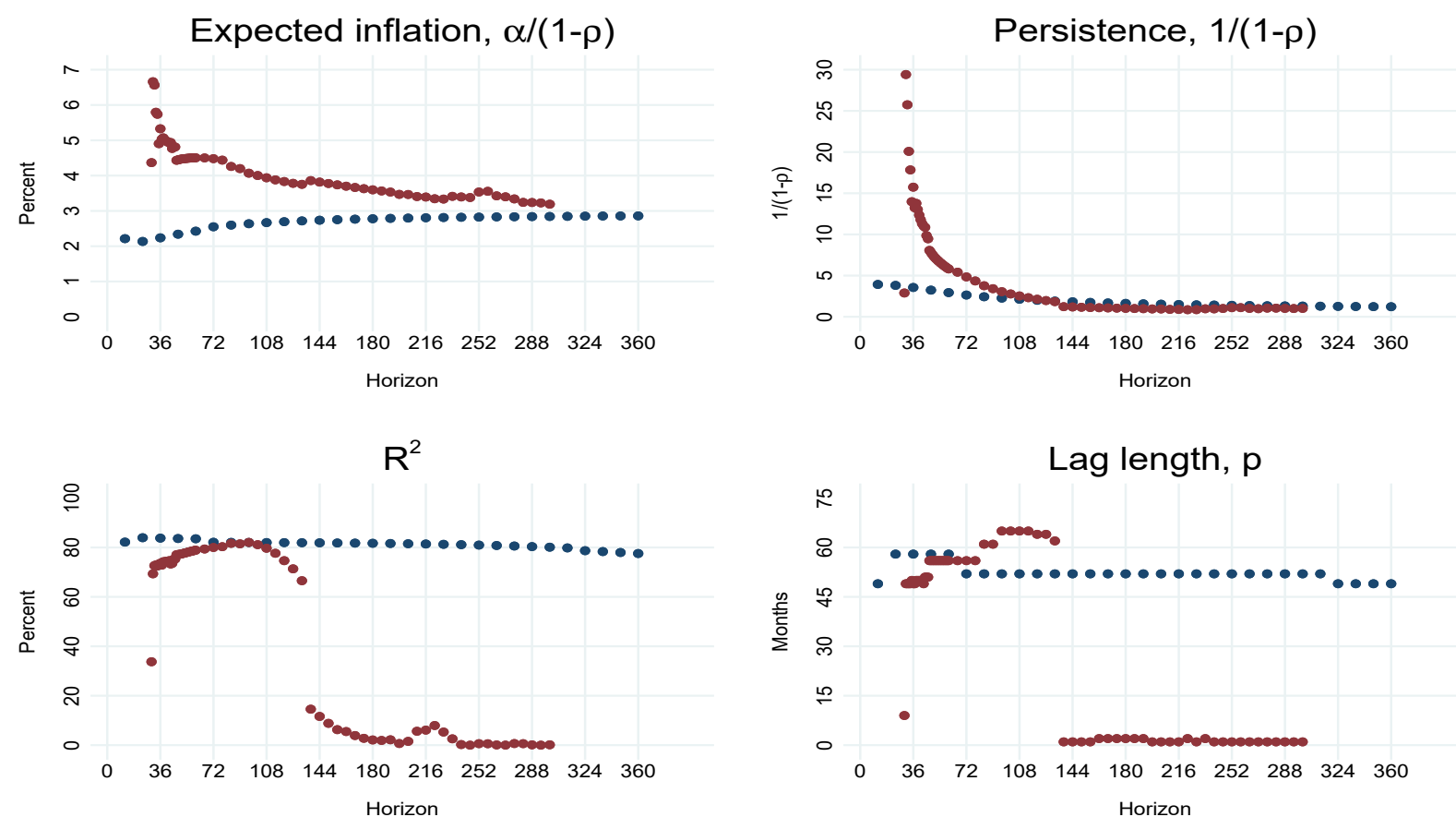

- US CPI UKRPI

Figure 14: Imputed inflation forecast parameter estimates.

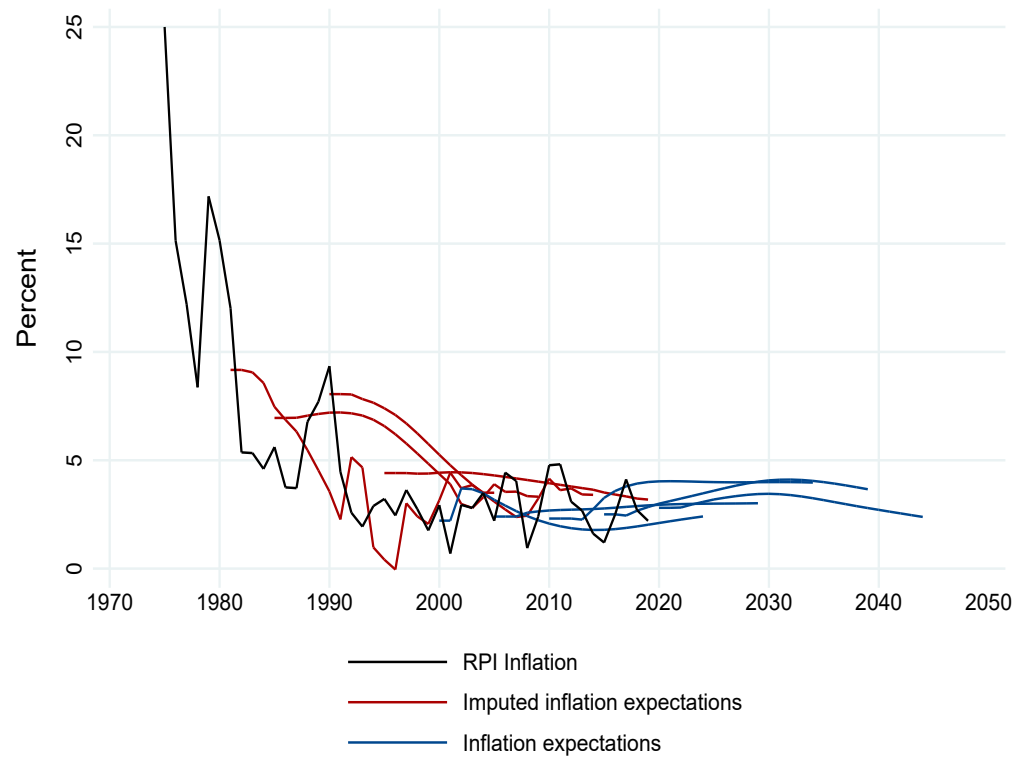

Figure 15: United Kingdom RPI inflation expectations, 1981-2020. 
- United States: Daily treasury yield curve rates are published by the US Treasury. This database consists of yields at the 1-, 2-, 3-, and 6-month horizons as well as the 1-, 2-, 3-, 5-, 7-, 10-, 20-, and 30-year horizons. To develop a complete yield curve consisting of yields at each monthly-horizon up to 30 years, we model the yield curve with the Svensson (1994) parametric model.

- United Kingdom: Yield curves from the Bank of England provide monthly-horizon rates up to 60 months and then additional rates at semi-annual-horizons out to 40 years. However, the dataset is often missing yields in the first 1-11 months. We then model the complete yield curve consisting of yields at each monthly-horizon up to 40 years using the Nelson and Siegel (1987) parametric model since this model adapts better than the Svensson model to lack of data in the short-end of the yield curve.

- Peru: Yield curve data are insufficient. However, the majority of floating rate bonds of Peru are bonds with step-up coupons for which the future coupons are known in advance and accounted for accordingly. For additional floating rate bonds, we take the coupon at the time of the reference data and let it stay fixed for projection purposes.

- Poland: Floating rate international bonds are indexed to short-term reference rates including 3- or 6-month LIBOR or EURIBOR. Data for LIBOR are from FRED, while data for EURIBOR are from the ECB. With EURIBOR and LIBOR data available up to 12 months, we use the Svensson model to estimate a yield curve out several years to compute forward rates on projected future payments beyond 1 year. For floating rate domestic bonds, we derive our term structure using yields on transactions in the transactions database used to construct the debts outstanding. A monthly-horizon yield curve is then fit to these data using the Nelson-Siegel model which adapts better (than Svensson) to yield data availability issues that arise throughout the sample.

Perpetual bonds Often referred to as consols, these bonds - popular prior to the start of the 20th century - have no maturity date and instead offer coupon payments in perpetuity. We treat these as if the government does not ever have to account for a principal payment and rather than paying coupons indefinitely, must account for a finite - albeit very long - schedule of coupon payments which we set to 100 years from any given time in which the bond is outstanding.

Callable notes and bonds For certain notes and bonds issued before 1985, the US Treasury reserved the right to stop paying interest before the date of maturity. We treat 
these notes and bonds as if the government assumes ex-ante that they will pay principal at maturity and not redeem prior to that date. There are currently no notes or bonds in circulation eligible to be called.

Certificates of indebtedness These US debt assets are the predecessor of the US treasury bill and were issued in parallel with treasury bills until the late 1960s (at which point they were permanently phased out). While similar to bills in duration, certificates of indebtedness are nominal coupon-bearing instruments (see above category) that pay a coupon at maturity and sometimes a coupon after 6 months.

\section{A.2 Comparing to CRSP Monthly US Treasury Database}

A similar source of monthly marketable treasury securities outstanding is the Center for Research in Security Prices (CRSP) Monthly US Treasury Database (2019). Although CRSP monthly data begin December, 1925, the database does not comprehensively cover the amount outstanding of individual securities until around 1950. For example, in January, 1930, of the individual securities in circulation (shown in Figure 16, a snapshot of our primary sources), the CRSP database only has quantity outstanding data existing for the 3\% Panama Canal Loan of 1961 and the $4 \frac{1}{4} \%$ Bonds of 1947-52-notably missing data for the Fourth Liberty Loan (which made up nearly $40 \%$ of all government debt at the time). In fact, no securities with maturity prior to June, 1946 have quantity data. This becomes evident in Figure 17 as the total marketable debt outstanding provided by CRSP begins to diverge from the headline amount (provided by the Federal Reserve Bank of Dallas) as we push back in time beyond 1950.

Our data thus provide an improvement by extension to the CRSP database as our data are comprehensive going back to January, 1869 and mirror the available headline data back to January, 1942 (when the headline data begin). 


\section{STATEMENT OF THE PUBLIC DEBT OF THE UNITED STATES JANUARY 31, 1930}

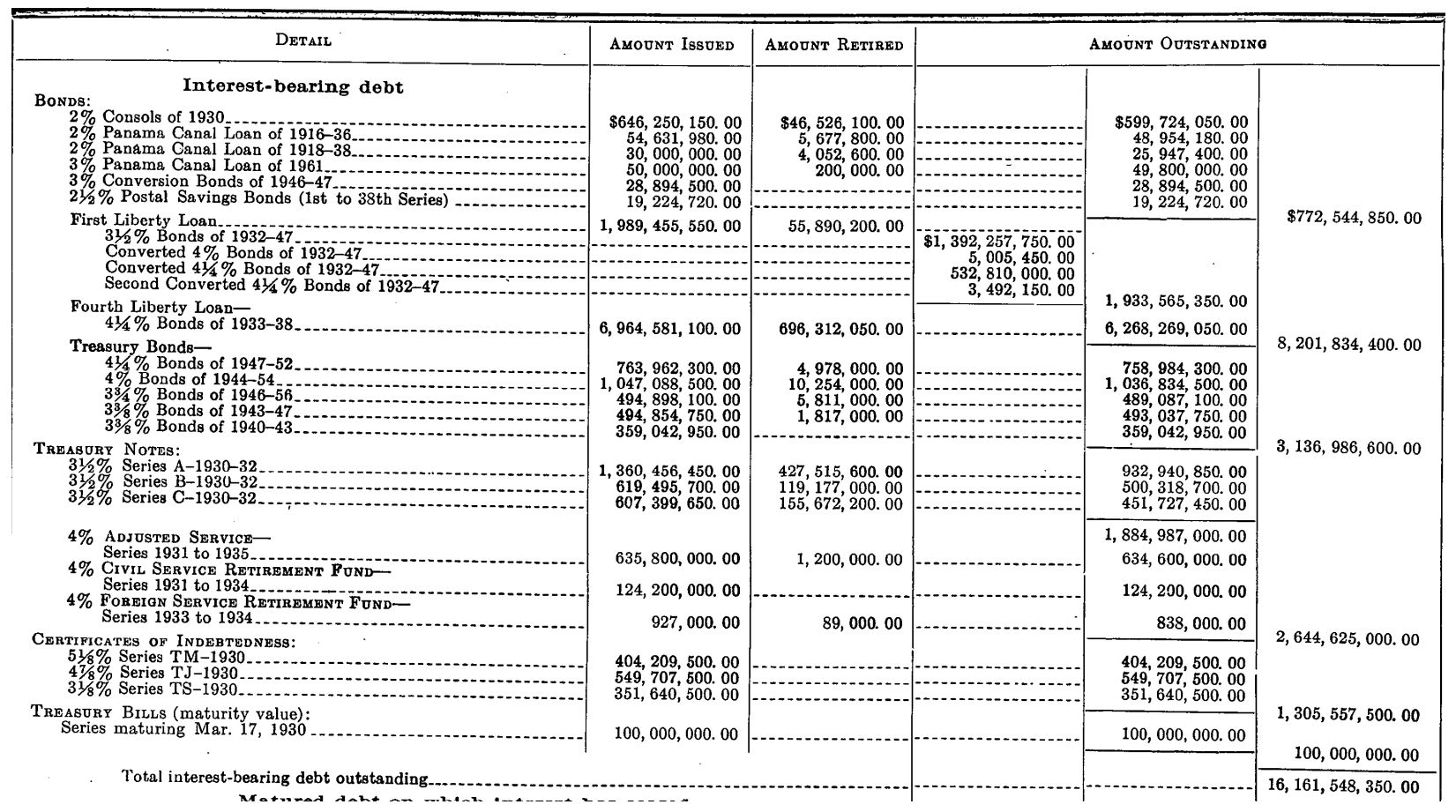

Figure 16: US Treasury Statement of the Public Debt, January 31, 1930.

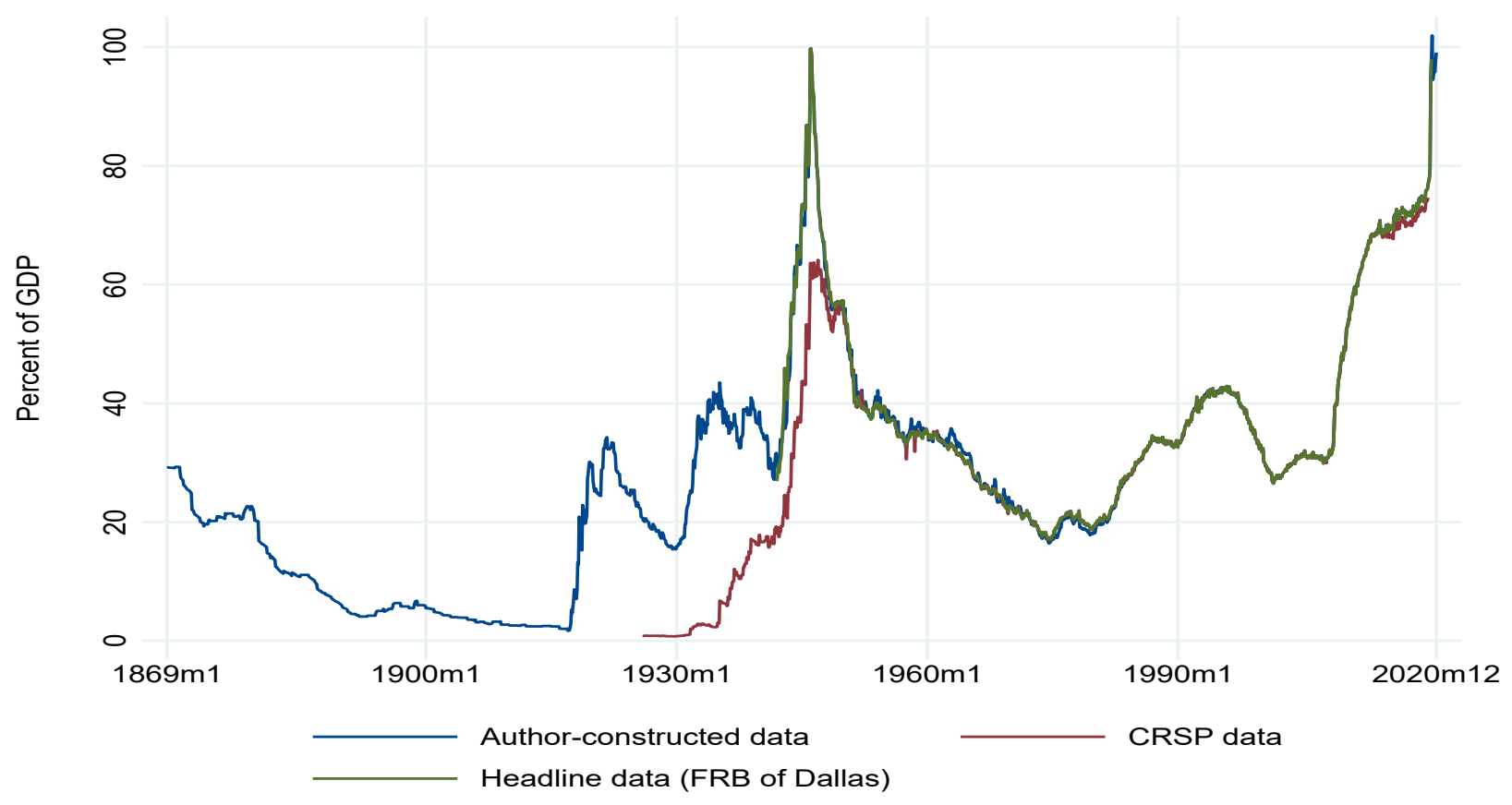

Figure 17: Marketable debt; comparison to CRSP and headline data. 


\section{A.3 Converting outstanding debts into streams of future pay- ments}

For almost all outstanding securities in our dataset, the stream of future payments is a function of the number of units outstanding, coupon rate, frequency of coupon payments, and maturity date. ${ }^{26}$ The mapping from these to its implied stream of payments depend on its type. For both the UK and US, most debt securities fall into five main groups: 1) nominal coupon-bearing instruments; 2) zero-coupon instruments; 3) real coupon-bearing instruments; 4) floating-rate coupon-bearing bonds; and 5) perpetual bonds. A common feature of these debt securities is that the the stream of associated payments is the same at all horizons except in at some terminal horizon.

We index assets by $i$ and and time by $t$, using $B_{i t}$ to denote the number of units of debt asset $i$ outstanding at time $t$. The future payouts from debts of type $i$ come in two types:

- $C_{i t s}$ (standing for coupon), the intermediate payments in period $t+s$ for $s=1, \ldots, M_{i t}$, where $M_{i t}$ is the time to the terminal payment (i.e. the residual maturity). Coupon payments may be zero in some periods if payable at a quarterly or semi-annual frequency (the most common frequencies).

- $P_{i t}$ (standing for principal), the terminal payment due from issuance of asset $i$, due in period $t+M_{i t}$.

The coupon and principal payments depend on the terms of the contract, which vary by asset. Table 4 summarizes this relationship. For the simplest assets, the coupon and principal payments depend only on the coupon rate $r_{i}$, and the coupon frequency, $F_{i}$ (i.e. the number of times per year a coupon is paid). Floating-rate and real bonds depend on other variables, which we denote as follows:

- $\Pi_{s t}=\prod_{h=1}^{s}\left(1+E_{t} \pi_{t+h}\right)^{1 / 12}$ is cumulative gross expected inflation between period $t$ and $t+s$, and $E_{t} \pi_{t+s}$ is the expected inflation at time $t$ for inflation in period $t+s$;

- $f_{t, T}=\left(\frac{\left(1+z_{T}\right)^{T}}{\left(1+z_{t}\right)^{t}}\right)^{\frac{1}{T-t}}-1$ is the forward rate at time $t$ for a bond maturing in period $T$;

- $z_{t}$ is the spot rate of a bond maturing in $t$ months.

Further details of bond-specific series, including the construction of inflation expectations and yield curves, are discussed in Appendix A.1.

\footnotetext{
${ }^{26} \mathrm{~A}$ small number of exceptions - mostly callable bonds - require additional assumptions, discussed later.
} 


\begin{tabular}{lllll}
\hline Instrument type & US name & UK name & $P_{i t}$ & $C_{i t s}$ \\
\hline Zero-coupon & Bills & Bills & $B_{i t}$ & 0 \\
Nominal coupon-bearing & Bonds & Gilts & $B_{i t}$ & 0 or $B_{i t} r_{i} / F_{i}$ \\
Perpetual bonds & Consol & Consol & 0 & 0 or $B_{i t} r_{i} / F_{i}$ \\
Real coupon-bearing & TIPS & Index-linked & $\Pi_{M_{i t}} B_{i t}$ & 0 or $\Pi_{s t} B_{i t} r_{i} / F_{i}$ \\
Floating coupon-bearing & FRNs & FRGs & $B_{i t}$ & 0 or $B_{i t} f_{t-1, T} / F_{i}$ \\
\hline
\end{tabular}

Note: Formulae include "or" as coupon payments may not be due in all periods.

Table 4: Stream of payments for an asset of residual maturity $M_{i t}$.

Using these formulae we calculate principal and coupon payments specific to each individual debt asset outstanding at the end of each month. ${ }^{27}$ We then construct our aggregate debt density in two stages. First, we calculate the fraction of payment obligations for individual security $i$ outstanding at time $t$ due $s$ months after $t$. This is:

$$
y_{i t}^{s}= \begin{cases}\frac{C_{i t s}}{P_{i t}+C_{i t}} & M_{i}-s \quad \bmod \frac{12}{F_{i}}=0 \\ \frac{C_{i t s}+P_{i t}}{P_{i t}+C_{i t}} & s=M_{i t}\end{cases}
$$

Where $C_{i t}=\sum_{s=1}^{M_{i}} C_{i t s}$, and so $y_{i t}^{s}$ is a density, as $\sum_{s=1}^{M_{i t}} y_{i t}^{s}=1$

Second, we aggregate a portfolio of all $n$ securities outstanding at time $t$. The fraction of the portfolio's outstanding obligations at time $t$ due $s$ months after $t$ is then defined as:

$$
y_{t}^{s}=\sum_{i=1}^{n_{t}} \omega_{i t} y_{i t}^{s}
$$

Where $n_{t}$ is the number of debt assets outstanding at time $t$ and

$$
\omega_{i t}=\frac{P_{i}+C_{i}}{\sum_{i=1}^{n} P_{i}+C_{i}}
$$

is the fraction of future payments due to bond $i$. Then $\sum_{s=1}^{\infty} y_{t}^{s}=1$, and $y_{t}^{s}$ the fraction of the future obligations promised at time $t$ which are due at time $t+s$. We thus refer to $\left\{y_{t}^{s}\right\}_{s=1}^{\infty}$ as the empirical maturity density at time $t$. The interpretation of the empirical maturity density is closely related to the zero coupon equivalent measure of total debt proposed by Dias et al. (2014), who sum all future obligations from each bond to derive a measure of total outstanding obligations that (amongst other useful properties) cannot be manipulated

\footnotetext{
${ }^{27} \mathrm{~A}$ small fraction of US bonds are callable and thus the distribution of future payments is contingent on US Treasury choices. When constructing our stream of payments we treat callable bonds as if the option to call is not exercised. As an opposite extreme, we also consider the assumption that the US Treasury will "call" a callable bond at the first date available. The results of this empirical analysis are in Appendix C.3
} 
by reclassifying payments between principal and coupon. Our debt maturity density $y_{t}^{s}$ therefore represents the fraction of the zero coupon equivalent which must be paid in each subsequent period. ${ }^{28}$

\section{B Mathematical details of the conceptual framework}

Here we show formally the key results of Section 3.

\section{B.1 Densities and weights}

The dynamic evolution of debt expressed in equation (1) thus implies that the relationship between $f_{t}, g_{t}$ and $f_{t+1}$ can be expressed as a weighted average. ${ }^{29}$

Proposition 1. Equations (1) - (3) hold if and only if there exists $w_{t} \in[0,1]$ such that.

$$
f_{t+1}(s)=w_{t}\left(\frac{f_{t}(s+1)}{1-f_{t}(1)}\right)+\left(1-w_{t}\right) g_{t}(s) \quad \forall s
$$

Moreover, given $f_{t}, g_{t}$ any $f_{t+1}$ defined by (6) is a probability mass function for any $w_{t} \in$ $\left[\bar{w}_{t}, 1\right]$, where:

$$
\bar{w}_{t}=\min _{s: g_{t}(s)<0}\left(\frac{-g_{t}(s)}{f_{t}(s+1) /\left(1-f_{t}(1)\right)-g_{t}(s)}\right)
$$

Two observations are relevant here. First, Proposition 1 says we can take the issuance density and weights as primitives in describing the maturity structure of public debt. That is, given initial $b_{0}, f_{0}$, we can back out the whole sequence of corresponding future obligations $b_{t}^{s}$ from $g_{t}, w_{t}$ alone. We lose no generality by expressing the problem in these terms; we can think of $g_{t}, w_{t}$ as a complete description of the government's debt maturity choices, and any model or accounting of public debt can be mapped into choices for $g_{t}$ and $w_{t}$.

The second point worth noting is that that the weight $w_{t}$ is a simple decreasing function of aggregate issuance relative to aggregate outstanding debt, $i_{t} / b_{t}$.

$$
w_{t}=\frac{1-f_{t}(1)}{1-f_{t}(1)+i_{t} / b_{t}} \in[0,1]
$$

\footnotetext{
${ }^{28}$ Our maturity density is also nominal. There are two reasons to prefer this over a real equivalent. First, the majority of obligations are expressed in nominal terms. Second, that a real series requires data on expected inflation at long horizons back to the start of the sample, a hard task for such a lengthy sample. For nominal series, one need only use inflation expectations for indexed bonds, which have been issued only more recently and so have readily available expected inflation series for the relevant period. That said, we still construct real maturity densities as best we can, and replicate our empirical analysis using real maturity densities in Appendix C.

${ }^{29}$ All proofs are in Appendix B.5.
} 
Higher aggregate issuance relative to outstanding debt simply means a higher weight on the issuance distribution in equation (6). This also explains why there is a lower bound on $w_{t}$. If net issuance $g_{t}(s)$ is negative at some horizon $s$, then too much issuance overall (i.e. is $w_{t}$ is too low) will result in negative debt holdings at the end of the period.

\section{B.2 Parametric debt densities}

So far, we have allowed the debt maturity structure $f_{t}(s)$ to be any probability mass function. We now specialize to the case where the the maturity structure of the government debt can be expressed parametrically. That is, we assume that there exists a sequence of parameters $\omega_{1}, \omega_{2}, \ldots$ such that $f_{t}(s)=f\left(s \mid \omega_{t}\right) \forall t, s$. We use $\Omega$ to denote the set of all possible parameters.

Compressing the debt maturity structure to a parametric representation is an important modeling choice in many analyses of public debt maturity, as it simplifies the behavior of the entire maturity structure to the evolution of $\omega_{t}$ to $\omega_{t+1}$. This mapping is a key object of inquiry for many papers in the literature, albeit sometimes implicitly.

If the dynamic evolution of debt is defined by equations $(1)-(3)$, then for any $\omega_{t}, \omega_{t+1}$, the issuance required can be determined as a residual. That is:

$$
\begin{aligned}
g_{t}(s) & =g\left(s \mid \omega_{t}, \omega_{t+1}, w_{t}\right) \\
& :=\frac{f\left(s \mid \omega_{t+1}\right)}{1-w_{t}}-\left(\frac{w_{t}}{1-w_{t}}\right)\left(\frac{f\left(s+1 \mid \omega_{t}\right)}{1-f\left(1 \mid \omega_{t}\right)}\right)
\end{aligned}
$$

Thus, any parametric form imposed on the debt distributions $f_{1}, f_{2}, \ldots$ implicitly defines a parametric form for the issuance distributions $g_{1}, g_{2}, \ldots$ as well. In the next section we ask: when is the implied issuance distribution consistent with issuance in specific asset markets without arbitrary restrictions?

\section{B.3 Market structure}

We now assume that there exist a fixed (possibly infinite) number of debt markets $N$, indexed by $j$. In each market a single asset trades, defined by payment density $h_{j}(s)$. A participant selling $z$ units of asset $j$ commits to repaying $z h_{j}(s)$ in period $t+s$. Thus, $\sum_{s=1}^{\infty} h_{j}(s)=1$ for all $j$.

If the fraction of net government debt issuance in market $j$ at time $t$ is $\sigma_{t}^{j}$, then the 
issuance density can therefore be written as:

$$
g_{t}(s)=\sum_{j=1}^{N} \sigma_{t}^{j} h_{j}(s) \quad \text { where }\left(\sigma_{t}^{1}, \ldots, \sigma_{t}^{N}\right)=\sigma_{t} \in \mathcal{S} \forall t
$$

Where $\mathcal{S}=\left\{\sigma \in \mathbb{R}^{N} \mid \sum_{i=1}^{N} \sigma^{i}=1\right\}$ is the simply the set of asset weights which sum to unity.

For any arbitrary parametric density function $f\left(s \mid \omega_{t}\right)$, it is not necessarily true that there is an issuance density which can be expressed this way, at least not without further constraints on the vector of issuance shares, $\sigma_{t}$. Thus, we make the following definition:

Definition 1 (Unrestricted market access). Let

$$
\begin{aligned}
f: \mathbb{N} \times \Omega & \rightarrow[0,1] \\
(s, \omega) & \mapsto f(s \mid \omega)
\end{aligned}
$$

be a density such that for any $\omega_{t} \in \Omega$, any $\sigma_{t} \in \mathcal{S}$ and any $w_{t} \in[\bar{w}, 1]$ there exists $\omega_{t+1} \in \Omega$ such that:

$$
f\left(s \mid \omega_{t+1}\right)=w_{t}\left(\frac{f\left(s+1 \mid \omega_{t}\right)}{1-f\left(1 \mid \omega_{t}\right)}\right)+\left(1-w_{t}\right)\left(\sum_{j=1}^{N} \sigma_{t}^{j} h_{j}(s)\right) \quad \forall s
$$

where

$$
\bar{w}_{t}=\min _{s: \sum_{j=1}^{N} \sigma_{t}^{j} h_{j}(s)<0}\left(\frac{-\sum_{j=1}^{N} \sigma_{t}^{j} h_{j}(s)}{f\left(s+1 \mid \omega_{t}\right) /\left(1-f\left(1 \mid \omega_{t}\right)\right)-\sum_{j=1}^{N} \sigma_{t}^{j} h_{j}(s)}\right)
$$

Then we say that $f(s \mid \omega)$ can be rationalized by unrestricted access to the asset markets defined by $h_{1}, \ldots, h_{N}$.

The key part of this definition is where it says "for any". For market access to be unrestricted we require that for any parametric starting debt distribution (encoded in $\omega_{t}$ ), then any choice of issuance densities in the hypothesized markets (encoded in $\sigma_{t}, w_{t}$ ) will produce a next-period debt distribution which can be parameterized the same way (encoded in $\left.\omega_{t+1}\right)$. The only restriction on this is that issuance satisfy a non-negativity constraint on the resultant obligations (equation (10), which is just (7) rewritten).

Crucially, there is no restriction on $\sigma_{t}$ beyond $\sigma_{t} \in \mathcal{S}$. Many models which fail to meet this definition impose extra constraints on the government's issuance choices, limiting $\sigma_{t}$ to a set smaller than $\mathcal{S}$. This means that such frameworks cannot be justified by appeals to market incompleteness alone. Instead, they demand not only that certain asset markets exist but also that governments access to them is also somehow limited, and that this limit is expressed via restriction on the choices of $\sigma_{t}$. Indeed, in Section 3.2 we will see that 
many commonly-used parametric debt densities fail to meet this criterion and are in fact inconsistent with unrestricted market access.

\section{B.4 Mixture distributions}

We now turn our attention to mixture distributions. These are a particular type of parametric debt densities. Specifically, they are linear combinations of some underlying basis densities where the elements of $\omega_{t}$ are the weights on some these densities, indexed by $i$ :

$$
f\left(s \mid \omega_{t}\right)=\sum_{i}^{M} \omega_{i, t} f_{i}(s) \quad \omega_{t} \in \Omega \subseteq \mathcal{S}
$$

We will find it helpful to denote by $\mathbf{f}(s)$ the vector of basis functions $\left(f_{1}(s), \ldots, f_{M}(s)\right)^{\prime}$, because then:

$$
f\left(s \mid \omega_{t}\right)=\omega_{t} . \mathbf{f}(s)
$$

Our focus on mixture distributions arises naturally given we require unrestricted market access.

Proposition 2. If for any $t$ there exists $T>t$ such that $w_{T}<1$, then any density which can be rationalized by unrestricted market access will eventually limit to a mixture distribution.

The intuition for this proposition is that so long as the government does not decide at some point cease issuing debt entirely (this is the condition on $w_{T}$ ), then outstanding obligations will be only debt issued in the available markets. ${ }^{30}$ As issuance $g_{t}(s)$ in these markets is itself a mixture, then so too is outstanding debt, $f_{t}(s) .{ }^{31}$

The necessary and sufficient conditions for a mixture distribution to be consistent with unrestricted market access are rather simple.

Proposition 3 (Unrestricted market access for mixtures). A mixture distribution can be rationalized by unrestricted market access if and only if there exists an $M \times M$ matrix, $W$ satisfying:

$$
\begin{aligned}
W \mathbf{f}(s) & =\mathbf{f}(s+1) \quad \forall s \\
W \mathbf{1} & =\mathbf{1}-\mathbf{f}(1)
\end{aligned}
$$

where $\mathbf{f}(s)=\left(f_{1}(s), \ldots, f_{2}(s)\right)^{\prime}$ is the vector of the mixture basis at $s$ and $\mathbf{1}$ is an $M \times 1$ vector of ones.

\footnotetext{
${ }^{30}$ Reminder: All proofs are in Appendix B.5

${ }^{31}$ Moreover, the number of parameters is at least the number of markets, so $N \geq M$.
} 
Intuitively, equation (11) says that any mixture of the basis densities can also be represented as a mixture of the same basis densities when the whole balance sheet matures by one period. Equation (12) is just the requirement that beasis distirbutions sum to one.

This proposition is important because it sets up our main result, Theorem 1, which says that there are only two solutions to equations (11) and (12): $M$ exponentially-decayingcoupon bonds, or a full set of zero-coupon bonds at every horizon between 1 and some maximum horizon $T$.

Theorem 1. Let $\mathbf{f}$ satisfy the conditions of Proposition 3. Then there exist a matrix $P$ and non-negative integers $T$ and $M$, with $T \leq M$ such that:

1. For all $s, \mathbf{f}(s)=\hat{\mathbf{f}}(s)$, with the elements of $\hat{\mathbf{f}}$ satisfying

$$
\begin{array}{rlrl}
\text { For } i & =1, \ldots, M \quad \exists \lambda_{1}, \ldots \lambda_{M} \text { s.t. } & \hat{f}_{i}(s)=\lambda_{i}^{s-1}\left(1-\lambda_{i}\right) \forall s \\
\text { If } T>0 \text { then for } i=M+1, \ldots, M+T & \hat{f}_{i}(s)= \begin{cases}1 & s=i-M \\
0 & s \neq i\end{cases}
\end{array}
$$

2. The rows of $P$ is sum to one, and can be expressed as:

$$
P=\left[\begin{array}{cc} 
& Q_{2} \\
Q_{1} & 0_{T \times(M-T)}
\end{array}\right]
$$

where $Q_{1}$ is $M \times M, Q_{2}$ is $T \times T$ and both are invertible.

In other words, the solutions to equations (11) and (12) are linear combinations of more primitive densities, the $\hat{\mathbf{f}}$. These come in two types. The first, denoted by $i \leq M$, is the series of exponentially-decaying-coupon bonds, where a fixed fraction $1-\lambda_{i}$ of each outstanding bond pays out in every period. These are often termed exponential-coupon bonds, with their genesis being in Hatchondo and Martinez (2009). The second set, for $i>M$ is the sequence of one-period bonds, each paying out only at one horizon between 1 and $T .{ }^{32}$ The role of the matrix $P$ is to convert from the primitive densities $\hat{\mathbf{f}}$ to the markets available, $\mathbf{f}$.

An important implication of this result is that the only framework for approximating an empirical debt density in a way that reduces the dimensionality of the data is to use asset markets that are weighted averages of exponential-coupon bonds. That $Q_{2}$ in particular is invertible is key to this. Because $Q_{2}$ is invertible, it implies that any non-exponential-coupon

\footnotetext{
${ }^{32}$ Note that $T \leq M$ does not restrict the analysis here. Because an exponential-coupon bond with parameter $\lambda_{i}=0$ is just a one-period zero-coupon bond, one can always represent a case where $T>M$ just by adding $T-M$ redundant extra exponential-coupon bonds with parameter $\lambda_{i}=0$ without meaningfully expanding the set of markets.
} 
assets must be able to replicate a full set of all zero-coupon bonds between horizons 1 and $T$. If $\hat{\mathbf{f}}$ included fewer than $T$ distinct zero-coupon bonds then $Q_{2}$ would be rank deficient. And so using zero-coupon bonds to capture an empirical debt density with maximum maturity $T$ requires $T$ assets; it does not compress the data at all.

The details of the proof are in Appendix B.5. Since this is our central result and the basic idea is relatively straightforward, we also sketch it here. The important step is to decompose $W$ in Proposition 3 into its Jordan canonical form, $W=A(\Lambda+\Psi) A^{-1}$ where $A$ is a change of basis, $\Lambda$ is square and diagonal, and $\Psi$ a square matrix in which all entries are zeros, except for the first off-diagonal which may have some entries which are one. Without loss of generality, we can assume that $\mathbf{f}$ is ordered such that these off-diagonal entries are on the first $T$ rows:

$$
\Psi=\left\{\psi_{i j}\right\}= \begin{cases}1 & i=j-1, i<T \\ 0 & \text { otherwise }\end{cases}
$$

To build intuition, consider the case where $A$ is the identity matrix. Substituting into equation (11):

$$
\mathbf{f}(s+1)=(\Lambda+\Psi) \mathbf{f}(s)
$$

So the matrices $\Lambda$ and $\Psi$ determine how the mixture components evolve. Again for the purpose of intuition, consider separately the cases where $\Psi=0$ (as occurs when $W$ is diagonalizable) and where $\Lambda=0$.

If $\Psi=0$ then $\Lambda \mathbf{f}(s)=\mathbf{f}(s)$. Because $\Lambda$ is diagonal then $f_{i}(s+1)=\lambda_{i} f_{i}(s) \forall i, s$, i.e. that the $f_{i}(s)$ are exponentially-decaying-coupon bonds with parameter $\lambda_{i}$.

$\underline{\text { If } \Lambda=0}$, assume that $T=M$ (again, just for intuition) then equation (12) immediately implies that $\mathbf{f}(1)$ is the unit vector $(0,0, \ldots, 1)^{\prime}$. Labeling the last row as the density for asset $1, f_{1}(s)=1$ if $s=1$ and is zero elsewhere, i.e. the density associated with the one-period zero-coupon bond. Because $\Psi$ "shifts up" the entries of $\mathbf{f}(s)$, then $f_{i+1}(s+1)=f_{i}(s)$ for $s=1, \ldots T$. Thus $f_{i}(s)=1$ if $s=i$ and is zero otherwise. In other words, asset market $i$ is the $i$-period zero-coupon bond.

The full proof is then is simply a matter of running through the same steps without the simplifying assumptions in the sketch, principally when $A$ is not the identity matrix, $\Lambda, \Phi$ are both nonzero, and $T \neq M$. Finally, because $Q_{1}, Q_{2}$ are select rows and columns of $A$, then they inherit invertibility from $A$. 


\section{B.5 Proofs}

Of Proposition 1. Follows immediately from combining equations (1) - (3), with:

$$
w_{t}=\frac{1-f_{t}(1)}{1-f_{t}(1)+i_{t} / b_{t}} \in[0,1]
$$

The restriction on $\bar{w}$ follows almost immediately from inverting the non-negativity constraint on $f_{t+1}(s)$.

Without loss of generality in what follows we consider only the case where $\Omega$ is nonredundant.

Definition 2 (Non-redundancy). $\Omega$ is non-redundant if for all $\omega_{t+1} \in \Omega$ there exist $\omega_{t} \in \Omega$, $\sigma_{t} \in\left\{x \in \mathbb{R}^{N} \mid \sum_{i=1}^{N}=1\right\}$, and $w_{t} \in[\bar{w}, 1]$ with $\bar{w}$ defined by equation (10), such that equation (9) holds.

Non-redundancy is not a meaningful restriction on our analysis. It simply says that there are no points in parameter space of the debt distributions which cannot be attained by any sequence of issuance policies. If there were, one could simply remove the offending point from $\Omega$ without shrinking the set of possible debt distributions which could be attained.

We can now derive necessary conditions for unrestricted market access in this case. This is a useful intermediate step in the proof of Theorem 1.

Proposition 4 (Necessary conditions for unrestricted market access). If $f(s \mid \omega)$ can be rationalized by unrestricted access to the asset markets defined by $h_{1}, \ldots, h_{N}$, and $\Omega$ is nonredundant, then:

1. Truncation: $\forall \omega \in \Omega, \exists \tilde{\omega} \in \Omega$ such that:

$$
f(s \mid \tilde{\omega})=\frac{f(s+1 \mid \omega)}{1-f(1 \mid \omega)} \forall s
$$

2. Parametric mixture $\forall \omega, \omega^{\prime} \in \Omega, \forall \alpha \in \mathbb{R} \exists \tilde{\omega} \in \Omega$ such that:

$$
f(s \mid \tilde{\omega})=\alpha f\left(s \mid \omega^{\prime}\right)+(1-\alpha) f(s \mid \omega) \forall s
$$

Intuitively, these conditions are that a change in the parameters of the debt density can be used to capture 1) the impact of maturing debt on the government's debt portfolio , and 2) a weighted average of other densities in the same parametric family. These intuitive concepts can be expressed as the requirement that the density preserve its parametric form under truncation and mixing. 


\section{Of Proposition 4.}

1. The definition of unrestricted market access says that for any $\omega \in \Omega$ says that there exists an $\omega^{\prime}$ satisfying equation (10) when $w_{t}=1$.

2. As $\Omega$ is non-redundant, for any $\omega \in \Omega$ there exists $\hat{\omega}, \sigma, w$ such that:

$$
f(s \mid \omega)=w\left(\frac{f(s+1 \mid \hat{\omega})}{1-f(1 \mid \hat{\omega})}\right)+(1-w)\left(\sum_{j=1}^{N} \sigma^{j} h_{j}(s)\right) \quad \forall s
$$

Because $f(\cdot)$ can be rationalized by unrestricted access, then for any other $w^{\prime} \in[\bar{w}, 1]$, there must exist some $\tilde{\omega} \in \Omega$ such that

$$
f(s \mid \tilde{\omega})=w^{\prime}\left(\frac{f(s+1 \mid \hat{\omega})}{1-f(1 \mid \hat{\omega})}\right)+\left(1-w^{\prime}\right)\left(\sum_{j=1}^{N} \sigma^{j} h_{j}(s)\right) \quad \forall s
$$

Eliminating the issuance term using equation (13) and tidying up gives:

$$
\begin{aligned}
f(s \mid \tilde{\omega}) & =\left(\frac{w^{\prime}-w}{1-w}\right)\left(\frac{f(s+1 \mid \hat{\omega})}{1-f(1 \mid \hat{\omega})}\right)+\left(\frac{1-w^{\prime}}{1-w}\right) f(s \mid \omega) \quad \forall s \\
& =\left(\frac{w^{\prime}-w}{1-w}\right) f\left(s \mid \omega^{\prime}\right)+\left(\frac{1-w^{\prime}}{1-w}\right) f(s \mid \omega) \quad \forall s
\end{aligned}
$$

Where the last line follows from the first part of the proposition. This holds for all $w$, arbitrarily close to unity, and so $\alpha=\left(w^{\prime}-w\right) /(1-w)$ has a range of $\mathbb{R}$ (if $w=1$ or $\bar{w}$ we can just switch the roles of $w$ and $\left.w^{\prime}\right)$.

\section{Of Proposition 2.}

This follows straightforwardly from recursive substitution of equation (6):

$$
\begin{aligned}
f_{t+1}(s) & =w_{t}\left(\frac{f_{t}(s+1)}{1-f_{t}(1)}\right)+\left(1-w_{t}\right) g_{t}(s) \\
& =Q_{t}^{t} f_{0}(s+1+t)+\sum_{s=0}^{t} Q_{t}^{s}\left(1-w_{t-s}\right) g_{t-s}(s+s)
\end{aligned}
$$

Where:

$$
Q_{t}^{s}= \begin{cases}1 & s=0 \\ \prod_{r=0}^{s-1}\left(\frac{w_{t-r}}{1-f_{t-r}(1)}\right) & \end{cases}
$$


Equation (14) is a decomposition of outstanding debts into those inherited at the start of period 0 and issuance since. Under the conditions in the proposition, $Q_{t}^{t} \rightarrow 0$ as $t \rightarrow \infty$.

Moreover, if the government issues in markets $1, \ldots, N$, then $g_{t}(s)=\sum_{j=1}^{N} \sigma_{t}^{j} h_{j}(s)$, then in the limit we have that:

$$
\begin{aligned}
f_{t+1}(s) & =\sum_{s=0}^{t} Q_{t}^{s}\left(1-w_{t-s}\right) g_{t-s}(s+s) \\
& =\sum_{s=0}^{t} Q_{t}^{s}\left(1-w_{t-s}\right) \sum_{j=1}^{N} \sigma_{t-s}^{j} h_{j}(s) \\
& =\sum_{j=1}^{N}\left(\sum_{s=0}^{t} Q_{t}^{s}\left(1-w_{t-s}\right) \sigma_{t-s}^{j}\right) h_{j}(s)
\end{aligned}
$$

Which is a mixture distribution with the asset densities $h_{j}(s)$ playing the role of the basis densities.

Of Proposition 3. If $f(s \mid \omega)$ is a mixture distribution which can be rationalized by market access, then the truncation condition requires that for any $\omega \in \Omega$, there exists $\tilde{\omega} \in \Omega$ such that:

$$
f(s \mid \tilde{\omega})=\frac{(s+1) \mid \omega)}{1-f(1 \mid \omega)}
$$

Or, in vector notation:

$$
\tilde{\omega}^{\prime} \mathbf{f}(s)=\frac{\omega^{\prime} \mathbf{f}(s+1)}{1-f(1 \mid \omega)}
$$

Where $\omega^{\prime} \mathbf{1}=\tilde{\omega}^{\prime} \mathbf{1}=1$

This holds for all $\omega \in \Omega$, including each of the unit direction vectors vectors $\mathbf{1}_{i}$, which has a 1 in position $i$ and zeros elsewhere. As $\omega_{i}^{\prime} \mathbf{f}(s)=f_{i}(s)$ :

$$
\left(1-f_{i}(1)\right) \tilde{\omega}_{i}^{\prime} \mathbf{f}=f_{i}(s+1) \quad \forall s, i
$$

We can stack these equations, to give:

$$
W \mathbf{f}(s)=\mathbf{f}(s+1) \quad \forall s
$$

Where the $i$ th row of $W$ is given by $\left(1-f_{i}(1)\right) \tilde{\omega}_{i}$. As $\tilde{\omega}_{i}^{\prime} 1=1$ :

$$
W \mathbf{1}=\mathbf{1}-\mathbf{f}(1)
$$


As required.

To show the converse, pick any $\omega_{t}, \sigma_{t} \in \mathcal{S}$ and any $w_{t} \in\left[\underline{w}_{t}, 1\right]$ and let $W$ be any $M \times M$ matrix satisfying the conditions of the proposition.. Then next-period obligations are:

$$
\begin{aligned}
f_{t+1}(s) & =\frac{w_{t} \omega_{t}^{\prime} \mathbf{f}(s+1)}{1-\omega_{t}^{\prime} \mathbf{f}(1)}+\left(1-w_{t}\right) \sigma_{t}^{\prime} \mathbf{f}(s) \\
& =\frac{w_{t} \omega_{t}^{\prime} W \mathbf{f}(s)}{1-\omega_{t}^{\prime} \mathbf{f}(1)}+\left(1-w_{t}\right) \sigma_{t}^{\prime} \mathbf{f}(s) \\
& =\left(\frac{w_{t} W^{\prime} \omega_{t}^{\prime}}{1-\omega_{t}^{\prime} \mathbf{f}(1)}+\left(1-w_{t}\right) \sigma_{t}^{\prime}\right) \mathbf{f}(s) \\
& \equiv \omega_{t+1}^{\prime} \mathbf{f}(s)
\end{aligned}
$$

Where the lower bound $\underline{w}_{t}$ guarantees that the $\omega_{t+1}$ so-defined is in $\mathcal{S}$.

Then so long as the so-defined $f_{i}(s)$ are proper densities, $f(s \mid \omega)$ can be rationalized by unrestricted market access to $f_{1}, \ldots, f_{M}$.

To check that these indeed are densities, we define:

$$
J=\sum_{s=1}^{\infty} \mathbf{f}(s)
$$

Then:

$$
\begin{aligned}
J & =\sum_{s=1}^{\infty} \mathbf{f}(s) \\
& =\sum_{s=1}^{\infty} W^{n} \mathbf{f}(1) \quad \text { as } W \mathbf{f}(s)=\mathbf{f}(s+1) \quad \forall s \\
& =(I-W)^{-1} \mathbf{f}(1)
\end{aligned}
$$

But $W \mathbf{1}=\mathbf{1}-\mathbf{f}(1)$, which can be rearranged as:

$$
\mathbf{f}(1)=(I-W) \mathbf{1}
$$

So:

$$
J=(I-W)^{-1}(I-W) \mathbf{1}=\mathbf{1}
$$

Thus, the $f_{i}$ are proper distributions, completing the proof

Of Theorem 1. The matrix $W$ in Proposition 3 is square (of size $M$ ) and so has a Jordan 
canonical form, given by:

$$
W=A(\Lambda+\Psi) A^{-1}
$$

where $A, \Lambda, \Psi$ are all $M \times M$ matrices with elements $A_{i j}, \lambda_{i j}, \psi_{i j}$ such that:

$$
\lambda_{i j}=\left\{\begin{array}{ll}
\lambda_{i} & i=j \\
0 & i \neq j
\end{array} \quad \Psi=\left\{\psi_{i j}\right\}= \begin{cases}1 & i=j-1, i<T \\
0 & \text { otherwise }\end{cases}\right.
$$

In other words, $\Lambda$ is diagonal, and $\Psi$ is zero everywhere except for $T$ first off-diagonal entries, which are one. Without loss of generality we assume that $\mathbf{f}$ is ordered such that the offdiagonals in $\Psi$ occur in the first $T \leq M$ entries. ${ }^{33}$ We let $\tilde{A}$ be the diagonal matrix of row-sums of $A$, i.e. $\tilde{A}=\operatorname{diag}(A \mathbf{1})$. Then $Q=\tilde{A}^{-1} A$ is the matrix $A$, except with the row sums normalized to one. Because both $A$ and $\tilde{A}$ are invertible, so too is $Q$. Then we can rewrite equation (11) as:

$$
\begin{aligned}
\mathbf{f}(s+1) & =W \mathbf{f}(s) \\
& =A(\Lambda+\Psi) A^{-1} \mathbf{f}(s) \\
\Rightarrow \quad A^{-1} \mathbf{f}(s+1) & =(\Lambda+\Psi) A^{-1} \mathbf{f}(s) \\
\tilde{A} Q^{-1} \mathbf{f}(s+1) & =(\Lambda+\Psi) \tilde{A} Q^{-1} \mathbf{f}(s) \\
Q^{-1} \mathbf{f}(s+1) & =\tilde{A}(\Lambda+\Psi) \tilde{A}^{-1} Q^{-1} \mathbf{f}(s) \\
Q^{-1} \mathbf{f}(s+1) & =(\Lambda+\Psi) Q^{-1} \mathbf{f}(s)
\end{aligned}
$$

Where the last line follows from $\tilde{A}(\Lambda+\Psi) \tilde{A}^{-1}=\Lambda+\Psi$, which holds because $\tilde{A}$ is diagonal.

We further define:

$$
\Phi=\left[\begin{array}{cc}
\Lambda & 0 \\
0 & \Psi
\end{array}\right] \quad R=\left[\begin{array}{c}
I_{M} \\
I_{M}
\end{array}\right]
$$

Then:

$$
\Lambda+\Psi=R \Phi R^{\prime}
$$

Where $I_{M}$ is the $M \times M$ identity matrix.

\footnotetext{
${ }^{33}$ Note that $T \leq M$ always. This means that if we want to represent a setting with $T$ zero-coupon bonds and $H$ exponential-coupon bonds with $H<T$ then the corresponding Jordan normal form will populate $\Lambda$ with $T-H$ extra rows and columns of zeros, i.e. an extra $T-H$ redundant one-period bond markets.
} 
Then:

$$
\begin{aligned}
Q^{-1} \mathbf{f}(s) & =R^{\prime} \Phi R P^{-1} \mathbf{f}(s+1) \\
R Q^{-1} \mathbf{f}(s) & =\left(R R^{\prime}\right) \Phi R Q^{-1} \mathbf{f}(s+1) \\
& =\Phi R Q^{-1} \mathbf{f}(s+1)
\end{aligned}
$$

Where the last line follows because the block-diagonal structure of $\Phi$ means that $\left(R R^{\prime}\right) \Phi=\Phi$.

Let $\hat{\mathbf{f}}(s)=R Q^{-1} \mathbf{f}(s)$. Then:

$$
\hat{\mathbf{f}}(s+1)=\Phi \hat{\mathbf{f}}(s)
$$

Then because $\Psi$ is block-diagonal, we can analyze the effect of $\Psi$ separately on the upper and lower $M$ rows of $\hat{\mathbf{f}}$, just as in the sketch.

For the first $M$ rows of $\hat{\mathbf{f}}$, the diagonal structure of $\Lambda$ means $\hat{f}_{i}(s+1)=\lambda_{i} \hat{f}_{i}(s)$, implying that $\hat{f}_{i}(s)=\lambda_{i}^{s-1}\left(t-\lambda_{i}\right)$. In other words, the first $M$ rows of $\hat{\mathbf{f}}(s)$ are an exponentiallydecaying-coupon bond with a fraction $1-\lambda_{i}$ maturing each period.

To complete the proof, we consider two cases.

Case I: $T=M$ Equation (12) is now:

$$
\hat{\mathbf{f}}(1)=\mathbf{1}-\Phi \mathbf{1}=(\underbrace{0,0, \ldots, 0}_{M+T-1 \text { times }}, 1)^{\prime}
$$

Isolating the very last row gives us that:

$$
\hat{f}_{M+T}(1)=1
$$

That is, the one-period bond. $\Phi$ acts to "shift up" every element - creating a chain of assets each incrementing the debt maturity of the previous by one period, the other elements of the lower half of $\hat{\mathbf{f}}(s)$ satisfy:

$$
\begin{aligned}
\hat{f}_{M+T-i}(s+1) & =\hat{f}_{M+T-i}(s) \\
\Rightarrow \quad \hat{f}_{M+T-i}(s) & =\hat{f}_{M+T}(s-1) \\
& = \begin{cases}1 & s=i-1 \\
0 & s \neq i\end{cases}
\end{aligned}
$$

That is, the sequence of zero-coupon one-period bonds. This is the same as the functional form in the statement of the theorem.

All that now remains is to show that $\mathbf{f}(s)=P \hat{\mathbf{f}}(s)$ and that the properties of $P$ stated 
in the proof are satisfied.

$$
\begin{aligned}
R^{\prime} \hat{\mathbf{f}}(s) & =\left(R^{\prime} R\right) Q^{-1} \mathbf{f}(s) \\
& =2 Q^{-1} \mathbf{f}(s)
\end{aligned}
$$

Where the last line follows because $R^{\prime} R=2 I_{M}$. Rearranging, we get that:

$$
\begin{aligned}
(s) & =\frac{1}{2} P R / \hat{\mathbf{f}}(s) \\
& =\frac{1}{2}[Q Q] \hat{\mathbf{f}}(s)
\end{aligned}
$$

Let $Q_{1}=Q_{2}=\frac{1}{2} Q$ and $P=\left[Q_{1} Q_{2}\right]$. Then both $Q_{1}$ and $Q_{2}$ are invertible and

$$
\mathbf{f}(s)=P \hat{\mathbf{f}}(s)
$$

And because the rows of $P$ sum to unity, $\mathbf{f}$ is a weighted average of the densities in $\hat{\mathbf{f}}$, as required.

Case II: $T<M$ In this case, the same logic runs through, except that now equation (12) is:

$$
\hat{\mathbf{f}}(1)=\mathbf{1}-\Phi \mathbf{1}=(\underbrace{0,0, \ldots, 0}_{M+T-1 \text { times }}, \underbrace{1,1, \ldots, 1}_{M-T-1 \text { times }})^{\prime}
$$

In other words, we have $M-T$ copies of the one-period bond. We thus redefine $\hat{\mathbf{f}}$, dropping the last $M-T$ entries, so that there is now only a single one-period bond. In this case, we also have to redefine the mapping from $\hat{\mathbf{f}}$ to $\mathbf{f}$. In particular, we let $Q_{2}=\frac{1}{2} Q_{T}$, where:

$$
Q_{T}=\left[\begin{array}{ll}
I_{T} & 0_{T \times(M-T)}
\end{array}\right] Q\left[\begin{array}{c}
I_{T} \\
1_{(M-T) \times T}
\end{array}\right]
$$

That is, $Q_{T}$ is a $T \times T$ matrix where the first $T-1$ columns is the corresponding upper-left submatrix of $Q$ and the last column is the sum of columns $M+1$ to $T$. This transformation reduces the rank of $Q$ by $M-T$. As $Q$ was full rank initially, then so too is $Q_{T}$. Thus, $Q_{T}$ is invertible. And, because $Q_{T}$ inherits the rowsums from $Q$, it also has unit rowsums.

Then we let $Q_{1}=\frac{1}{2} Q$ and define:

$$
P=\left[\begin{array}{cc}
Q_{1} & Q_{2} \\
& 0
\end{array}\right]
$$

Then the rowsums of $P$ are one, and $Q_{1}$ and $Q_{2}$ are invertible, as required. 


\section{Robustness exercises}

\section{C.1 Robustness to different sample periods}

Tables 5-7 repeat our headline analysis for samples since 1960 and 1980, as well as back to 1869. In the later samples, the estimated $\theta_{i}$ are very similar to those in our headline results, although with slightly different average weights. In other words, we characterize a stable set of assets, but governments chose different issuance patterns over time - consistent with the patterns in Figure 7. Prior to 1920, though, the estimated $\theta_{i}$ are quite different, consistent with our interpretation that a single stylized interpretation of asset markets which spans World War I is not statistically valid. 
Table 5: MLE Estimates, Exponentially decaying coupon 1960-2020

\begin{tabular}{|c|c|c|c|c|c|c|c|c|}
\hline & \multicolumn{4}{|c|}{ United States } & \multicolumn{4}{|c|}{ United Kingdom } \\
\hline & $M=1$ & $M=2$ & $M=3$ & $M=4$ & $M=1$ & $M=2$ & $M=3$ & $M=4$ \\
\hline & \multicolumn{8}{|c|}{ Bond decay parameters } \\
\hline \multirow[t]{2}{*}{$\theta_{1}$} & $0.015^{* * *}$ & $0.010^{* * *}$ & $0.009^{* * *}$ & $0.009^{* * *}$ & $0.006^{* * *}$ & $0.003^{* * *}$ & $0.003^{* * *}$ & $0.003^{* * *}$ \\
\hline & $(0.0005)$ & $(0.0006)$ & $(0.0007)$ & $(0.0007)$ & $(0.0002)$ & $(0.0005)$ & $(0.0004)$ & $(0.0004)$ \\
\hline \multirow[t]{2}{*}{$\theta_{2}$} & & $0.139 * * *$ & $0.035^{* * *}$ & $0.033^{* * *}$ & & $0.008^{* * *}$ & $0.006^{* * *}$ & $0.006^{* * *}$ \\
\hline & & $(0.0237)$ & $(0.0069)$ & $(0.0058)$ & & $(0.0006)$ & $(0.0005)$ & $(0.0005)$ \\
\hline \multirow[t]{2}{*}{$\theta_{3}$} & & & $0.245^{* * *}$ & $0.159^{* *}$ & & & $0.009^{* * *}$ & $0.009 * * *$ \\
\hline & & & $(0.0469)$ & $(0.0579)$ & & & $(0.0007)$ & $(0.0007)$ \\
\hline \multirow[t]{3}{*}{$\theta_{4}$} & & & & $0.319^{* * *}$ & & & & $0.421^{* * *}$ \\
\hline & & & & $(0.0917)$ & & & & $(0.1206)$ \\
\hline & & & & Average & weights & & & \\
\hline \multirow[t]{2}{*}{$\bar{\omega}_{1}$} & & $0.688^{* * *}$ & $0.496^{* * *}$ & $0.493^{* * *}$ & & $0.243^{* * *}$ & $0.176^{* * *}$ & $0.192^{* * *}$ \\
\hline & & $(0.0225)$ & $(0.0329)$ & $(0.0287)$ & & $(0.0316)$ & $(0.0204)$ & $(0.0209)$ \\
\hline \multirow[t]{2}{*}{$\bar{\omega}_{2}$} & & $0.312^{* * *}$ & $0.325^{* * *}$ & $0.300^{* * *}$ & & $0.757^{* * *}$ & $0.309^{* * *}$ & $0.304^{* * *}$ \\
\hline & & $(0.0225)$ & $(0.0408)$ & $(0.0392)$ & & $(0.0316)$ & $(0.0425)$ & $(0.0472)$ \\
\hline \multirow[t]{2}{*}{$\bar{\omega}_{3}$} & & & $0.179^{* * *}$ & $0.127^{* * *}$ & & & $0.515^{* * *}$ & $0.477^{* * *}$ \\
\hline & & & $(0.0224)$ & $(0.0364)$ & & & $(0.0483)$ & $(0.0484)$ \\
\hline \multirow[t]{2}{*}{$\bar{\omega}_{4}$} & & & & $0.081^{* *}$ & & & & $0.027^{* * *}$ \\
\hline & & & & $(0.0306)$ & & & & $(0.0079)$ \\
\hline $\mathrm{T}$ & 732 & 732 & 732 & 732 & 732 & 732 & 732 & 732 \\
\hline S & 1200 & 1200 & 1200 & 1200 & 1200 & 1200 & 1200 & 1200 \\
\hline Params. & 1 & 734 & 1467 & 2200 & 1 & 734 & 1467 & 2200 \\
\hline Log lik & -3813.51 & -3693.76 & -3682.56 & -3681.26 & -4518.36 & -4481.55 & -4474.93 & -4462.02 \\
\hline AIC & 7629.01 & 8855.51 & 10299.11 & 11762.53 & 9038.72 & 10431.10 & 11883.86 & 13324.05 \\
\hline
\end{tabular}


Table 6: MLE Estimates, Exponentially decaying coupon 1980-2020

\begin{tabular}{|c|c|c|c|c|c|c|c|c|}
\hline & \multicolumn{4}{|c|}{ United States } & \multicolumn{4}{|c|}{ United Kingdom } \\
\hline & $M=1$ & $M=2$ & $M=3$ & $M=4$ & $M=1$ & $M=2$ & $M=3$ & $M=4$ \\
\hline & \multicolumn{8}{|c|}{ Bond decay parameters } \\
\hline \multirow[t]{2}{*}{$\theta_{1}$} & $0.014^{* * *}$ & $0.010^{* * *}$ & $0.009^{* * *}$ & $0.009^{* * *}$ & $0.007^{* * *}$ & $0.006^{* * *}$ & $0.006^{* * *}$ & $0.005^{* * *}$ \\
\hline & $(0.0006)$ & $(0.0007)$ & $(0.0009)$ & $(0.0008)$ & $(0.0003)$ & $(0.0005)$ & $(0.0005)$ & $(0.0007)$ \\
\hline \multirow[t]{2}{*}{$\theta_{2}$} & & $0.131^{* * *}$ & $0.039^{* * *}$ & $0.027^{* * *}$ & & $0.009^{* * *}$ & $0.008^{* * *}$ & $0.006^{* * *}$ \\
\hline & & $(0.0311)$ & $(0.0123)$ & $(0.0077)$ & & $(0.0011)$ & $(0.0013)$ & $(0.0008)$ \\
\hline \multirow[t]{2}{*}{$\theta_{3}$} & & & $0.263^{* * *}$ & $0.064^{* *}$ & & & $0.010^{* * *}$ & $0.009^{* * *}$ \\
\hline & & & $(0.0788)$ & $(0.0265)$ & & & $(0.0019)$ & $(0.0010)$ \\
\hline \multirow[t]{3}{*}{$\theta_{4}$} & & & & $0.314^{* * *}$ & & & & $0.010^{* * *}$ \\
\hline & & & & $(0.0913)$ & & & & $(0.0023)$ \\
\hline & & & & Average & weights & & & \\
\hline \multirow[t]{2}{*}{$\bar{\omega}_{1}$} & & $0.725^{* * *}$ & $0.576^{* * *}$ & $0.564^{* * *}$ & & $0.533^{* * *}$ & $0.455^{* * *}$ & $0.279^{* * *}$ \\
\hline & & $(0.0273)$ & $(0.0406)$ & $(0.0429)$ & & $(0.0650)$ & $(0.0600)$ & $(0.0288)$ \\
\hline \multirow[t]{2}{*}{$\bar{\omega}_{2}$} & & $0.275^{* * *}$ & $0.285^{* * *}$ & $0.156^{* * *}$ & & $0.467^{* * *}$ & $0.272^{*}$ & $0.251^{* * *}$ \\
\hline & & $(0.0273)$ & $(0.0493)$ & $(0.0438)$ & & $(0.0650)$ & $(0.1386)$ & $(0.0013)$ \\
\hline \multirow[t]{2}{*}{$\bar{\omega}_{3}$} & & & $0.139^{* * *}$ & $0.174^{* * *}$ & & & $0.273^{* *}$ & $0.293^{* *}$ \\
\hline & & & $(0.0257)$ & $(0.0418)$ & & & $(0.1276)$ & $(0.1154)$ \\
\hline \multirow[t]{2}{*}{$\bar{\omega}_{4}$} & & & & $0.106^{* * *}$ & & & & $0.177^{*}$ \\
\hline & & & & $(0.0258)$ & & & & (0.1099) \\
\hline $\mathrm{T}$ & 492 & 492 & 492 & 492 & 492 & 492 & 492 & 492 \\
\hline S & 1200 & 1200 & 1200 & 1200 & 1200 & 1200 & 1200 & 1200 \\
\hline Params. & 1 & 494 & 987 & 1480 & 1 & 494 & 987 & 1480 \\
\hline Log lik & -2605.22 & -2542.99 & -2537.81 & -2535.90 & -2932.17 & -2926.94 & -2926.65 & -2926.43 \\
\hline AIC & 5212.44 & 6073.98 & 7049.61 & 8031.81 & 5866.34 & 6841.89 & 7827.30 & 8812.86 \\
\hline
\end{tabular}


Table 7: MLE Estimates, 1869-2020

\begin{tabular}{|c|c|c|c|c|c|c|c|c|}
\hline & \multicolumn{4}{|c|}{ United States } & \multicolumn{4}{|c|}{ United Kingdom } \\
\hline & $M=1$ & $M=2$ & $M=3$ & $M=4$ & $M=1$ & $M=2$ & $M=3$ & $M=4$ \\
\hline & \multicolumn{8}{|c|}{ Bond decay parameters } \\
\hline \multirow[t]{2}{*}{$\theta_{1}$} & $0.004^{* * *}$ & $0.002^{* * *}$ & $0.002^{* * *}$ & $0.002^{* * *}$ & $0.003^{* * *}$ & $0.002^{* * *}$ & $0.002^{* * *}$ & $0.002^{* * *}$ \\
\hline & $(0.0001)$ & $(0.0001)$ & $(0.0001)$ & $(0.0001)$ & $(0.0001)$ & $(0.0001)$ & $(0.0001)$ & $(0.0001)$ \\
\hline \multirow[t]{2}{*}{$\theta_{2}$} & & $0.012^{* * *}$ & $0.009^{* * *}$ & $0.008^{* * *}$ & & $0.007^{* * *}$ & $0.003^{* * *}$ & $0.003^{* * *}$ \\
\hline & & $(0.0004)$ & $(0.0004)$ & $(0.0004)$ & & $(0.0004)$ & $(0.0002)$ & $(0.0002)$ \\
\hline \multirow[t]{2}{*}{$\theta_{3}$} & & & $0.136^{* * *}$ & $0.033^{* * *}$ & & & $0.008^{* * *}$ & $0.005^{* * *}$ \\
\hline & & & $(0.0190)$ & $(0.0053)$ & & & $(0.0006)$ & $(0.0004)$ \\
\hline \multirow[t]{3}{*}{$\theta_{4}$} & & & & $0.243^{* * *}$ & & & & $0.009^{* * *}$ \\
\hline & & & & $(0.0350)$ & & & & $(0.0008)$ \\
\hline & & & & Average & weights & & & \\
\hline \multirow[t]{2}{*}{$\bar{\omega}_{1}$} & & $0.336^{* * *}$ & $0.316^{* * *}$ & $0.310^{* * *}$ & & $0.564^{* * *}$ & $0.379^{* * *}$ & $0.346^{* * *}$ \\
\hline & & $(0.0042)$ & $(0.0013)$ & $(0.0015)$ & & $(0.0116)$ & $(0.0137)$ & $(0.0029)$ \\
\hline \multirow[t]{2}{*}{$\bar{\omega}_{2}$} & & $0.664^{* * *}$ & $0.517^{* * *}$ & $0.429^{* * *}$ & & $0.436^{* * *}$ & $0.319^{* * *}$ & $0.291^{* * *}$ \\
\hline & & $(0.0042)$ & $(0.0085)$ & $(0.0119)$ & & $(0.0116)$ & $(0.0263)$ & $(0.0122)$ \\
\hline \multirow[t]{2}{*}{$\bar{\omega}_{3}$} & & & $0.167^{* * *}$ & $0.161^{* * *}$ & & & $0.302^{* * *}$ & $0.122^{* * *}$ \\
\hline & & & $(0.0084)$ & $(0.0124)$ & & & $(0.0152)$ & $(0.0133)$ \\
\hline \multirow[t]{2}{*}{$\bar{\omega}_{4}$} & & & & $0.100^{* * *}$ & & & & $0.242^{* * *}$ \\
\hline & & & & $(0.0084)$ & & & & $(0.0169)$ \\
\hline $\mathrm{T}$ & 1817 & 1817 & 1817 & 1817 & 1819 & 1819 & 1819 & 1819 \\
\hline $\mathrm{S}$ & 1200 & 1200 & 1200 & 1200 & 1200 & 1200 & 1200 & 1200 \\
\hline Params. & 1 & 1819 & 3637 & 5455 & 1 & 1821 & 3641 & 5461 \\
\hline Log lik & -11654.62 & -10953.29 & -10767.39 & -10744.04 & -12540.67 & -12312.82 & -12290.30 & -12283.28 \\
\hline $\mathrm{AIC}$ & 23311.24 & 25544.58 & 28808.77 & 32398.09 & 25083.34 & 28267.64 & 31862.59 & 35488.55 \\
\hline
\end{tabular}




\section{C.2 Results using real obligations analysis}

All analyses until this point have been conducted using nominal payment obligations. In this section, we parameterize real debt densities. That is, we deflate a stream of nominal payment obligations at time $t$ using the expected inflation term structure at time $t$ to derive a stream of real payment obligations using the following formula:

$$
B_{m t}^{\text {dollars }}=B_{m t}^{\text {dollars }} m t / \Pi_{m t}
$$

where

- $B_{m t}^{\text {dollars }_{t}}$ is payments outstanding due in period $t+m$, quoted in period $t$ dollars.

- $B_{m t}^{\text {dollars }_{m t}}$ is payments outstanding due in period $t+m$, quoted in period $m t$ dollars.

- $\Pi_{m t}=\prod_{h=1}^{m}\left(1+E_{t} \pi_{t+h}\right)^{1 / 12}$ is cumulative expected inflation between period $t$ and $t+m$, and $E_{t} \pi_{t+h}$ is the expected inflation taken at time $t$ for inflation in $m$ months.

30-year CPI inflation expectations for the US and UK each month beginning January 1920 (see Figure 18) are imputed from Federal Reserve Bank of Cleveland's projections discussed in Appendix A.1. The imputation procedure is identical to that used for imputing UK RPI ${ }^{34}$ and the details of the optimal model estimates are included in Figure 14.

Unsurprisingly, the decay rates of the fitted assets are a little higher. The real versions of the debt maturity distributions decay at the rate of expected inflation, as more distant payouts become more heavily discounted. That, for example, the US one-bond decay rate is around 0.002 higher than in the headline case is consistent with an average inflation rate of 2.4 percent (as decay rates are monthly).

\footnotetext{
${ }^{34}$ Similar to RPI inflation, CPI inflation data are sourced from the Global Financial Data (GFD) databasebeginning at a monthly frequency on January 1914 for the UK and on January 1875 for the US.
} 
Table 8: MLE Estimates, 1920-2020, Real units

\begin{tabular}{|c|c|c|c|c|c|c|c|c|}
\hline & \multicolumn{4}{|c|}{ United States } & \multicolumn{4}{|c|}{ United Kingdom } \\
\hline & $M=1$ & $M=2$ & $M=3$ & $M=4$ & $M=1$ & $M=2$ & $M=3$ & $M=4$ \\
\hline & \multicolumn{8}{|c|}{ Bond decay parameters } \\
\hline \multirow[t]{2}{*}{$\theta_{1}$} & $0.014^{* * *}$ & $0.010^{* * *}$ & $0.008^{* * *}$ & $0.008^{* * *}$ & $0.004^{* * *}$ & $0.002^{* * *}$ & $0.002^{* * *}$ & $0.002^{* * *}$ \\
\hline & $(0.0004)$ & $(0.0004)$ & $(0.0004)$ & $(0.0004)$ & $(0.0001)$ & $(0.0001)$ & $(0.0001)$ & $(0.0002)$ \\
\hline \multirow[t]{2}{*}{$\theta_{2}$} & & $0.114^{* * *}$ & $0.030 * * *$ & $0.029^{* * *}$ & & $0.011^{* * *}$ & $0.009^{* * *}$ & $0.007^{*}$ \\
\hline & & $(0.0164)$ & $(0.0040)$ & $(0.0033)$ & & $(0.0008)$ & $(0.0007)$ & $(0.0041)$ \\
\hline \multirow[t]{2}{*}{$\theta_{3}$} & & & $0.231^{* * *}$ & $0.182^{* * *}$ & & & $0.422^{* * *}$ & $0.016^{* *}$ \\
\hline & & & $(0.0302)$ & $(0.0339)$ & & & $(0.0619)$ & $(0.0071)$ \\
\hline \multirow[t]{3}{*}{$\theta_{4}$} & & & & $0.343^{* * *}$ & & & & $0.444^{* * *}$ \\
\hline & & & & $(0.1165)$ & & & & $(0.0636)$ \\
\hline & \multicolumn{8}{|c|}{ Average weights } \\
\hline \multirow[t]{2}{*}{$\bar{\omega}_{1}$} & & $0.679^{* * *}$ & $0.497^{* * *}$ & $0.491^{* * *}$ & & $0.545^{* * *}$ & $0.545^{* * *}$ & $0.518^{* * *}$ \\
\hline & & $(0.0157)$ & $(0.0211)$ & $(0.0153)$ & & $(0.0191)$ & $(0.0182)$ & $(0.0206)$ \\
\hline \multirow[t]{2}{*}{$\bar{\omega}_{2}$} & & $0.321^{* * *}$ & $0.322^{* * *}$ & $0.317^{* * *}$ & & $0.455^{* * *}$ & $0.404^{* * *}$ & $0.300^{* * *}$ \\
\hline & & $(0.0157)$ & $(0.0244)$ & $(0.0187)$ & & $(0.0191)$ & $(0.0176)$ & $(0.0245)$ \\
\hline \multirow[t]{2}{*}{$\bar{\omega}_{3}$} & & & $0.181^{* * *}$ & $0.135^{* * *}$ & & & $0.050^{* * *}$ & $0.135^{* * *}$ \\
\hline & & & $(0.0156)$ & $(0.0214)$ & & & $(0.0073)$ & $(0.0195)$ \\
\hline \multirow[t]{2}{*}{$\bar{\omega}_{4}$} & & & & $0.057^{* * *}$ & & & & $0.047^{* * *}$ \\
\hline & & & & $(0.0191)$ & & & & $(0.0072)$ \\
\hline $\mathrm{T}$ & 1205 & 1205 & 1205 & 1205 & 1205 & 1205 & 1205 & 1205 \\
\hline S & 1200 & 1200 & 1200 & 1200 & 1200 & 1200 & 1200 & 1200 \\
\hline Params. & 1 & 1207 & 2413 & 3619 & 1 & 1207 & 2413 & 3619 \\
\hline Log lik & -6357.39 & -6130.78 & -6096.08 & -6093.71 & -7935.18 & -7784.86 & -7727.08 & -7720.22 \\
\hline AIC & 12716.78 & 14675.56 & 17018.15 & 19425.43 & 15872.37 & 17983.73 & 20280.15 & 22678.45 \\
\hline
\end{tabular}



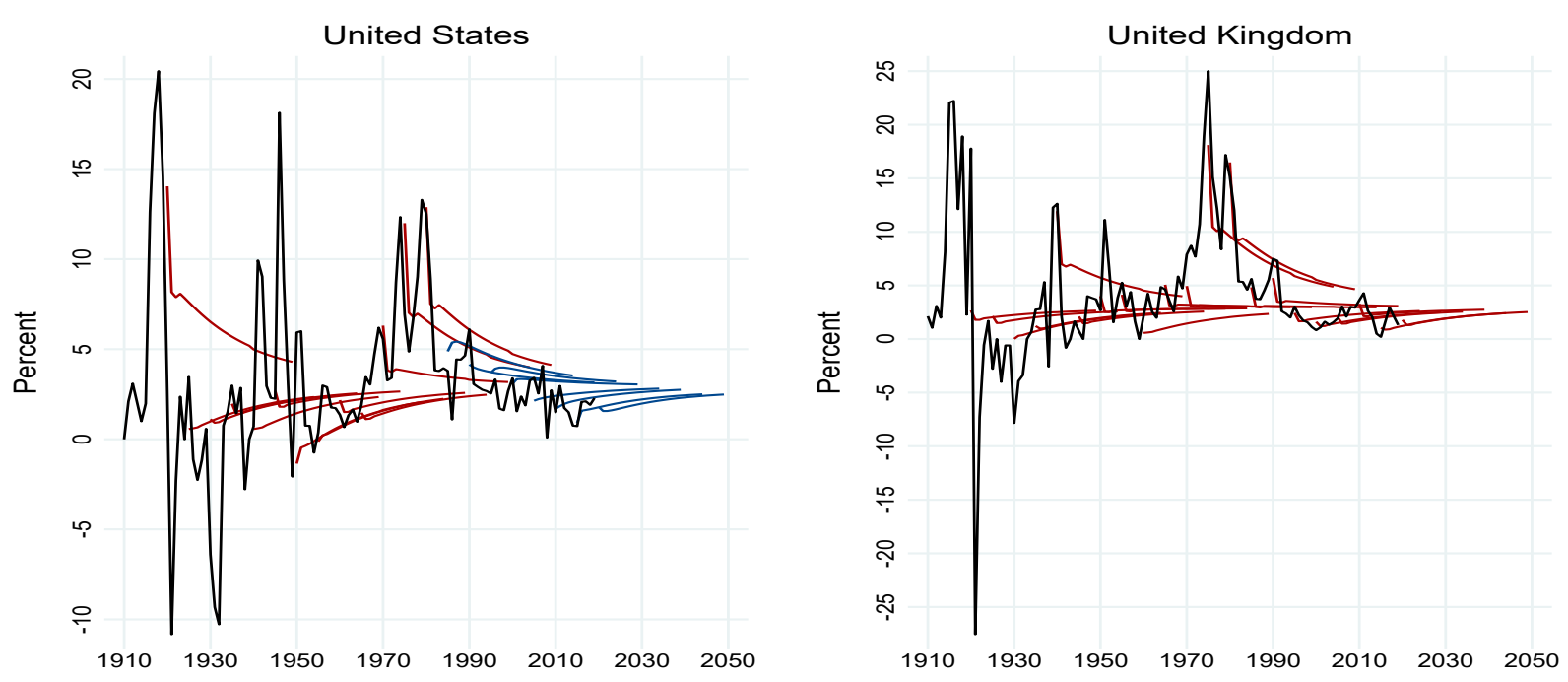

CPI Inflation

Imputed inflation expectations

Inflation expectations

Figure 18: Imputed inflation expectations, 1920-2020.

\section{C.3 Called-at-first-availability analysis}

As discussed in Appendix A.1, for certain historical bonds, the US Treasury reserved the right to pay back principal and stop paying interest before the bonds matured. Although these bonds have been phased out, they were prolific in the first half of our 100-year sample. Until this point, we have assumed callable bonds will not be called. To get a sense of the potential affect of these bonds on our parameterization, we take the opposite approach of before and assume that the call option will be taken at date of first availability.

This exercise has the mechanical effect of shortening the payment schedule of every bond that includes a call option. We can see this in Tables 9 and 10 through slightly higher decay rates over the 100-year sample across all model specifications. The respective average weights are relatively unchanged. 
Table 9: MLE Estimates, Exponentially decaying coupon 1920-2020, Callable assumption

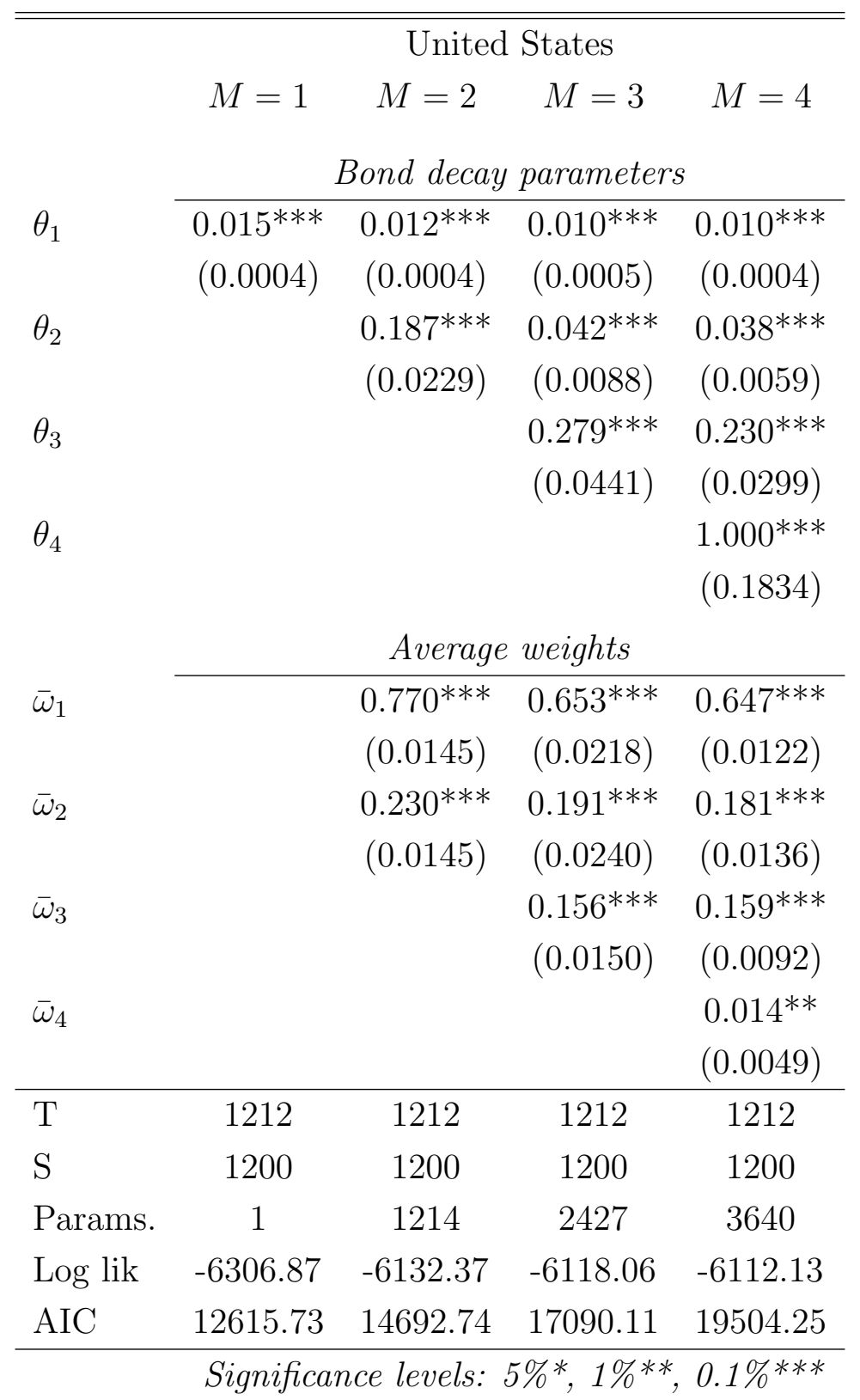


Table 10: MLE Estimates, Constant coupon 1920-2020, Callable assumption

\begin{tabular}{|c|c|c|c|c|}
\hline & \multicolumn{4}{|c|}{ United States } \\
\hline & $M=1$ & $M=2$ & $M=3$ & $M=4$ \\
\hline & \multicolumn{4}{|c|}{ Bond maturities } \\
\hline \multirow[t]{2}{*}{$\mu_{1}$} & $306.1^{* * *}$ & $54.4^{* * *}$ & $10.4^{* * *}$ & $11.4^{* * *}$ \\
\hline & $(0.17)$ & $(0.21)$ & $(0.15)$ & $(0.16)$ \\
\hline \multirow[t]{2}{*}{$\mu_{2}$} & & $347.3^{* * *}$ & $101.4^{* * *}$ & $83.2^{* * *}$ \\
\hline & & $(0.41)$ & $(0.34)$ & $(0.46)$ \\
\hline \multirow[t]{2}{*}{$\mu_{3}$} & & & $314.3^{* * *}$ & $107.0^{* * *}$ \\
\hline & & & $(0.53)$ & $(0.92)$ \\
\hline \multirow[t]{3}{*}{$\mu_{4}$} & & & & $295.5^{* * *}$ \\
\hline & & & & $(0.62)$ \\
\hline & \multicolumn{4}{|c|}{ Average weights } \\
\hline \multirow[t]{2}{*}{$\bar{\omega}_{1}$} & & $0.541^{* * *}$ & $0.240^{* * *}$ & $0.244^{* * *}$ \\
\hline & & $(0.02)$ & $(0.01)$ & $(0.01)$ \\
\hline \multirow[t]{2}{*}{$\bar{\omega}_{2}$} & & $0.459^{* * *}$ & $0.445^{* * *}$ & $0.283^{* * *}$ \\
\hline & & $(0.02)$ & $(0.02)$ & $(0.03)$ \\
\hline \multirow[t]{2}{*}{$\bar{\omega}_{3}$} & & & $0.316^{* * *}$ & $0.171^{* * *}$ \\
\hline & & & $(0.02)$ & $(0.03)$ \\
\hline \multirow[t]{2}{*}{$\bar{\omega}_{4}$} & & & & $0.303^{* * *}$ \\
\hline & & & & $(0.02)$ \\
\hline $\mathrm{T}$ & 1212 & 1212 & 1212 & 1212 \\
\hline $\mathrm{S}$ & 1200 & 1200 & 1200 & 1200 \\
\hline Params. & 1 & 1214 & 2427 & 3640 \\
\hline Log lik & -7504.30 & -6608.50 & -6628.86 & -6746.34 \\
\hline AIC & 15010.59 & 15644.99 & 18111.71 & 20772.69 \\
\hline
\end{tabular}




\section{Extra Figures and Tables for Emerging markets}

Here we present key figures and tables omitted from the text for brevity.
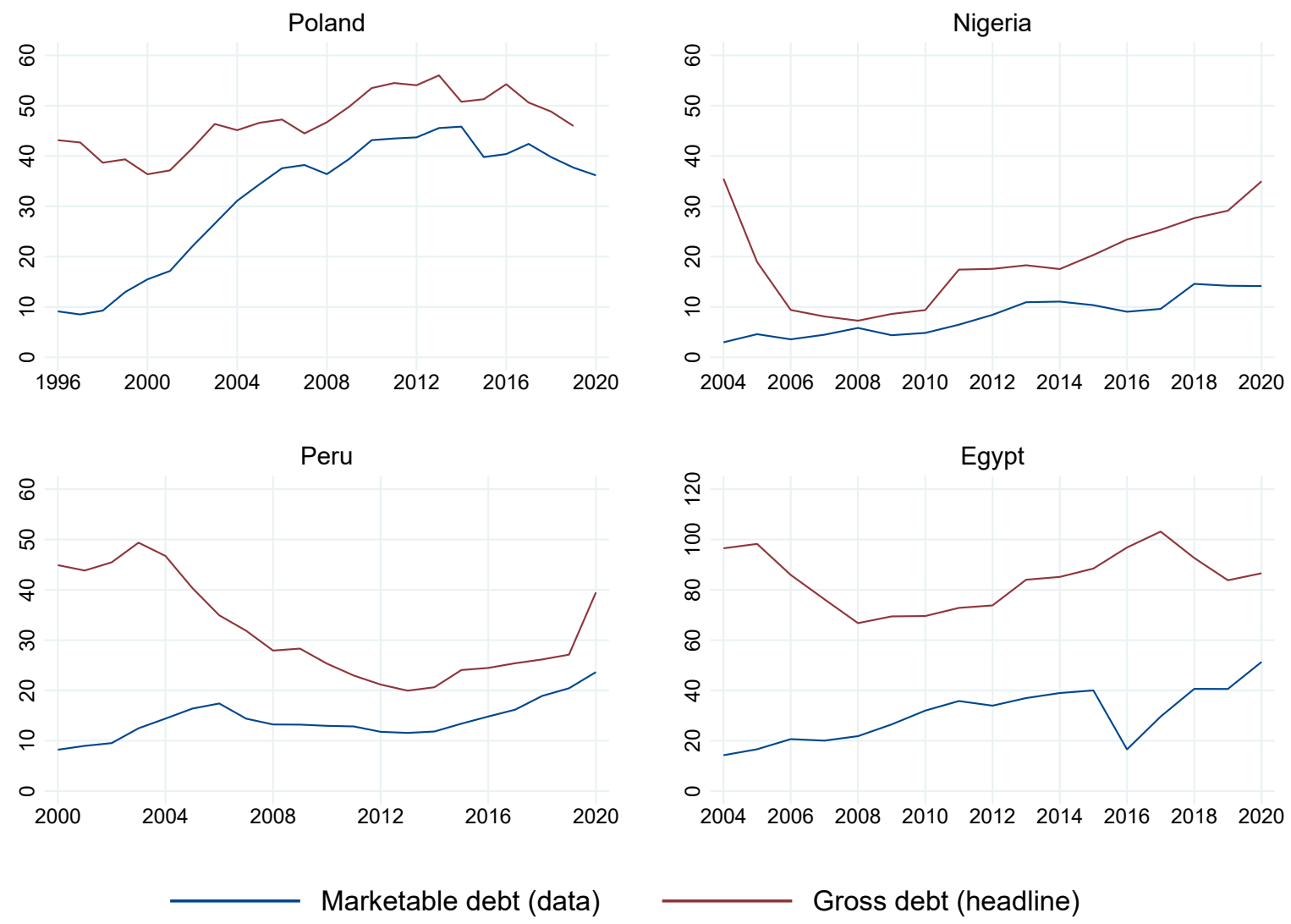

Figure 19: Face value of total and marketable debt outstanding, emerging markets 


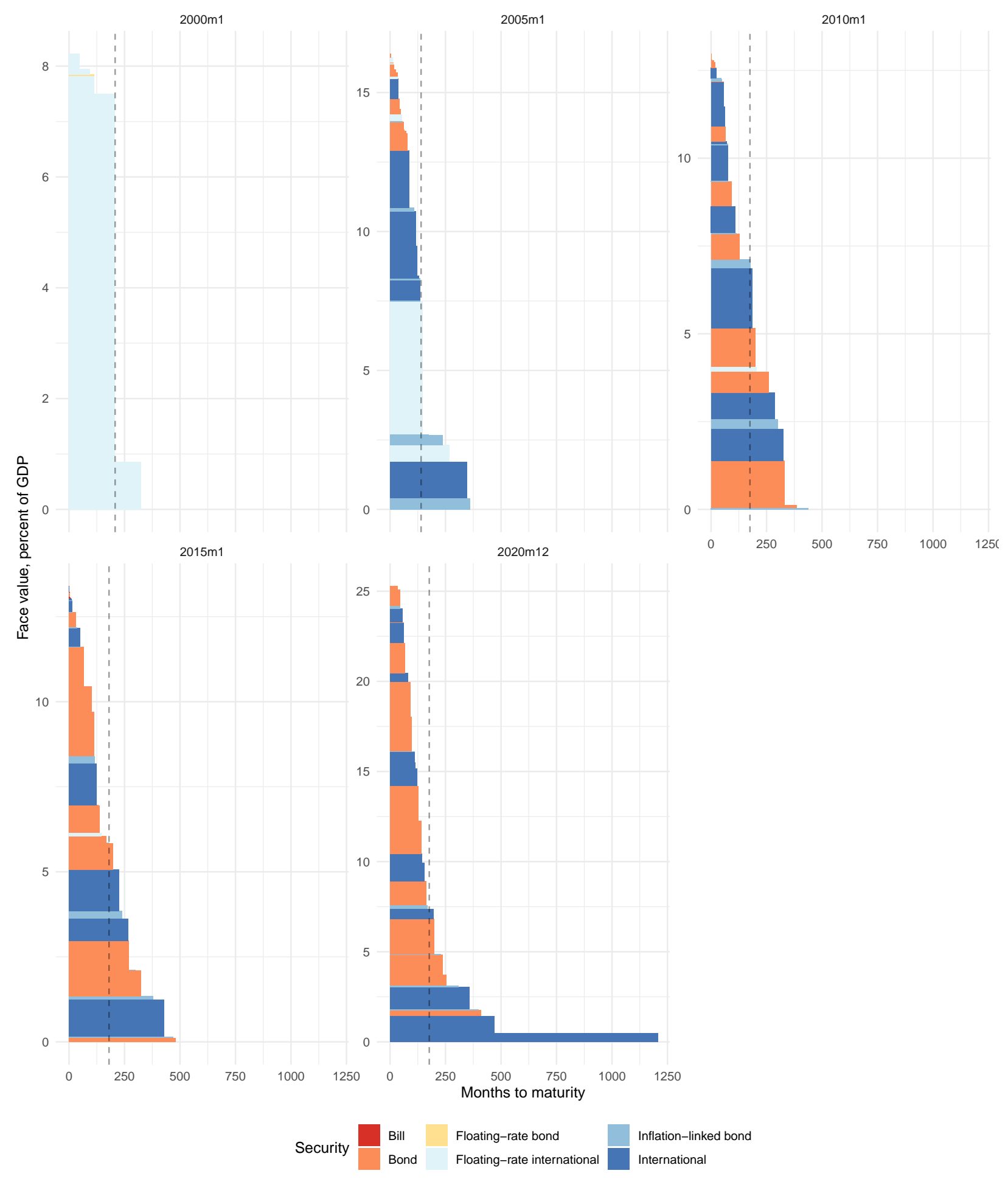

Figure 20: Peru government debt obligations by half-decade, 2000-2020. Vertical line indicates average maturity. 


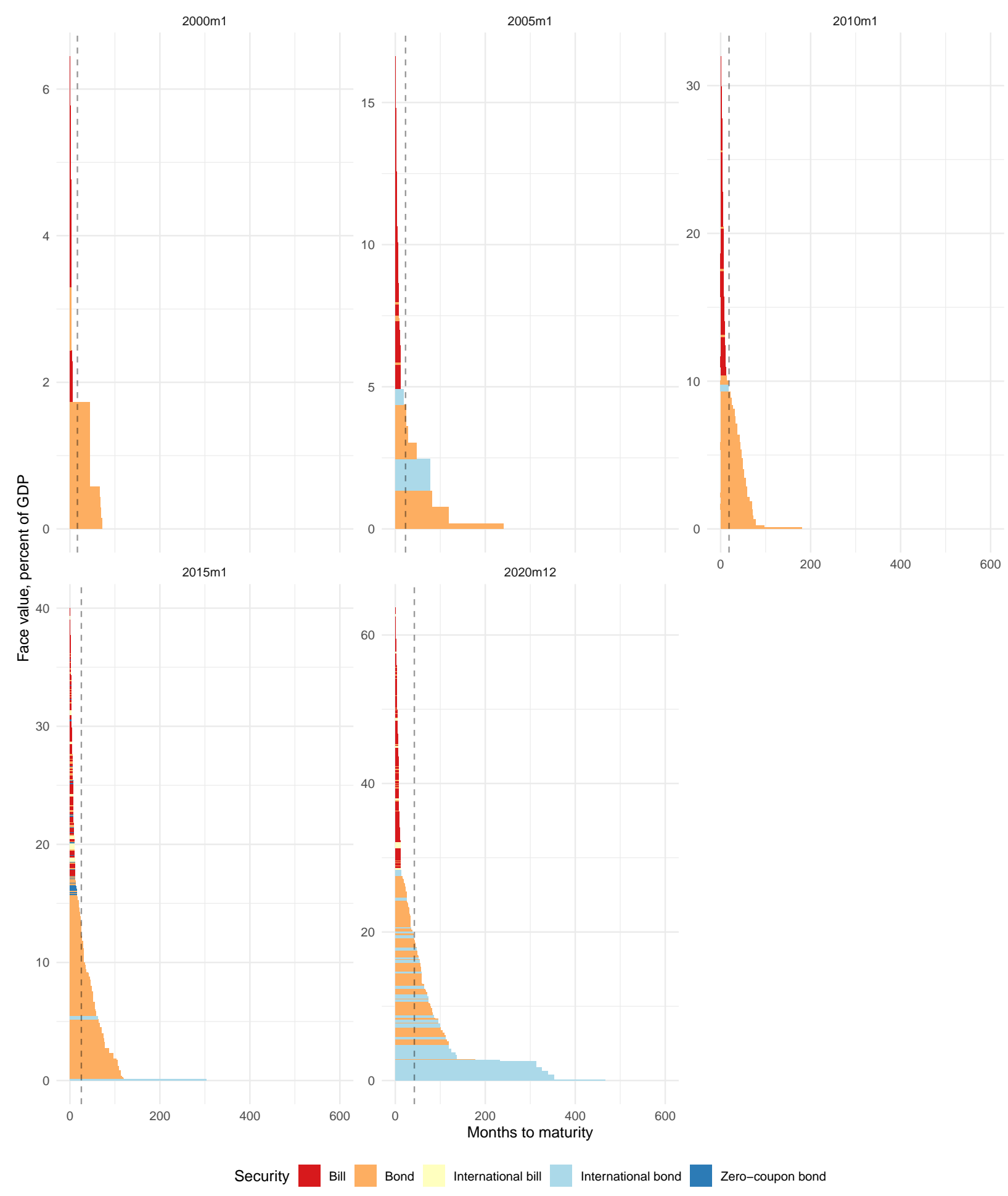

Figure 21: Egypt government debt obligations by half-decade, 2000-2020. Vertical line indicates average maturity. 


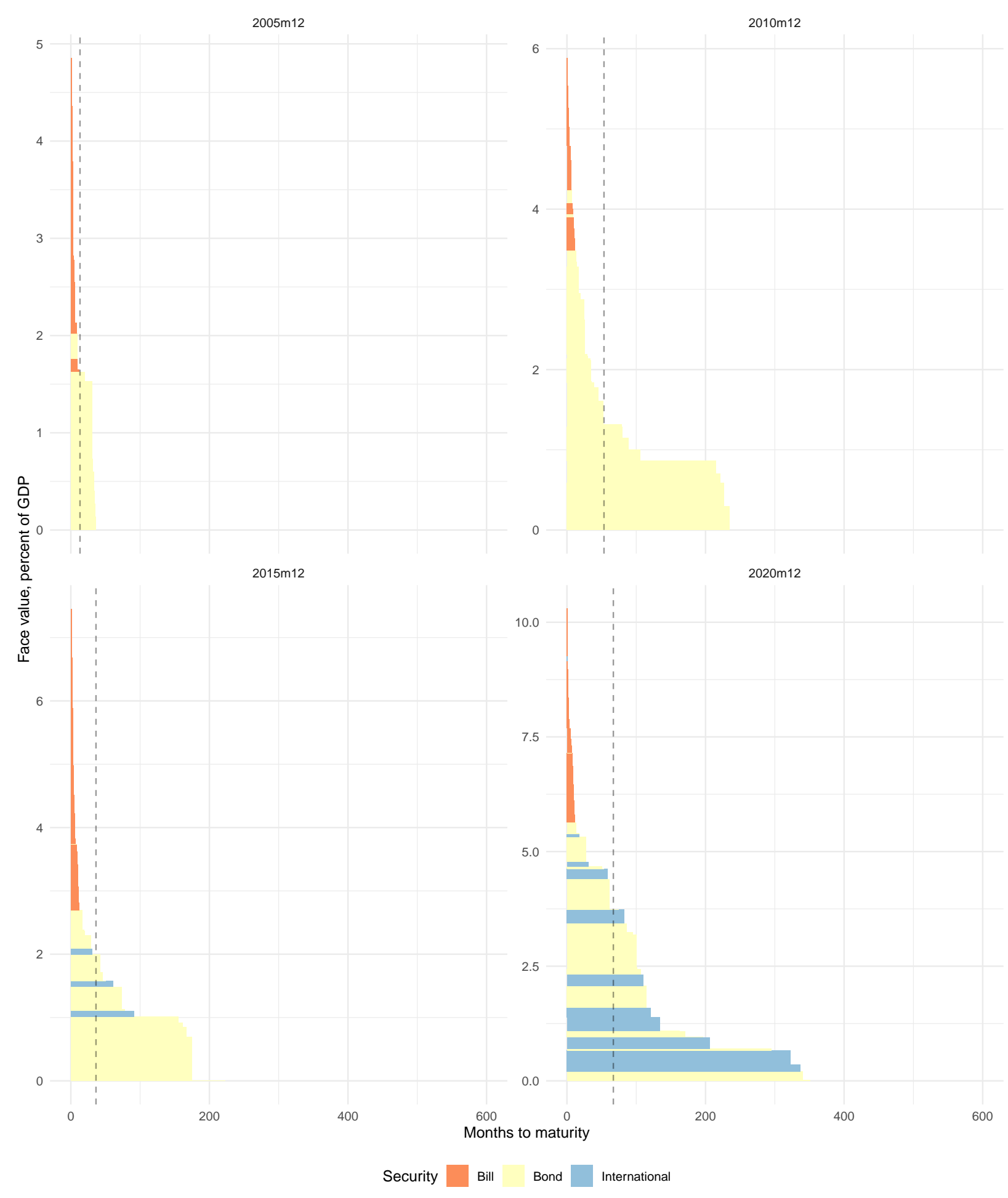

Figure 22: Nigeria government debt obligations by half-decade, 2005-2020. Vertical line indicates average maturity. 
Table 11: MLE Estimates, Exponentially decaying coupon

\begin{tabular}{|c|c|c|c|c|c|c|c|c|}
\hline & \multicolumn{4}{|c|}{ Egypt, 1995-2020 } & \multicolumn{4}{|c|}{ Nigeria, 2002-2020 } \\
\hline & $M=1$ & $M=2$ & $M=3$ & $M=4$ & $M=1$ & $M=2$ & $M=3$ & $M=4$ \\
\hline & \multicolumn{8}{|c|}{ Bond decay parameters } \\
\hline \multirow[t]{2}{*}{$\theta_{1}$} & $0.032^{* * *}$ & $0.020^{* * *}$ & $0.020^{* * *}$ & $0.020^{* * *}$ & $0.029^{* * *}$ & $0.014^{* * *}$ & $0.012^{* * *}$ & $0.012^{* * *}$ \\
\hline & $(0.0018)$ & $(0.0017)$ & $(0.0016)$ & $(0.0016)$ & $(0.0019)$ & $(0.0016)$ & $(0.0016)$ & $(0.0015)$ \\
\hline \multirow[t]{2}{*}{$\theta_{2}$} & & $0.218^{* * *}$ & $0.159^{* * *}$ & $0.157^{* * *}$ & & $0.204^{* * *}$ & $0.054^{* *}$ & $0.045^{* * *}$ \\
\hline & & $(0.0261)$ & $(0.0244)$ & $(0.0229)$ & & $(0.0248)$ & $(0.0190)$ & $(0.0110)$ \\
\hline \multirow[t]{2}{*}{$\theta_{3}$} & & & $0.328^{* * *}$ & $0.288^{* *}$ & & & $0.240^{* * *}$ & $0.162^{* * *}$ \\
\hline & & & $(0.0510)$ & $(0.1041)$ & & & $(0.0403)$ & $(0.0271)$ \\
\hline \multirow[t]{3}{*}{$\theta_{4}$} & & & & $0.359^{* * *}$ & & & & $0.343^{* * *}$ \\
\hline & & & & $(0.1189)$ & & & & $(0.0592)$ \\
\hline & \multicolumn{8}{|c|}{ Average weights } \\
\hline \multirow[t]{2}{*}{$\bar{\omega}_{1}$} & & $0.594^{* * *}$ & $0.566^{* * *}$ & $0.565^{* * *}$ & & $0.462^{* * *}$ & $0.346^{* * *}$ & $0.343^{* * *}$ \\
\hline & & $(0.0334)$ & $(0.0146)$ & $(0.0087)$ & & $(0.0352)$ & $(0.0336)$ & $(0.0139)$ \\
\hline \multirow[t]{2}{*}{$\bar{\omega}_{2}$} & & $0.406^{* * *}$ & $0.281^{* * *}$ & $0.274^{* * *}$ & & $0.538^{* * *}$ & $0.220^{* * *}$ & $0.153^{* * *}$ \\
\hline & & $(0.0334)$ & $(0.0160)$ & $(0.0040)$ & & $(0.0352)$ & $(0.0490)$ & $(0.0165)$ \\
\hline \multirow[t]{2}{*}{$\bar{\omega}_{3}$} & & & $0.153^{* * *}$ & $0.080^{* *}$ & & & $0.433^{* * *}$ & $0.300^{* * *}$ \\
\hline & & & $(0.0210)$ & $(0.0355)$ & & & $(0.0460)$ & $(0.0387)$ \\
\hline \multirow[t]{2}{*}{$\bar{\omega}_{4}$} & & & & $0.081^{* *}$ & & & & $0.204^{* * *}$ \\
\hline & & & & $(0.0380)$ & & & & $(0.0374)$ \\
\hline $\mathrm{T}$ & 308 & 308 & 308 & 308 & 228 & 228 & 228 & 228 \\
\hline S & 1200 & 1200 & 1200 & 1200 & 1200 & 1200 & 1200 & 1200 \\
\hline Params. & 1 & 310 & 619 & 928 & 1 & 230 & 459 & 688 \\
\hline Log lik & -1359.45 & -1289.11 & -1283.71 & -1283.48 & -1034.35 & -926.68 & -917.37 & -911.71 \\
\hline AIC & 2720.91 & 3198.21 & 3805.43 & 4422.97 & 2070.70 & 2313.37 & 2752.73 & 3199.42 \\
\hline
\end{tabular}


Table 12: MLE Estimates, Constant coupon

\begin{tabular}{|c|c|c|c|c|c|c|c|c|}
\hline & \multicolumn{4}{|c|}{ Peru, 1999-2020 } & \multicolumn{4}{|c|}{ Poland, 1991-2020 } \\
\hline & $M=1$ & $M=2$ & $M=3$ & $M=4$ & $M=1$ & $M=2$ & $M=3$ & $M=4$ \\
\hline & \multicolumn{8}{|c|}{ Bond maturities } \\
\hline \multirow[t]{2}{*}{$\mu_{1}$} & $394.1^{* * *}$ & $186.0^{* * *}$ & $101.2^{* *}$ & $98.0^{* * *}$ & $188.1^{* * *}$ & $62.1^{* * *}$ & $58.2^{* * *}$ & $11.6^{* * *}$ \\
\hline & $(0.37)$ & $(1.36)$ & $(8.56)$ & $(7.33)$ & $(0.22)$ & $(0.31)$ & $(0.38)$ & $(0.31)$ \\
\hline \multirow[t]{2}{*}{$\mu_{2}$} & & $367.2^{* * *}$ & $182.0^{* * *}$ & $103.0^{* * *}$ & & $168.3^{* * *}$ & $118.8^{* * *}$ & $62.2^{* * *}$ \\
\hline & & $(0.73)$ & $(0.90)$ & $(13.77)$ & & $(0.64)$ & $(1.08)$ & $(0.70)$ \\
\hline \multirow[t]{2}{*}{$\mu_{3}$} & & & $345.5^{* * *}$ & $181.1^{* * *}$ & & & $172.8^{* * *}$ & $119.8^{* * *}$ \\
\hline & & & $(1.15)$ & $(1.03)$ & & & $(1.75)$ & (1.09) \\
\hline \multirow[t]{3}{*}{$\mu_{4}$} & & & & $345.5 .2^{* * *}$ & & & & $174.9^{* * *}$ \\
\hline & & & & $(1.13)$ & & & & $(1.85)$ \\
\hline & \multicolumn{8}{|c|}{ Average weights } \\
\hline \multirow[t]{2}{*}{$\bar{\omega}_{1}$} & & $0.449^{* * *}$ & $0.053^{*}$ & $0.039^{*}$ & & $0.629^{* * *}$ & $0.539^{* * *}$ & $0.273^{* * *}$ \\
\hline & & $(0.05)$ & $(0.03)$ & $(0.03)$ & & $(0.03)$ & $(0.04)$ & $(0.02)$ \\
\hline \multirow[t]{2}{*}{$\bar{\omega}_{2}$} & & $0.551^{* *}$ & $0.377^{* * *}$ & 0.021 & & $0.371^{* * *}$ & $0.319^{* * *}$ & $0.280^{* * *}$ \\
\hline & & $(0.05)$ & $(0.06)$ & $(0.02)$ & & $(0.03)$ & $(0.04)$ & $(0.04)$ \\
\hline \multirow[t]{2}{*}{$\bar{\omega}_{3}$} & & & $0.570^{* * *}$ & $0.366^{* * *}$ & & & $0.142^{* * *}$ & $0.311^{* * *}$ \\
\hline & & & $(0.05)$ & $(0.06)$ & & & $(0.03)$ & $(0.04)$ \\
\hline \multirow[t]{2}{*}{$\bar{\omega}_{4}$} & & & & $0.574^{* * *}$ & & & & $0.136^{* * *}$ \\
\hline & & & & $(0.05)$ & & & & $(0.03)$ \\
\hline $\mathrm{T}$ & 264 & 264 & 264 & 264 & 348 & 348 & 348 & 348 \\
\hline S & 1212 & 1212 & 1212 & 1212 & 1200 & 1200 & 1200 & 1200 \\
\hline Params. & 1 & 266 & 531 & 796 & 1 & 350 & 699 & 1048 \\
\hline Log lik & -1687.89 & -1673.96 & -1708.09 & -1746.23 & -2029.95 & -1945.63 & -1907.25 & -1791.79 \\
\hline AIC & 3377.79 & 3879.92 & 4478.17 & 5084.46 & 4061.91 & 4591.27 & 5212.50 & 5679.59 \\
\hline
\end{tabular}


Table 13: MLE Estimates, Constant coupon

\begin{tabular}{|c|c|c|c|c|c|c|c|c|}
\hline & \multicolumn{4}{|c|}{ Egypt, 1995-2020 } & \multicolumn{4}{|c|}{ Nigeria, 2002-2020 } \\
\hline & $M=1$ & $M=2$ & $M=3$ & $M=4$ & $M=1$ & $M=2$ & $M=3$ & $M=4$ \\
\hline & \multicolumn{8}{|c|}{ Bond maturities } \\
\hline \multirow[t]{2}{*}{$\mu_{1}$} & $102.1^{* * *}$ & $79.1^{* * *}$ & $10.3^{* * *}$ & $11.4^{* * *}$ & $146.1^{* * *}$ & $40.1^{* * *}$ & $11.3^{* * *}$ & $11.3^{* * *}$ \\
\hline & $(0.22)$ & $(0.37)$ & $(0.19)$ & $(0.19)$ & $(0.29)$ & $(0.21)$ & $(0.20)$ & $(0.20)$ \\
\hline \multirow[t]{2}{*}{$\mu_{2}$} & & $118.8^{* * *}$ & $83.7^{* * *}$ & $79.8^{* * *}$ & & $162.6^{* * *}$ & $64.1^{* * *}$ & $58.1 * * *$ \\
\hline & & $(1.25)$ & $(0.72)$ & $(0.93)$ & & $(1.29)$ & $(0.62)$ & $(0.79)$ \\
\hline \multirow[t]{2}{*}{$\mu_{3}$} & & & $136.2^{* * *}$ & $97.7 * * *$ & & & $166.7^{* * *}$ & $98.6^{* * *}$ \\
\hline & & & $(0.83)$ & $(1.96)$ & & & $(1.60)$ & $(3.52)$ \\
\hline \multirow[t]{3}{*}{$\mu_{4}$} & & & & $134.2^{* * *}$ & & & & $159.9^{* * *}$ \\
\hline & & & & $(0.95)$ & & & & $(2.00)$ \\
\hline & \multicolumn{8}{|c|}{ Average weights } \\
\hline \multirow[t]{2}{*}{$\bar{\omega}_{1}$} & & $0.796^{* * *}$ & $0.460^{* * *}$ & $0.475^{* * *}$ & & $0.732^{* * *}$ & $0.571^{* * *}$ & $0.571^{* * *}$ \\
\hline & & $(0.04)$ & $(0.02)$ & $(0.02)$ & & $(0.03)$ & $(0.03)$ & $(0.03)$ \\
\hline \multirow[t]{2}{*}{$\bar{\omega}_{2}$} & & $0.204^{* * *}$ & $0.397^{* * *}$ & $0.307^{* * *}$ & & $0.268^{* * *}$ & $0.205^{* * *}$ & $0.166^{* * *}$ \\
\hline & & $(0.04)$ & $(0.03)$ & $(0.04)$ & & $(0.03)$ & $(0.03)$ & $(0.03)$ \\
\hline \multirow[t]{2}{*}{$\bar{\omega}_{3}$} & & & $0.143^{* * *}$ & $0.101^{* * *}$ & & & $0.224^{* * *}$ & $0.094^{* *}$ \\
\hline & & & $(0.03)$ & $(0.03)$ & & & $(0.03)$ & $(0.04)$ \\
\hline \multirow[t]{2}{*}{$\bar{\omega}_{4}$} & & & & $0.116^{* * *}$ & & & & $0.169^{* * *}$ \\
\hline & & & & $(0.03)$ & & & & $(0.03)$ \\
\hline $\mathrm{T}$ & 308 & 308 & 308 & 308 & 228 & 228 & 228 & 228 \\
\hline $\mathrm{S}$ & 1200 & 1200 & 1200 & 1200 & 1200 & 1200 & 1200 & 1200 \\
\hline Params. & 1 & 310 & 619 & 928 & 1 & 230 & 459 & 688 \\
\hline Log lik & -1759.31 & -1567.78 & -1388.94 & -1386.75 & -1508.20 & -1300.86 & -1184.40 & -1206.81 \\
\hline AIC & 3520.62 & 3755.57 & 4015.88 & 4629.50 & 3018.40 & 3061.71 & 3286.79 & 3789.62 \\
\hline
\end{tabular}

